Portland State University

PDXScholar

Winter 3-17-2014

\title{
An Analysis of Bicycle-Vehicle Interactions at Signalized Intersections with Bicycle Boxes
}

William Robert Farley

Portland State University

Follow this and additional works at: https://pdxscholar.library.pdx.edu/open_access_etds

Part of the Leisure Studies Commons, Other Civil and Environmental Engineering Commons, and the Transportation Engineering Commons

Let us know how access to this document benefits you.

\section{Recommended Citation}

Farley, William Robert, "An Analysis of Bicycle-Vehicle Interactions at Signalized Intersections with Bicycle Boxes" (2014). Dissertations and Theses. Paper 1618.

https://doi.org/10.15760/etd.1617

This Thesis is brought to you for free and open access. It has been accepted for inclusion in Dissertations and Theses by an authorized administrator of PDXScholar. Please contact us if we can make this document more accessible: pdxscholar@pdx.edu. 
An Analysis of Bicycle-Vehicle Interactions at

Signalized Intersections with Bicycle Boxes

by

William Robert Farley

A thesis submitted in partial fulfillment of the requirements for the degree of

Master of Science

in

Civil and Environmental Engineering

Thesis Committee:

Christopher Monsere, Chair

Kelly Clifton

Jennifer Dill

Portland State University

2014 


\begin{abstract}
A before-and-after analysis was performed at eleven intersections where a bike box was installed in Portland, Oregon to explore the safety effects of the treatment. Video data were gathered prior to installation at 14 intersections where a bike box installation was planned by the Portland Bureau of Transportation. Cameras were set up to capture three full twenty-four hour days (72 hours) of data for each intersection from Tuesday through Thursday. Of the 14 original selected intersections, 11 intersections actually received the bike box treatment. Video data were again gathered for these intersections after the installation of the bike box for another three full twenty-four hour days (72 hours) between Tuesday and Thursday.
\end{abstract}

One day of data (24 hours) was selected for observation from both the before and after periods in the analysis for each study intersection during midweek. Safety effects were evaluated by three metrics: 1) observed conflicts; 2) observed cyclist behavior for all conflicts as measured by head or shoulder checks; and 3) reported crash data. To develop the conflict data, a log was created of each motor vehicle and bicycle passing through the intersection for approximately 528 hours of video. All conflicts that were observed during the period were further reviewed by an expert panel that scored conflicts by severity. Following this review, a total of 18 conflicts were observed during the before period. The total exposure in the before period was 39,497 motor vehicles in the vehicle lane adjacent to the bike lane (10,454 of which were right-turning) and 7,849 bicycles. A total of 19 conflicts were observed during the after period. Total exposure was 42,381 
motor vehicles in the vehicle lane adjacent to the bike lane (11,053 of which were rightturning) and 5,852 bicycles.

The sample size of observed conflicts was insufficient to draw statistically significant conclusions for any of the specific intersections that were treated. When taking in account the total amount of conflicts, the limited data suggest a slight increase in the rate of conflicts when normalized against a product of right-turning vehicles and bicycles observed in the intersection. The data also suggest that the installation of a bike box at an intersection reduces the rate of conflicts per hundred motor vehicles and increases the rate of conflicts per hundred bicyclists. Data regarding head-checks from the bicyclist shows an increase in bicyclists observing the possibility of conflicts approaching from behind as they pass through the intersection. A review or crash data at each of the intersections shows an increase at three of the observed intersections and a decrease at the remaining five. 


\section{Acknowledgements}

First off I would like to thank the faculty from Portland State University's Transportation Engineering program for the opportunity to expand my knowledge in such a wonderful field. I would also like to thank everyone that pushed me to continue writing on the thesis and convinced me not to give up as well as my fellow students in the ITS lab that made the lab such a great place to work. 


\section{Table of Contents}

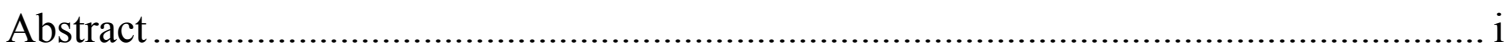

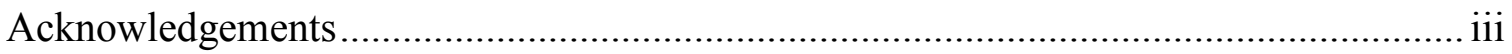

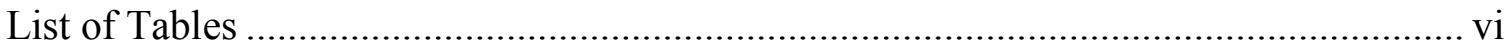

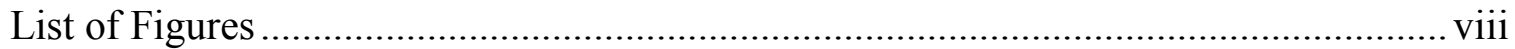

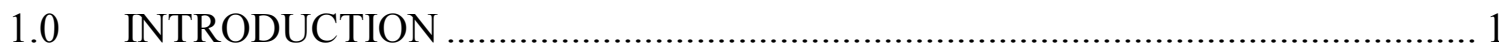

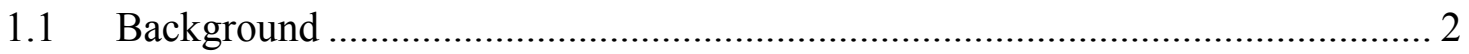

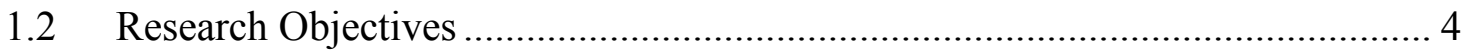

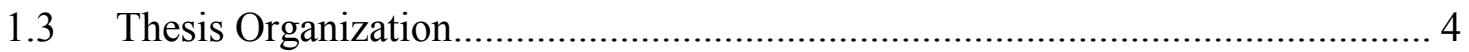

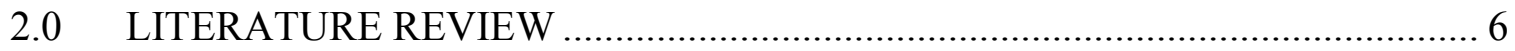

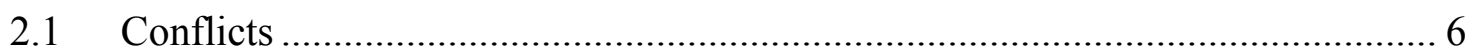

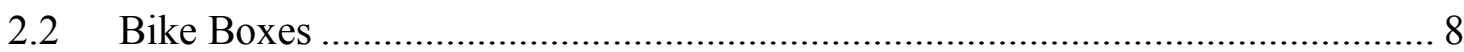

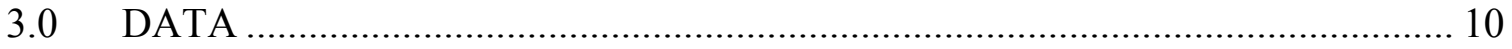

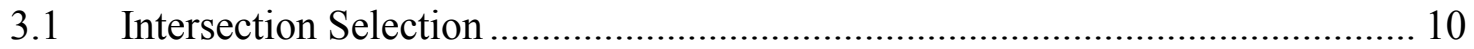

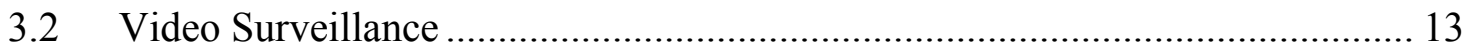

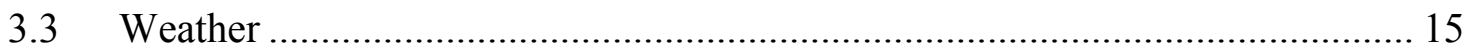

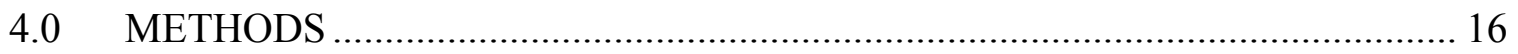

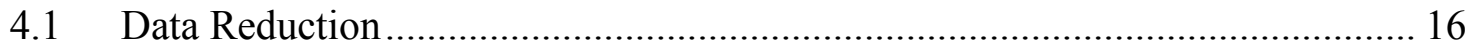

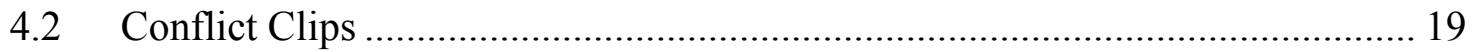


4.3 Re-Observing Intersection Conflicts ....................................................... 21

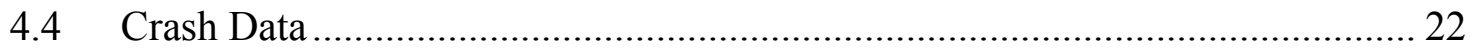

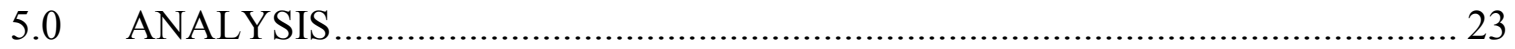

5.1 Intersection Volumes............................................................................. 23

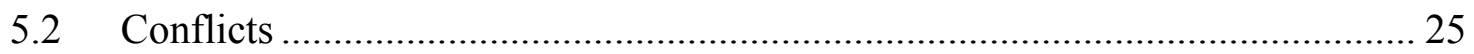

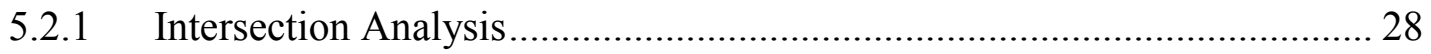

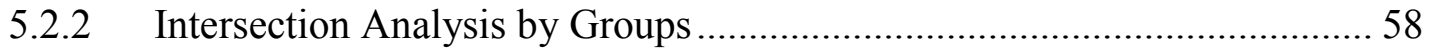

5.2.3 Normalized Conflict Rates.............................................................. 61

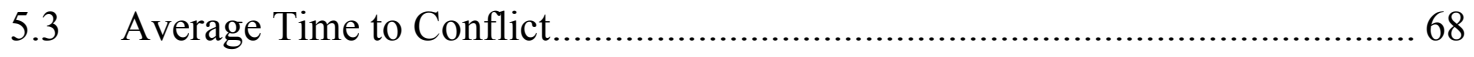

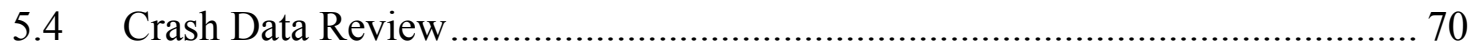

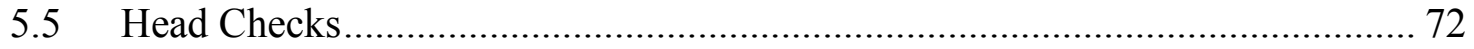

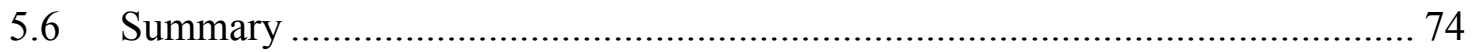

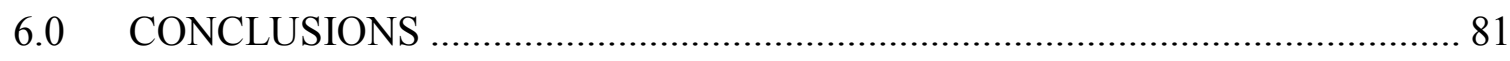

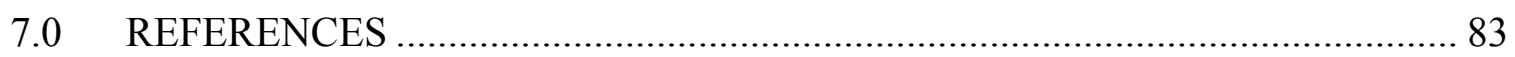

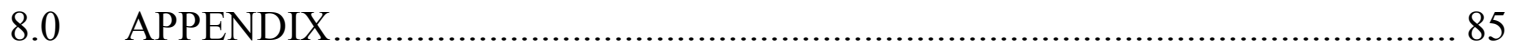

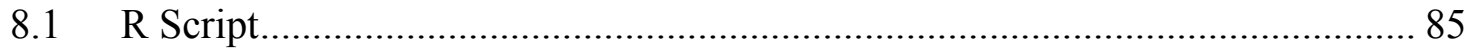




\section{List of Tables}

Table 1: Phase I Intersections and Dates of Observation ................................................. 3

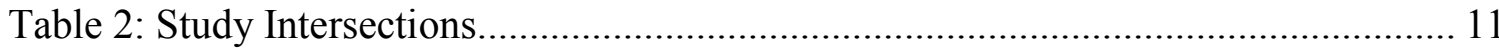

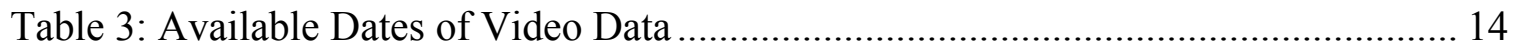

Table 4: Dates Studied Before and After Installation.................................................... 18

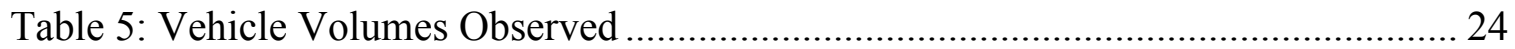

Table 6: Summary of Observed Conflicts at Bike Box Intersections ............................... 26

Table 7: Conflicts at NE Couch St at Grand Ave …………....................................... 30

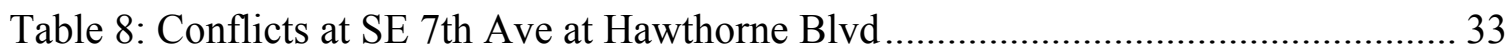

Table 9: Conflicts at SE 7th Ave at Madison St .......................................................... 36

Table 10: Conflicts at SE 26th Ave NB at Powell Blvd ................................................. 39

Table 11: Conflicts at SE 26th Ave SB at Powell Blvd..................................................... 41

Table 12: Conflicts at N Interstate Ave at Alberta St ................................................... 44

Table 13: Conflicts at SE Gladstone St EB at Cesar E Chavez Blvd ................................ 47

Table 14: Conflicts at SE Gladstone St WB at Cesar E Chavez Blvd .............................. 48

Table 15: Conflicts at SE Lincoln St EB at Cesar E Chavez Blvd ................................. 51

Table 16: Conflicts at SE Lincoln St WB at Cesar E Chavez Blvd................................. 54

Table 17: Conflicts at SE Madison St at Grand Ave .................................................... 56

Table 18: Conflicts at SE 26th Ave at Powell Blvd....................................................... 58

Table 19: Conflicts at SE Lincoln St at Cesar E Chavez Blvd ........................................ 60

Table 20: Conflicts Normalized to Number of Right Turns ............................................ 62

Table 21: Conflicts Normalized to Number of Bicycles .................................................... 64 


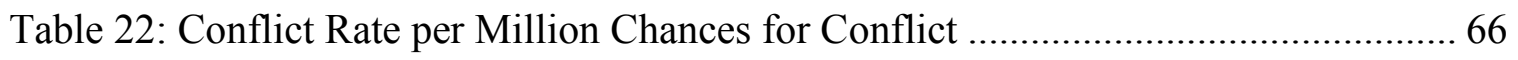

Table 23: Intersection Conflicts Normalized to Number of Right Turns ........................ 67

Table 24: Intersection Conflicts Normalized to Number of Bicycles............................ 68

Table 25: Average Annual Daily Bike Traffic ....................................................... 70

Table 26: Summary of Crash Data by Year and Crash Rate per MEB.......................... 71

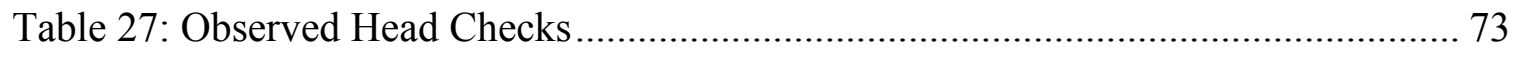

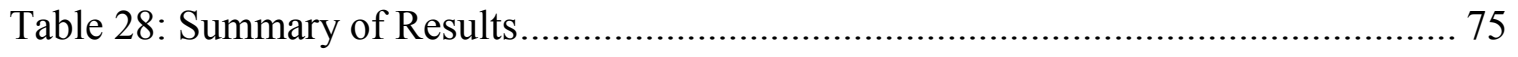




\section{List of Figures}

Figure 1: Map of Bike Box Locations .................................................................... 12

Figure 2: Average Monthly High Temperature and Precipitation ................................... 15

Figure 3: Minor \& Major Conflict Totals at Study Intersections .................................... 27

Figure 4: NE Couch St at Grand Ave Camera Views...................................................... 29

Figure 5: Event Log Before and After at NE Couch St at Grand Ave.............................. 31

Figure 6: SE 7th Ave at Hawthorne Blvd Camera Views ................................................ 33

Figure 7: Event Log Before and After at SE 7th Ave at Hawthorne Blvd ....................... 34

Figure 8: SE 7th Ave at Madison St Camera Views................................................... 36

Figure 9: Event Log Before and After at SE 7th Ave at Madison St.............................. 37

Figure 10: SE 26th Ave NB at Powell Blvd Camera Views............................................. 38

Figure 11: Event Log Before and After at SE 26th Ave NB at Powell Blvd .................. 39

Figure 12: SE 26th Ave SB at Powell Blvd Camera Views .............................................. 41

Figure 13: Event Log Before and After at SE 26th Ave SB at Powell Blvd .................... 42

Figure 14: N Interstate Ave at Alberta St Camera Views.............................................. 44

Figure 15: Event Log Before and After at N Interstate Ave at Alberta St....................... 45

Figure 16: SE Gladstone St EB at Cesar E Chavez Blvd Camera Views......................... 46

Figure 17: SE Gladstone St WB at Cesar E Chavez Blvd Camera Views ....................... 48

Figure 18: Event Log Before and After at SE Gladstone St WB at CEC ........................ 49

Figure 19: SE Lincoln St EB at Cesar E Chavez Blvd Camera Views.............................. 51

Figure 20: Event Log Before and After at SE Lincoln St EB at CEC ............................. 52

Figure 21: SE Lincoln St WB at Cesar E Chavez Blvd Camera Views ........................... 53 
Figure 22: Event Log Before and After at SE Lincoln St WB at CEC........................... 54

Figure 23: SE Madison St at Grand Ave Camera Views........................................... 56

Figure 24: Event Log Before and After at SE Madison St at Grand Ave....................... 57

Figure 25: Event Log Before and After Comparing Both Directions of SE 26th Ave at

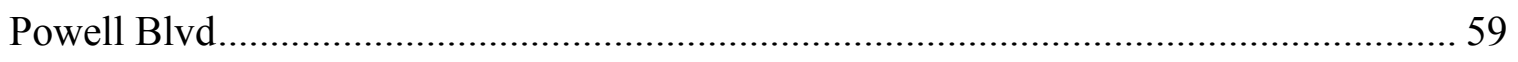

Figure 26: Event Log Before and After Comparing Both Directions of SE Lincoln St at

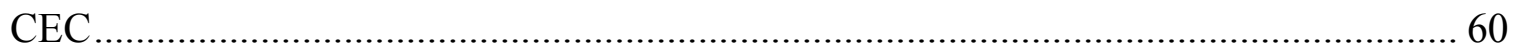

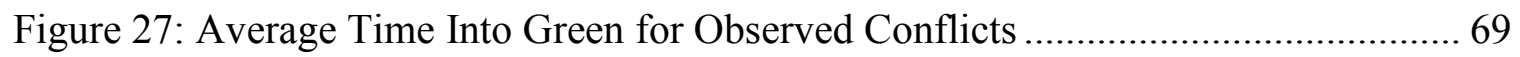




\subsection{INTRODUCTION}

Bicycle ridership has increased by $211 \%$ over the last 11 years here in Portland, Oregon, according to counts performed yearly by the Portland Bureau of Transportation (COP, 2013). With the increase in ridership, however, an increase in the possibility of bicycle/motor vehicle crashes is likely to occur. In fact, according to data from the National Highway Traffic Safety Administration, fatalities from bicycle/motor vehicle crashes has increased nine percent from 2010 to 2011 -and over 30 percent of the total fatal crashes occurred at intersections.

The bike box, also known as an advanced stop box, have been in use for over 25 years in parts of Northern Europe and are an intersection treatment used to encourage bicyclists to position themselves in a more visible area to flowing traffic, to allow bicyclists to move through the intersection first and thereby avoid initial turning traffic, to keep bicyclists from breathing direct vehicle fumes, and to allow bicyclists to travel through the intersection more conveniently and in a safer manner in turn encouraging bicycling as a mode of transport (Hong-bo \& Huil-ing, 2009). According to the Federal Highway Administration, the bike box is intended to reduce conflicts between motorized vehicles and bicyclists, particularly involving right-turning movements across the path of the bicyclist, and to increase bicyclist visibility.

Bike boxes were introduced in Portland, Oregon, at signalized intersections in 2008 to help address right-hook collisions between motorized vehicles and bicyclists. The bike box was initially installed at twelve intersections and consisted of an advanced stop line, 
green textured thermoplastic markings with a bicycle stencil and "WAIT HERE" stenciled prior to the stop line, intersection striping, and regulatory signage including the prohibition of turning right on the red signal indication. These installations were studied in prior research (Dill et al., 2010)

The objective of this thesis research is to attempt to identify any safety impacts related to the installation of the bike box at an intersection. Using video data contributed by the City of Portland, a conflict analysis was performed to attempt to quantify an impact of the infrastructure treatment on the motor vehicle/bicycle conflicts that can occur at signalized intersections. To supplement the research, a review of the previous five years of crash data at each of the study intersections was performed to compare crash rates after the installation of the bike box. The behavior of the bicyclist was also observed to identify if the installation of the intersection treatment affected the awareness of the bicyclists.

\subsection{Background}

This study is a continuation of a previous study performed by Dill, Monsere, and McNeil at Portland State University. The original study was a before-and-after analysis of twelve intersections, including two "control" intersections. The research focused on the understanding of the bike boxes by motorists and bicyclists as well as the impact of the bike boxes on safety.

For the original study of the bike boxes, twelve intersections consisting of ten locations receiving treatment and two locations being used as control were observed at different periods of time. Data were collected for each intersection during two peak periods as 
well as one off-peak period. The intersections that were observed and periods of study are listed in Table 1. Information gathered from the study included the total number of motorists in the lane adjacent to the bicycle lane and total number of vehicles turning right. For each bicyclist, a time of arrival at the intersection, the path of approach (bike or motor vehicle lane), signal phase, if any conflict occurred, bicyclist direction of travel, and other data were documented.

\section{Table 1: Phase I Intersections and Dates of Observation}

\begin{tabular}{|c|c|c|c|}
\hline \multicolumn{2}{|c|}{ Intersection } & \multicolumn{2}{|c|}{ Dates Observed } \\
\hline Bike Box Located On & Cross Street & Before & After \\
\hline NW Everett Street & NW 16th Avenue & $3 / 20 / 2008-3 / 21 / 2008$ & $5 / 28 / 2009-5 / 29 / 2009$ \\
\hline SE Hawthorne Boulevard & SE 11th Avenue & $3 / 12 / 2008-3 / 13 / 2008$ & $4 / 27 / 2009-4 / 28 / 2009$ \\
\hline SE Hawthorne Boulevard & SE 7th Avenue & $1 / 8 / 2008-1 / 9 / 2008$ & $4 / 27 / 2009-4 / 28 / 2009$ \\
\hline SW Madison Street & SW 3rd Avenue & $2 / 12 / 2008-2 / 13 / 2008$ & $6 / 8 / 2009-6 / 9 / 2009$ \\
\hline SW 6th Avenue & SW Broadway & $3 / 20 / 2008-3 / 21 / 2008$ & $6 / 18 / 2009-6 / 19 / 2009$ \\
\hline SW Broadway & SW Taylor Road & $3 / 18 / 2008-3 / 19 / 2008$ & $6 / 17 / 2009-6 / 18 / 2009$ \\
\hline SW 14th Avenue & W Burnside Street & 4/2/2008 - 4/3/2008 & $5 / 27 / 2009-5 / 28 / 2009$ \\
\hline NW Broadway & NW Hoyt Street & $1 / 17 / 2008$ & $6 / 10 / 2009-6 / 11 / 2009$ \\
\hline SW Terwilliger Boulevard & SW Taylors Ferry Road & $3 / 24 / 2008-3 / 26 / 2008$ & $5 / 6 / 2009-5 / 7 / 2009$ \\
\hline \multicolumn{4}{|l|}{ Control Intersections } \\
\hline NE Weidler Street & NE 7th Avenue & $5 / 6 / 2008-5 / 7 / 2008$ & $5 / 12 / 2009-5 / 13 / 2009$ \\
\hline NE Weidler Street & NE 16th Avenue & $5 / 6 / 2008-5 / 7 / 2008$ & $5 / 12 / 2009-5 / 13 / 2009$ \\
\hline
\end{tabular}


Goals of the original research were to answer the following questions:

- Do road users (motorists and bicyclists) understand the markings?

- Do road users behave as intended?

- Are the markings improving safety?

- Does color (green vs. no color) matter?

- Does the green thermoplastic alter road friction?

User compliance and the effects of the physical characteristics of the bike boxes were answered thoroughly in the resulting paper. However, for the goal of observing if bike boxes were improving safety, additional monitoring and evaluation over a longer period of time was to be required.

\subsection{Research Objectives}

To add additional data to the information about safety and conflicts, this research was designed to capture and evaluate much longer periods than the prior research. One day of data ( 24 hours) was selected for observation from both the before and after periods in the analysis for each study intersection during midweek. Safety effects were evaluated by three metrics: 1) observed conflicts; 2) observed cyclist behavior for all conflicts as measured by head or shoulder checks; and 3) reported crash data.

\subsection{Thesis Organization}

This paper will review literature that covers the topics of conflict studies as a means of measuring the impact of an infrastructure improvement on safety and how bicycle boxes have been used as intersection treatments. An explanation of the methodology including 
the selection and narrowing of the data as well as the evaluation of conflicts will follow. Next, the data resulting from the conflict analysis as well as a review of crash data and the awareness observed from the bicyclist will be shared with any interpretations and conclusions that can be made. 


\subsection{LITERATURE REVIEW}

While the literature behind the theory and methodology of conflict analyses is readily available for motor vehicle conflicts, studies pertaining to motor vehicle/bicycle conflicts are rare. Literature reviewing the research on the impacts of the installation of a bike box is also sparse. In this chapter, the literature on conflicts and the prior research on bike boxes are reviewed.

\subsection{Conflicts}

Since the primary analysis for this thesis is a comparison of the conflicts that occur between bicycles and vehicles with the installation of a bike box, a review of literature pertaining to the methodology and theory behind traffic conflict studies was performed.

A conflict study was selected as an efficient means to compare the safety impacts of the bike box before and after the treatment was installed at the intersection. Conflict studies are useful in determining what safety problems exist at a location and can even provide information on what countermeasures can be used to improve intersection safety. Traffic conflict studies can provide results quicker than traffic crash studies and typically requires a relatively small investment of time and no special equipment (Hummer, 1994).

Identifying a conflict between two road users is a rather subjective metric to observe. To help with creating criteria to flag whether a possible conflict needed to be observed in detail, definitions of traffic conflicts were reviewed in literature. Guttinger (1984) defined a traffic conflict as "an observable situation in which two or more road users

approach each other in space and time to such an extent that there is a risk of collision if 
their movements remain unchanged." Similar definitions were found in more recent research including defining the conflict as an interaction between two or more road users when one of the parties takes evasive action to avoid a collision, such as braking or weaving (Parker and Zegeer, 1988). Some research defined a conflict as being a near crash and expanded by saying it is any circumstance that requires a rapid, evasive maneuver by the subject vehicle, or any other vehicle, pedestrian, bicyclist, or animal to avoid a crash. The definition goes further into depth by saying that the rapid, evasive maneuver was considered steering, braking, accelerating, or any combination of inputs that approaches the limit of the vehicle's capabilities (Dingus et al., 2006).

Wall et all (2003) and D Allen et al. (2005) both used conflict studies in the review of advanced stop lines and their effects on capacity or safety. Wall observed traffic conflicts when looking at the effects of advanced stop line on capacity and used the definition of a conflict as an interaction that could potentially lead to a collision if evasive action was not taken by any party. Allen, when looking at user behavior at advanced stop lines in London, England, classified conflicts into one of five categories: 1) precautionary an anticipatory braking when the risk is minimal, 2) controlled lane change or braking to avoid collision, 3) rapid deceleration, lane change, or stop resulting in near miss, 4) emergency or violent braking or swerve resulting in near miss, 5) emergency action followed by a collision. 


\subsection{Bike Boxes}

A review of literature that focuses on the safety impacts of the advanced stop line or bike boxes on traffic conflicts was also performed to identify any possible methods to expand on this thesis study.

Hunter et al. (2000) examined the blue bike lanes in Portland, Oregon, to observe if the painting of the lanes reduced the number of conflicts between motorized vehicles and bicyclists. The study may have examined the effects of a different countermeasure, but the goal of the intersection treatment was the same as the bike box. The study observed bicyclist behavior as they traveled through the intersection included whether or not they looked behind them to identify possible conflicts. This methodology of observing "headchecks", or the act of the bicyclist observing behind them as they enter the intersection, was implemented into this thesis study. Hunter also performed skid tests of the paint and recorded video of the facilities. The research concluded that bicyclists were not as cautious after the installation of the paint, but more motorized vehicles would yield. Hunter recommended observing the marking of a bike lane separately from the bike lane being filled, which was performed in Phase I of this study.

Another study that was completed by Hunter in 2000 observed the effects of the installation of a bike box in Eugene, Oregon. This bike box's purpose was slightly different from the ones observed in this study in that the box allowed bikes to move from a left-side bicycle lane to the right-side bicycle lane at the far side of an intersection. Hunter used video data to observe both bicyclist and motorist behavior at the intersection. In the research, he defined conflicts as "an interaction such that at least one of the parties 
had to make a sudden change in speed or direction in order to avoid the other." The author also cites research from Herrstedt et al. (1994) in which the advanced stop line was found to significantly reduce the number of crashes between right-turning motorists and bicyclists going straight through the intersection.

A study performed in London, England, (D Allen et al., 2005) concluded that the installation of a bike boxes did not appear to have directly contributed to the number or severity of conflicts witnessed at the intersection. The study observed fourteen intersections of various layouts, including two control intersections, over two days using video data as well as crash history of the intersection. The study ranked conflicts as major or minor by classifying them into one of five categories based on the evasive action taken. Majority of the conflicts that were observed (92\%) were regarded as minor, which were further defined as precautionary or anticipatory action when risk of collision is minimal or controlled braking or lane change with ample time to avoid a collision.

A review of literature performed by Pucher, Dill, and Handy (2009) summarized five studies that focused on the impact of installing a bike box on an intersection. Four of the studies reviewed did not have conclusive data to support a conclusion. One study (Transport for London, 2005), however, found that the installation of a bike box resulted in no impacts to bicyclist safety at the intersection. 


\subsection{DATA}

This chapter gives a detailed overview of the intersections selected for the conflict analysis and subsequently the crash data review. The intersection configuration, dates and hours of video data provided by the City of Portland, the selected periods of study, and any external factors are documented in this section.

\subsection{Intersection Selection}

Fourteen intersections that the City of Portland had selected to receive the future addition of an advanced stop box were scheduled for a before and after observation. The intersections which received the installation of the advanced stop box, the lane configuration of the approach, and installation date are summarized in Table 2 with references to locations in Figure 1. 


\section{Table 2: Study Intersections}

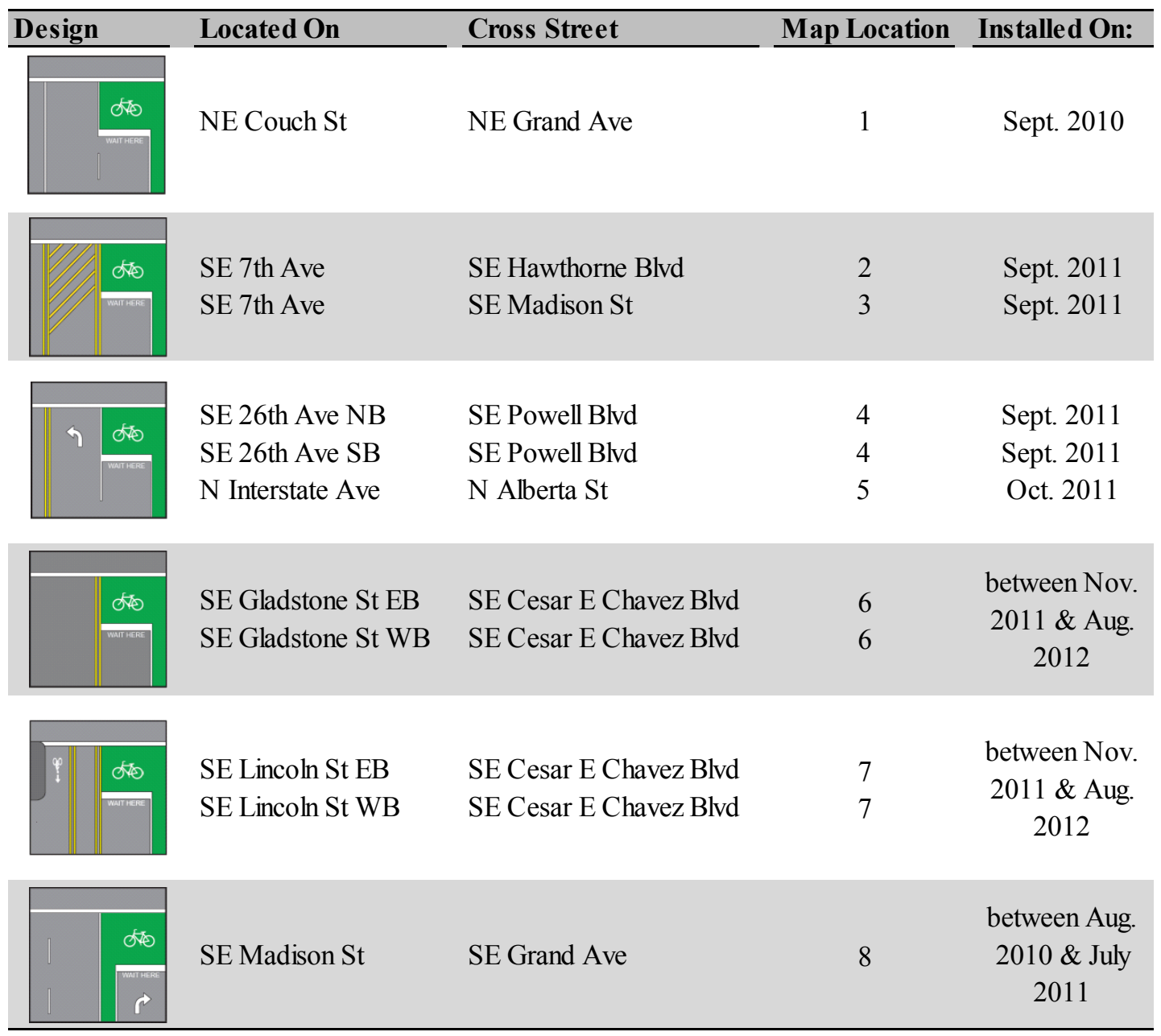




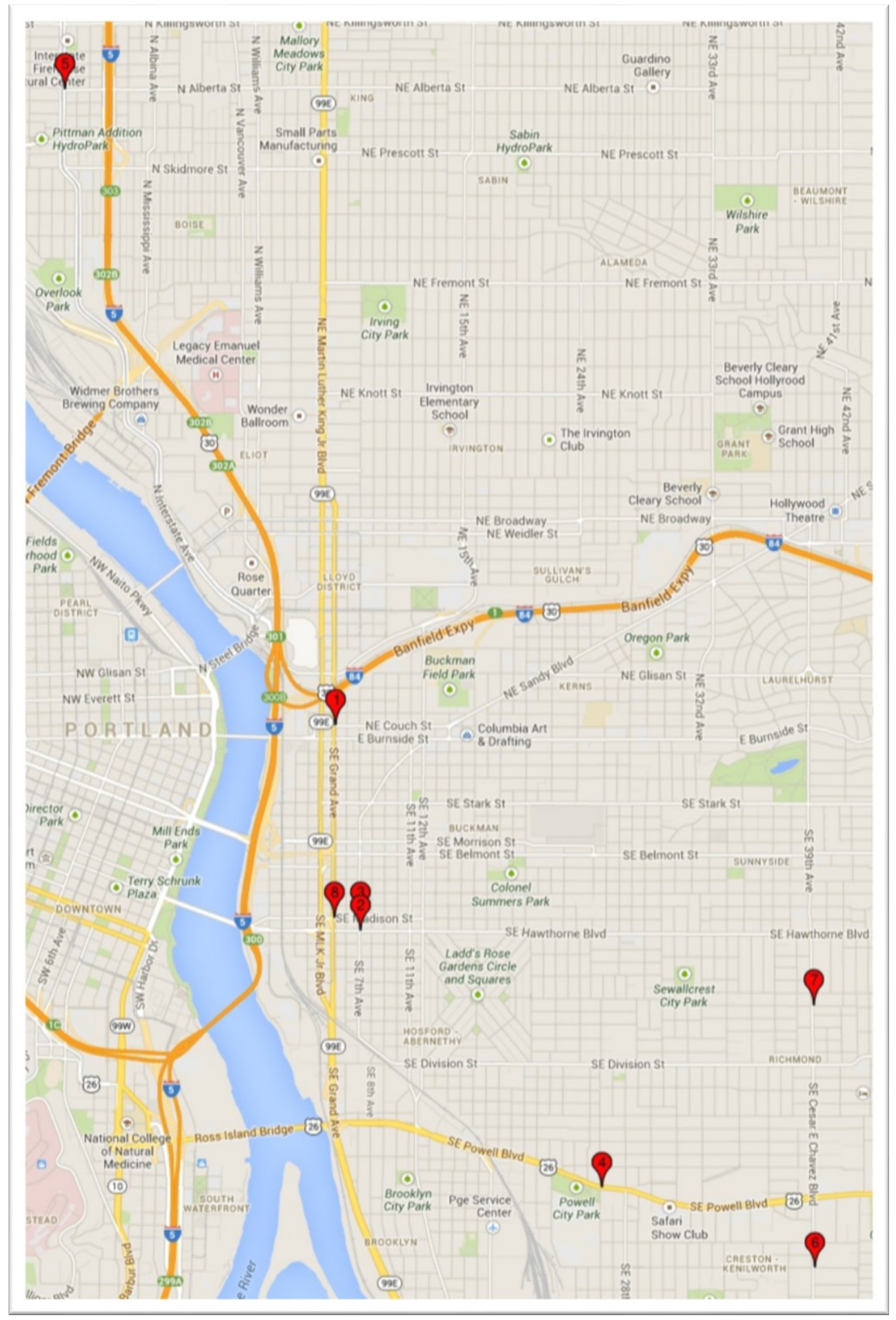

Figure 1: Map of Bike Box Locations 


\subsection{Video Surveillance}

The City of Portland installed cameras on nearby signal or utility poles and recorded video of each of the study intersections over a range of days for the full twenty-four hours of each day before the installation of the bike box. Approximately one year later, after the bike box had been installed and time was allowed for traffic to become familiar with the new traffic control device, the intersection was recorded again over a second range of dates for another full twenty-four hours of each day. Using these two sets of videos, a before and after analysis was performed.

Fourteen intersections receiving a bike box were originally selected for observation. Two video cameras were installed at each intersection to view the traffic and any conflicts: one camera viewing the stop bar (where the bike box would be located) and one camera viewing downstream with visibility of the traffic signals. Effort was also made to include the pedestrian crosswalk in the field of view to identify the purpose behind a yielding vehicle. These cameras were active for a range of dates within the fall season of 2010 .

For the study performed after the installation of the bike box, the intersections were again observed approximately one year later. Effort was made to capture the intersections in the same season as the before study so to have as similar conditions as possible. Similar views with both two cameras were also used: one camera viewing the area of the bike box and one camera viewing downstream from the intersection and traffic signal. The intersection of NE Grand Ave at NE Couch St was recorded in two different time periods: September, corresponding with the filming of the before video, and January, after the installation of an active bicycle warning sign that flashes for vehicles to yield 
when an upstream bicyclist is detected. With the exceptions of $\mathrm{N}$ Interstate Ave at $\mathrm{N}$ Tillamook St, N Willamette at N Portsmouth, and SW Terwilliger at SW Capitol Hwy, all intersections had an advanced stop box installed with ample time for users to gain familiarity. The plans to install a bike box at the three missing intersections were canceled or otherwise delayed, so the intersections were left out for the after study. The available study intersections, the dates of available video footage during both study periods, and the number of available hours of video data are listed in Table 3.

\section{Table 3: Available Dates of Video Data}

\begin{tabular}{|c|c|c|c|c|c|c|}
\hline \multirow{2}{*}{ Intersection } & \multicolumn{3}{|c|}{ Before Study Dates } & \multicolumn{3}{|c|}{ After Study Dates } \\
\hline & Start & End & Hours & Start & End & Hours \\
\hline \multirow[t]{3}{*}{ NE Couch St at Grand Ave } & $8 / 31 / 2010$ & $9 / 3 / 2010$ & 64 & $9 / 20 / 2011$ & $9 / 25 / 2011$ & 119 \\
\hline & 9/7/2010 & 9/9/2010 & 60 & $1 / 9 / 2012$ & $1 / 13 / 2012$ & 92 \\
\hline & $9 / 13 / 2010$ & $9 / 17 / 2010$ & 90 & & & \\
\hline SE 7th Ave at Hawthorne Blvd & $9 / 13 / 2010$ & $9 / 17 / 2010$ & 90 & $10 / 11 / 2011$ & $10 / 15 / 2011$ & 101 \\
\hline SE 7th Ave at Madison St & $9 / 20 / 2010$ & $9 / 24 / 2010$ & 103 & $9 / 20 / 2011$ & $9 / 24 / 2011$ & 95 \\
\hline \multirow[t]{2}{*}{ SE 26th Ave NB at Powell Blvd } & $9 / 27 / 2010$ & $10 / 1 / 2010$ & 93 & $2 / 6 / 2012$ & $2 / 8 / 2012$ & 48 \\
\hline & & & & $2 / 23 / 2012$ & $3 / 1 / 2012$ & 107 \\
\hline SE 26th Ave SB at Powell Blvd & $9 / 28 / 2010$ & $10 / 1 / 2010$ & 65 & $11 / 1 / 2011$ & $11 / 6 / 2011$ & 119 \\
\hline \multirow[t]{2}{*}{ N Interstate Ave at Alberta St } & $10 / 5 / 2010$ & $10 / 8 / 2010$ & 67 & $1 / 30 / 2012$ & $2 / 5 / 2012$ & 143 \\
\hline & $10 / 13 / 2010$ & $10 / 13 / 2010$ & 50 & & & \\
\hline \multirow[t]{2}{*}{ SE Gladstone St EB at CEC Blvd } & $10 / 11 / 2010$ & $10 / 13 / 2010$ & 48 & $10 / 18 / 2011$ & $10 / 23 / 2011$ & 111 \\
\hline & $10 / 15 / 2010$ & $10 / 16 / 2010$ & 20 & & & \\
\hline \multirow[t]{2}{*}{ SE Gladstone St WB at CEC Blvd } & $10 / 6 / 2010$ & $10 / 8 / 2010$ & 62 & $10 / 18 / 2011$ & $10 / 23 / 2011$ & 117 \\
\hline & $10 / 11 / 2010$ & $10 / 13 / 2010$ & 48 & & & \\
\hline SE Lincoln St EB at CEC Blvd & $10 / 18 / 2010$ & $10 / 22 / 2010$ & 91 & $1 / 31 / 2012$ & $2 / 5 / 2012$ & 93 \\
\hline SE Lincoln St WB at CEC Blvd & $10 / 18 / 2010$ & $10 / 22 / 2010$ & 92 & $1 / 30 / 2012$ & $2 / 3 / 2012$ & 93 \\
\hline \multirow[t]{2}{*}{ SE Madison St at Grand Ave } & $9 / 22 / 2010$ & $9 / 25 / 2010$ & 69 & $2 / 6 / 2011$ & $2 / 10 / 2011$ & 93 \\
\hline & $9 / 27 / 2010$ & $9 / 30 / 2010$ & 71 & & & \\
\hline SW Terwilliger Blvd at Capitol Hwy & $11 / 1 / 2010$ & $11 / 6 / 2010$ & 114 & & & \\
\hline N Willamette Blvd at Portsmouth Avє & $\epsilon 10 / 18 / 2010$ & $10 / 22 / 2010$ & 90 & & & \\
\hline $\mathrm{N}$ Interstate Ave at Tillamook St & $9 / 20 / 2010$ & $9 / 26 / 2010$ & 112 & & & \\
\hline
\end{tabular}


After data were collected at each of the intersections, methodology was employed to reduce and examine any impacts from the installation of the advanced stop box.

\subsection{Weather}

Weather data for the average high temperature and monthly precipitation were retrieved from the National Oceanic and Atmospheric Administration for the period of time between the before and after studies and is summarized in Figure 2. The data collection periods are highlighted with horizontal boxes.

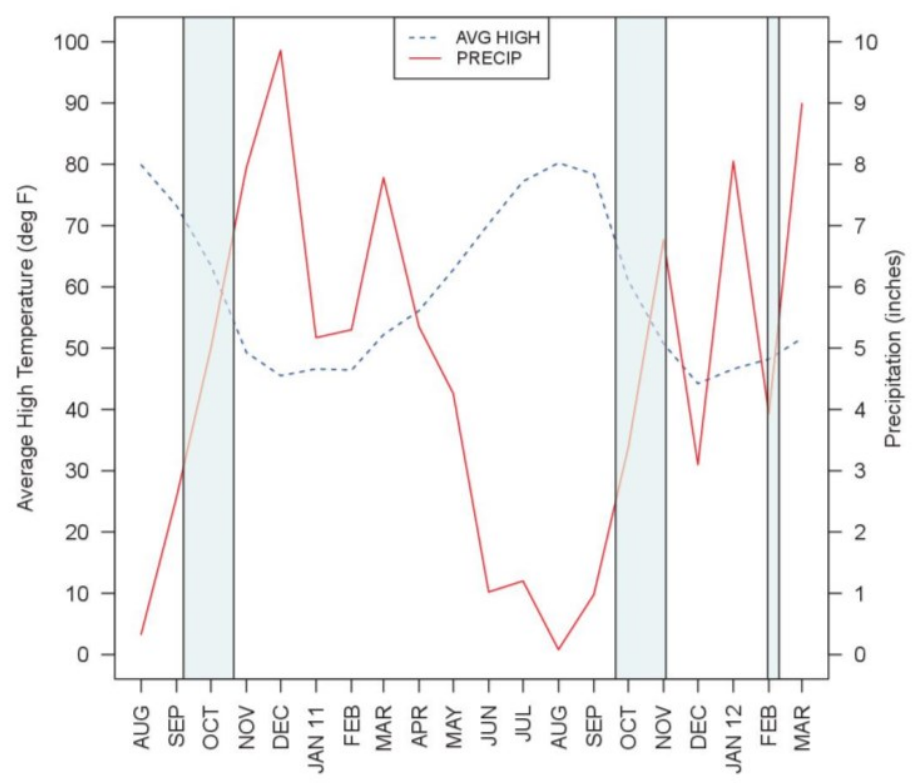

Figure 2: Average Monthly High Temperature and Precipitation 


\subsection{METHODS}

This section details the methodology for the conflict analysis including the reducing and interpreting the data retrieved from the video at each of the study intersections. Methodology behind the reduction of crash data is also explained.

To retrieve usable data from the videos, a log of the video data supplied by the City of Portland that included information on the available dates and amount of time video data were captured was created and organized by intersection. From the video data log, a single day was chosen from each intersection that had a full, uninterrupted video feed that captured the traffic over the entire twenty-four hour period starting at midnight. Vehicles traveling through the intersection were logged and any apparent conflicts were recorded in detail. After all intersections were observed, clips were taken of the conflicts and presented in front of professionals to identify if the conflict fell within the scope of the study and the severity of the incident. Conflicts that were unable to be determined at the time were marked for further review. The narrowed set of conflicts, including the unknown severities, was reviewed a second time by the panel and narrowed to minor and major conflicts. After the final review of the conflicts, further observations of the narrowed set of conflicts was made to observe individual events during the phase in which the conflict occurred as well as specific behaviors of the bicyclist.

\subsection{Data Reduction}

After the retrieval of the video data from the City of Portland, a log was created that detailed available dates and hours in which video was recorded. This video log was used 
to organize available data by intersection as well as keep track of which videos were to be watched and have the data reduced by a student. Areas were provided in the log to note which student watched the video and when it was completed.

For the sake of time, each intersection had one twenty-four hour video selected to be observed, shown in Table 4. The video selected to be observed was to be viewed from midnight to midnight without any large gaps in the video recording. The day selected also needed to be between Tuesday and Thursday so to have the typical weekly volumes of traffic traveling through it.

The video player used for the observations allowed the selection of video by date of recording and then by hour segment. The intersection videos would play with multiple camera views synced in time, or if the student desired, a single view could be selected and zoomed. Video playback speed could be adjusted to be faster or slower within the interface. Research assistants would typically watch the videos between normal playback speed and $4 \mathrm{x}$ speed, depending on amount of traffic and quality of the view. 
Table 4: Dates Studied Before and After Installation

\begin{tabular}{|c|c|c|}
\hline \multirow{2}{*}{ Intersection } & \multicolumn{2}{|c|}{ Date Observed } \\
\hline & Before & After \\
\hline \multirow[t]{2}{*}{ NE Couch St at NE Grand Ave } & $9 / 8 / 2010$ & $9 / 21 / 2011$ \\
\hline & & $1 / 10 / 2012$ \\
\hline SE 7th Ave at SE Hawthorne Blvd & $9 / 15 / 2010$ & $10 / 12 / 2011$ \\
\hline SE 7th Ave at SE Madison St & $9 / 22 / 2010$ & $9 / 21 / 2011$ \\
\hline SE 26th Ave NB at SE Powell Blvd & $9 / 28 / 2010$ & $2 / 7 / 2012$ \\
\hline SE 26th Ave SB at SE Powell Blvd & $9 / 29 / 2010$ & $11 / 2 / 2011$ \\
\hline $\mathrm{N}$ Interstate Ave at $\mathrm{N}$ Alberta St & $10 / 6 / 2010$ & $2 / 1 / 2012$ \\
\hline SE Gladstone St EB at SE Cesar E Chavez Blvd & $10 / 12 / 2010$ & $10 / 19 / 2011$ \\
\hline SE Gladstone St WB at SE Cesar E Chavez Blvd & $10 / 12 / 2010$ & $10 / 19 / 2011$ \\
\hline SE Lincoln St EB at SE Cesar E Chavez Blvd & $10 / 20 / 2010$ & $2 / 1 / 2012$ \\
\hline SE Lincoln St WB at SE Cesar E Chavez Blvd & $10 / 20 / 2010$ & $2 / 1 / 2012$ \\
\hline SE Madison St at NE Grand Ave & $9 / 29 / 2010$ & 2/9/2012 \\
\hline SW Terwilliger Blvd at SW Capitol Hwy & $11 / 3 / 2010$ & N/A \\
\hline N Willamette Blvd at N Portsmouth Ave & $10 / 21 / 2010$ & N/A \\
\hline $\mathrm{N}$ Interstate Ave at $\mathrm{N}$ Tillamook St & N/A & N/A \\
\hline
\end{tabular}

While observing the video and the traffic traveling through the intersection, each vehicle and bike traveling through the study area was logged in a spreadsheet using Microsoft Excel. Motorized vehicles were further broken down into the direction of travel (through, right, and sometimes left). To increase the ease of recording the data, observations were broken down into five-minute and fifteen-minute blocks on the spreadsheets. Calculations within the spreadsheet would automatically calculate the fifteen-minute and total tallies of bicycles, through-moving motor vehicles, and rightturning motor vehicles.

If a possible conflict between a vehicle and bicycle was observed by the viewer of the video, detailed metrics were recorded pertaining to the behaviors of each party as well as 
the phase of the signal. This included whether braking or evasive maneuvers were witnessed by either the bicycle or motor vehicle, if a collision occurred between the two parties, how much time had passed within the phase of the signal and the color of the indication, how many vehicles and bicycles traveled through the intersection during the phase before the moment of conflict, and if any pedestrians were present in the crosswalk during that time. Notes were also recommended to be taken in order to describe what the observer identified as the conflict.

\subsection{Conflict Clips}

After each video in the study was observed, all recorded conflicts were compiled and clipped into .AVI format for presentation in front of an expert panel. Clips of each conflict ranged from fifteen seconds to thirty seconds, depending on the activity in the intersection, with ample time given before the conflict occurred to give the panel an idea of what activity was occurring prior to the incident.

The clips were then presented in front of the expert panel consisting of Dr. Christopher Monsere, Dr. Jennifer Dill, and Nathan McNeil (the authors of the Phase I study of bike boxes). Each clip was watched up to five times to identify what the original observer flagged as a conflict while the panel would mark on a worksheet similar to the conflict detail spreadsheet given to the observer. The panel would record the assumed severity of the conflict (minor, substantial, or major conflict), what type of conflict was shown (right-hook or out of scope for the study), and if braking or avoidance by the bicyclist or vehicle was observed. After each of the panel had scored the severity of the conflict and noted what they believed to be occurring, the panel would then share his/her score of the 
incident and describe what events he/she had noticed during the clip. After each member of the panel explained whether the incident was within the scope of the study and if it was to be considered a minor conflict, a substantial conflict, a major conflict, or not a conflict at all, a consensus between the panel members would be reached and that severity would be documented. Conflicts in which members were unsure of the severity were noted for a later time.

Once all conflict clips were observed by the expert panels, the narrowed-down number of conflicts were grouped together by severity and edited into a single .AVI video with cue cards between clips to identify intersection and time when the conflict had occurred. Any unknown or disputed conflict severities were placed at the end of what was deemed the closest possible severity.

A second viewing of the conflicts was performed by the panel at a later time. This time, the entire set of clips (grouped by minor conflicts and substantial/major conflicts) would play through (including the conflicts with an unknown severity) while the panel would note the perceived severity on a worksheet that showed what the conflict had been rated during the first review. This time during the review, the conflicts were categorized into either minor or major conflicts. Substantial conflicts were reorganized into either of the other categories or dropped as being a conflict outside the scope of the study.

After the entire set of clips had completed, the members of the panel would reveal his/her severity of each of the conflicts, this time if it was considered a minor conflict or a major conflict. If any of the panel had a separate opinion of the conflict or had a question of the 
video, the clip would be replayed and the panel would come to a consensus of the severity of the clip. The consensus of the severity of each conflict was again documented for further study.

\subsection{Re-Observing Intersection Conflicts}

Each of the narrowed conflicts was re-observed in the original video, this time while logging new information. The timestamp of the video was recorded for each change of the signal phase (green, yellow, and red), for each vehicle or bicyclist passing through the stop bar of the intersection, and, for the case of NE Grand Avenue at NE Couch Street after the installation of the active bicycle warning sign, when the warning sign would light up and warn vehicles of an approaching bicyclist. Information was also gathered in these extra viewings including the direction of travel for the vehicle and whether or not the bicyclist paid attention to oncoming traffic over his/her shoulder when passing through the intersection. These "head-checks" by the bicyclist were to be used to see if the addition of the bike box made bicyclists take the perceived safety of the treatment for granted.

The yielding behavior when a conflict occurred was also able to be gathered during the re-observation of each of the conflict phases. Specifically, in the event of a conflict, which party permitted the other to proceed with his/her movement.

This additional information was used to make an event log of each of the conflict phases at the intersection. This log would be shown visually to depict the spacing of motor vehicles traveling past the stop bar at the intersection in relation to bicyclists. The 
conflict that occurred between the motor vehicle and bicyclist could be highlighted to see at what time during the green phase the conflict had occurred and if any trends existed. Since bike boxes are generally implemented to allow bicyclists to advance ahead of a motor vehicle queue to prevent right-hook conflicts, a period of five seconds after green indication was observed separately to identify if the installation of the bike box would impact conflict rates within the start of the phase. The direction of the motor vehicle and whether or not the bicyclist was attentive to traffic behind them would be depicted in the visual log.

\subsection{Crash Data}

Crash data for the study intersections were obtained using the Crash Data System provided by the Oregon Department of Transportation for dates from January $1^{\text {st }}, 2007$, to December $31^{\text {st }}, 2012$. Crashes were narrowed down to only those that involved a bicyclist.

To normalize and develop a crash rate that could be compared between the before period and the after period, bicycle volume data from the Hawthorne Bridge and biking growth factors observed by the Portland Bureau of Transportation were used. The bicycle volume data from the Hawthorne Bride were provided as factors to determine the annual average daily bike volume based on the day of week and month of year the counts were gathered. Using these factors, along with the total bikes observed during the latest observed twenty-four hour study period, the average annual daily bike volume was determine for each of the study intersections. This average annual daily bike volume was then adjusted by growth factors depending on the year the latest volume was counted. 


\subsection{ANALYSIS}

This section reviews the results from the data reduction and presents them in tabular and graphic form for comparison. Results are presented for both individual intersections and groups of intersections that were of similar lane configurations. Data from the research are then normalized in an attempt to discover any correlation between the installation of a bike box and the number of conflicts that occur at an intersection. The results for the crash data analysis and the bicycle head-checks after implementation of the painted bike box are also explored.

\subsection{Intersection Volumes}

The Excel spreadsheet that was used to log vehicles and bicyclists traveling through each study intersection was configured to sum the total number of vehicles observed over the total period of twenty-four hours. The volumes of vehicles observed for each intersection during each period of study is reported in Table 5 . 
Table 5: Vehicle Volumes Observed

\begin{tabular}{|c|c|c|c|c|c|c|c|c|c|c|c|c|}
\hline \multirow{3}{*}{ \# } & \multirow{3}{*}{ Intersection } & \multicolumn{4}{|c|}{ Before } & \multicolumn{4}{|c|}{ After } & \multicolumn{3}{|c|}{ \% Change } \\
\hline & & \multicolumn{3}{|c|}{ Autos } & \multirow{2}{*}{ Bicyclists } & \multicolumn{3}{|c|}{ Autos } & \multirow{2}{*}{ Bicyclists } & \multicolumn{2}{|c|}{ Autos } & \multirow{2}{*}{ Bicyclists } \\
\hline & & Left & Straight & Right & & Left & Straight & Right & & Right & Total & \\
\hline & $\begin{array}{l}\text { NE Couch St } \\
\text { - Grand Ave }\end{array}$ & $\mathrm{N} / \mathrm{A}$ & 3588 & 2162 & 555 & $\mathrm{~N} / \mathrm{A}$ & 4214 & 2299 & 909 & $6 \%$ & $13 \%$ & $64 \%$ \\
\hline & $\begin{array}{l}\text { SE 7th Ave } \\
\text { - Hawthorne Blvd }\end{array}$ & $\mathrm{N} / \mathrm{A}$ & 3761 & 428 & 316 & $\mathrm{~N} / \mathrm{A}$ & 4006 & 486 & 310 & $14 \%$ & $7 \%$ & $-2 \%$ \\
\hline 3 & $\begin{array}{l}\text { SE 7th Ave } \\
\text { - Madison St }\end{array}$ & $\mathrm{N} / \mathrm{A}$ & 5423 & 1160 & 798 & $\mathrm{~N} / \mathrm{A}$ & 5665 & 2170 & 818 & $87 \%$ & $19 \%$ & $3 \%$ \\
\hline & $\begin{array}{l}\text { SE 26th Ave NB } \\
\text { - Powell Blvd }\end{array}$ & N/A & 1681 & 826 & 603 & N/A & 1855 & 690 & 337 & $-16 \%$ & $2 \%$ & $-44 \%$ \\
\hline & $\begin{array}{l}\text { SE 26th Ave SB } \\
\text { - Powell Blvd }\end{array}$ & $\mathrm{N} / \mathrm{A}$ & 2140 & 1011 & 522 & $\mathrm{~N} / \mathrm{A}$ & 1835 & 723 & 298 & $-28 \%$ & $-19 \%$ & $-43 \%$ \\
\hline & $\begin{array}{l}\text { N Interstate Ave } \\
\text { - Alberta St }\end{array}$ & $\mathrm{N} / \mathrm{A}$ & 5677 & 539 & 346 & $\mathrm{~N} / \mathrm{A}$ & 5746 & 533 & 211 & $-1 \%$ & $1 \%$ & $-39 \%$ \\
\hline 6 & $\begin{array}{l}\text { SE Gladstone St EB } \\
\text { - CEC Blvd }\end{array}$ & 1044 & 642 & 550 & 189 & 1116 & 596 & 618 & 146 & $12 \%$ & $4 \%$ & $-23 \%$ \\
\hline 6 & $\begin{array}{l}\text { SE Gladstone St WB } \\
\text { - CEC Blvd }\end{array}$ & 119 & 646 & 306 & 217 & 115 & 593 & 288 & 173 & $-6 \%$ & $-7 \%$ & $-20 \%$ \\
\hline 7 & $\begin{array}{l}\text { SE Lincoln St EB } \\
\text { - CEC Blvd }\end{array}$ & 527 & 2 & 513 & 606 & 471 & 1 & 442 & 394 & $-14 \%$ & $-12 \%$ & $-35 \%$ \\
\hline & $\begin{array}{l}\text { SE Lincoln St WB } \\
\text { - CEC Blvd }\end{array}$ & 336 & 1 & 694 & 687 & 384 & 1 & 657 & 479 & $-5 \%$ & $1 \%$ & $-30 \%$ \\
\hline & $\begin{array}{l}\text { SE Madison St } \\
\text { - Grand Ave }\end{array}$ & $\mathrm{N} / \mathrm{A}$ & 3456 & 2265 & 3010 & $\mathrm{~N} / \mathrm{A}$ & 4730 & 2147 & 1777 & $-5 \%$ & $20 \%$ & $-41 \%$ \\
\hline
\end{tabular}


For the period observed before the installation of the bike box, $\mathrm{N}$ Willamette Boulevard at Portsmouth Avenue and SW Terwilliger Boulevard at Capitol Highway were observed, but dropped from the conflict comparison due to not receiving a bike box during the period of study.

For the period observed after the installation of the bike box, N Couch Street at Grand Avenue was observed twice: once in September shortly after the installation of the bike box and then again after the installation of an active bicycle warning sign. The data from the January observation were omitted from the conflict comparison due to not being at the same period of study and being effected by the installation of an active bicycle sign.

All before and after comparisons exclude intersections that did not receive a bike box during the analysis period as well as the additional observation of NE Couch Street at Grand Avenue.

\subsection{Conflicts}

For the group of study intersections observed before the installation of the advanced stop box, a total of 82 possible conflicts were flagged for review. These conflicts were narrowed down to 21 total conflicts when reviewed by the expert panel.

For the videos observed after the installation of the bike box, a total of 74 possible conflicts were flagged for the study intersections. These conflicts were narrowed down to 24 total conflicts after review.

Conflicts in intersections that did not receive an advanced stop box or that occurred during another period of study were not used in the comparisons of before and after. Of 
the 21 total conflicts observed before installation of the bike box, only 19 occurred at intersections that received a bike box. For the 24 conflicts occurring after the installation of the advanced stop box, the six conflicts observed in January for NE Grand Avenue at Couch Street were omitted due to the installation of an active bicycle warning sign. Table 6 summarizes the total conflicts observed at each intersection before and after the installation of the bike box. A graph showing the conflict splits at each intersection is given in Figure 3.

Table 6: Summary of Observed Conflicts at Bike Box Intersections

\begin{tabular}{|c|c|c|c|c|c|c|c|}
\hline \multirow{2}{*}{ \# } & \multirow{2}{*}{ Intersection } & \multicolumn{3}{|c|}{ Before } & \multicolumn{3}{|c|}{ After } \\
\hline & & Minor & Major & Total & Minor & Major & Total \\
\hline 1 & $\begin{array}{l}\text { NE Couch St } \\
\text { - Grand Ave }\end{array}$ & 4 & 2 & 6 & 8 & 1 & 9 \\
\hline 2 & $\begin{array}{l}\text { SE 7th Ave } \\
\text { - Hawthorne Blvd }\end{array}$ & 0 & 0 & 0 & 2 & 0 & 2 \\
\hline 3 & $\begin{array}{l}\text { SE 7th Ave } \\
\text { - Madison St }\end{array}$ & 0 & 0 & 0 & 1 & 0 & 1 \\
\hline 4 & $\begin{array}{l}\text { SE 26th Ave NB } \\
\text { - Powell Blvd }\end{array}$ & 5 & 0 & 5 & 0 & 0 & 0 \\
\hline 4 & $\begin{array}{l}\text { SE 26th Ave SB } \\
\text { - Powell Blvd }\end{array}$ & 0 & 1 & 1 & 4 & 0 & 4 \\
\hline 5 & $\begin{array}{l}\text { N Interstate Ave } \\
\text { - Alberta St }\end{array}$ & 3 & 0 & 3 & 0 & 0 & 0 \\
\hline 6 & $\begin{array}{l}\text { SE Gladstone St EB } \\
\text { - CEC Blvd }\end{array}$ & 0 & 0 & 0 & 0 & 0 & 0 \\
\hline 6 & $\begin{array}{l}\text { SE Gladstone St WB } \\
\text { - CEC Blvd }\end{array}$ & 1 & 0 & 1 & 0 & 0 & 0 \\
\hline 7 & $\begin{array}{l}\text { SE Lincoln St EB } \\
\text { - CEC Blvd }\end{array}$ & 1 & 0 & 1 & 0 & 0 & 0 \\
\hline 7 & $\begin{array}{l}\text { SE Lincoln St WB } \\
\text { - CEC Blvd }\end{array}$ & 0 & 0 & 0 & 2 & 0 & 2 \\
\hline 8 & $\begin{array}{l}\text { SE Madison St } \\
\text { - Grand Ave }\end{array}$ & 2 & 0 & 2 & 0 & 0 & 0 \\
\hline & Total Conflicts & 16 & 3 & 19 & 17 & 1 & 18 \\
\hline
\end{tabular}




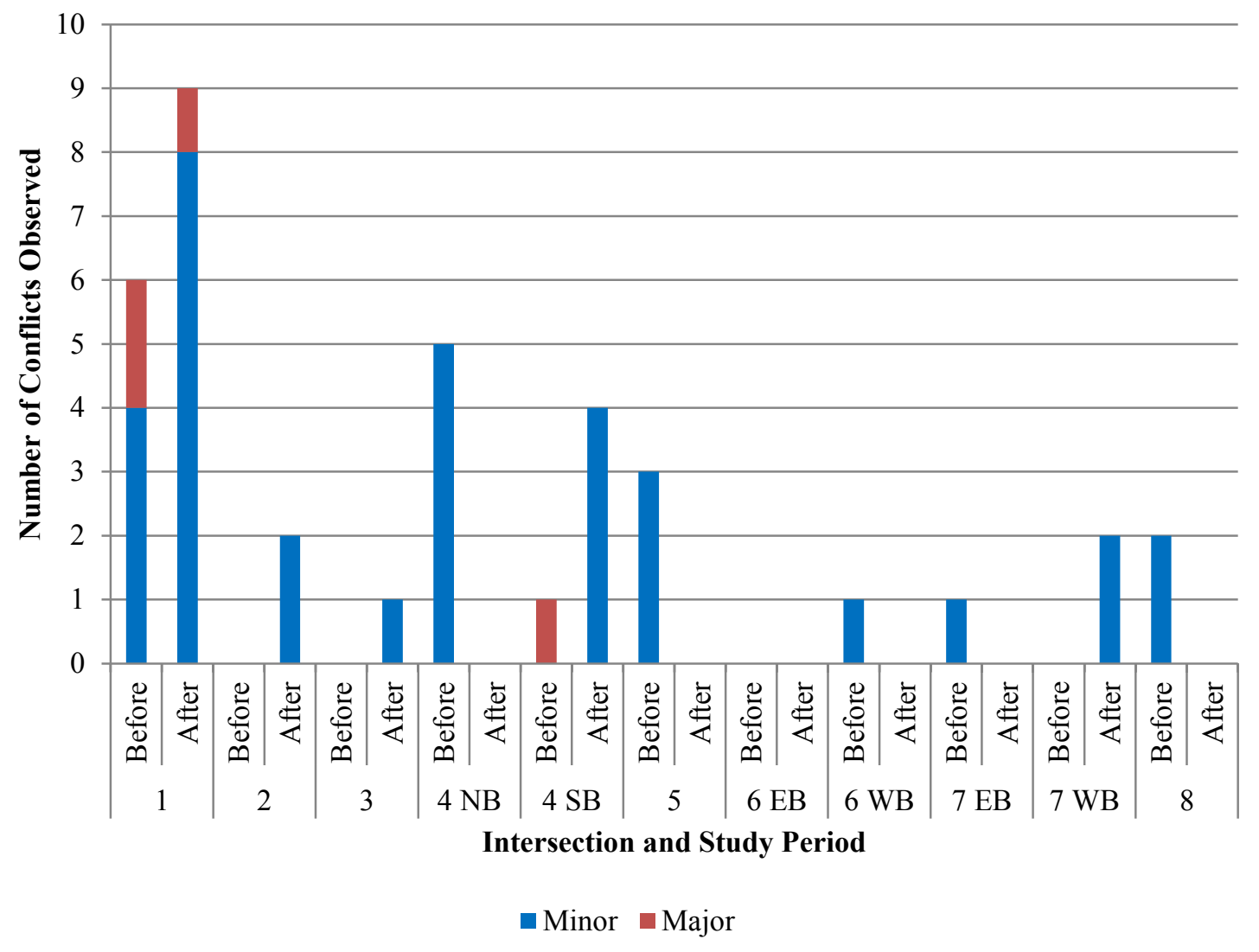

Figure 3: Minor \& Major Conflict Totals at Study Intersections

The small number of conflicts observed makes statistical comparisons challenging. The most conflicts were observed at the intersection of NE Couch Street at Grand Avenue, with only 15 total conflicts being observed during both valid periods of study. The following subsections review the results at each intersection in more detail. 


\subsubsection{Intersection Analysis}

Since the bike box was installed at an array of different type of intersections, each intersection was observed individually before grouping the intersections together by lane configuration. It should be noted that other factors not accounted for in the study such as grade at the intersection or the speed of the bicycles could attribute to the number of conflicts observed.

\subsubsection{NE Couch St at Grand Ave}

The intersection of NE Couch Street at Grand Avenue was observed in the fall prior to and after the installation of the advanced stop box. An additional observation was made in January of 2012 after an active bicycle warning sign was installed to warn motorists of approaching bicyclists, but results during this period were omitted from the conflict comparison. The bike box was installed on the westbound leg of NE Couch Street in the right-most lane. The approach on NE Couch Street is two lanes with a through lane and a shared through/right lane. On-street parking (in the form of a loading zone) and a curb bulb-out are located prior to the intersection. The bike lane on NE Couch Street leading up to the intersection is only present for the block between NE $6^{\text {th }}$ Avenue and NE $7^{\text {th }}$ Avenue. Street-car tracks run along the near-lane of NE Grand Avenue. It should be noted that the intersection is located at the bottom of a down-hill grade allowing bicyclists to maintain pace with vehicular traffic. Vehicles turning right at the intersection also have a tendency to turn into the second or third lane on NE Grand Avenue due to the streetcar tracks located in the nearest lane. This behavior in addition to the bicyclist's higher than normal speed may have been a possible reason behind some 
of the conflicts. Figure 4 shows the camera views of the intersection for all three observed periods.

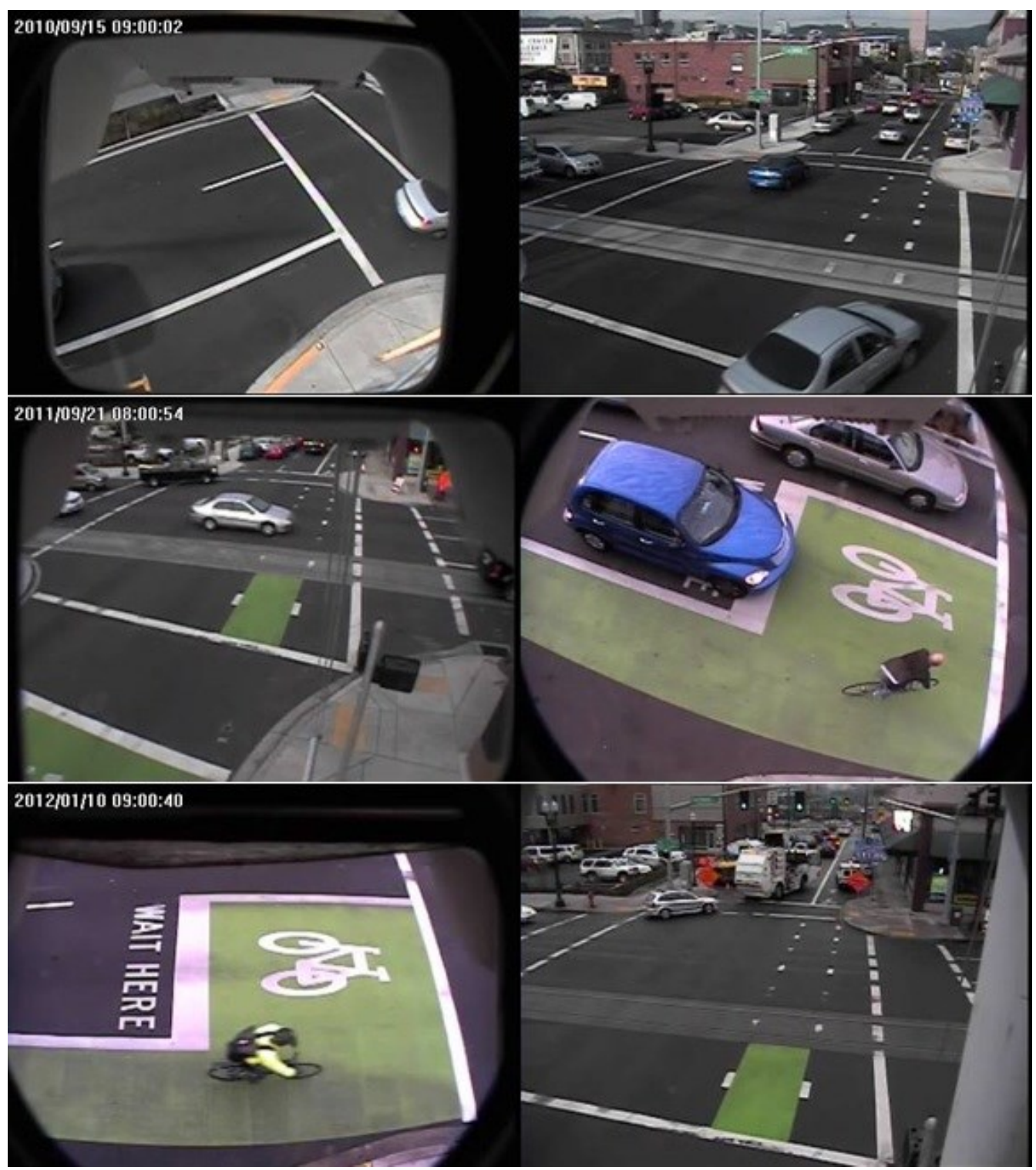

Figure 4: NE Couch St at Grand Ave Camera Views

A total of six conflicts were observed during the study period before the installation of the bike box. Of these, four conflicts were classified as minor and two were classified as major incidents. Nine total conflicts were observed during the study period after the 
installation of the advanced stop box, including eight minor and one major incident. Table 7 summarizes the conflicts over each of the analysis periods and provides a change in amount of conflicts between the before and after study periods as well as the number of conflicts which occurred within the initial start of the green indication (defined as within five seconds of the start of the green phase).

\section{Table 7: Conflicts at NE Couch St at Grand Ave}

\begin{tabular}{|c|c|c|c|c|c|c|}
\hline Period & Minor & Major & Total & Initial Green & Bike Yielded & Bike Passing \\
\hline Before & 4 & 2 & 6 & 1 & 6 & 4 \\
\hline After & 8 & 1 & 9 & 3 & 5 & 8 \\
\hline$\Delta$ & 4 & -1 & 3 & 2 & -1 & 4 \\
\hline
\end{tabular}

After the conflicts were narrowed, the intersection video was observed during each of the incidents and events were logged for the each entire phase. Figure 5 shows the event log during each conflict for both the before and after study periods. The event log, as described in the methodology section, depicts the events during a phase in which a conflict occurs. The chart separates motor vehicles and bicycles crossing into the intersection to show their relation in time as well as the motor vehicle's direction of travel or the bicyclist's attentiveness to traffic behind them. A reference line was provided in the chart to help identify conflicts that occur within five seconds of the green indication, or when the bike box is assumed to impact the conflict rate the most. 

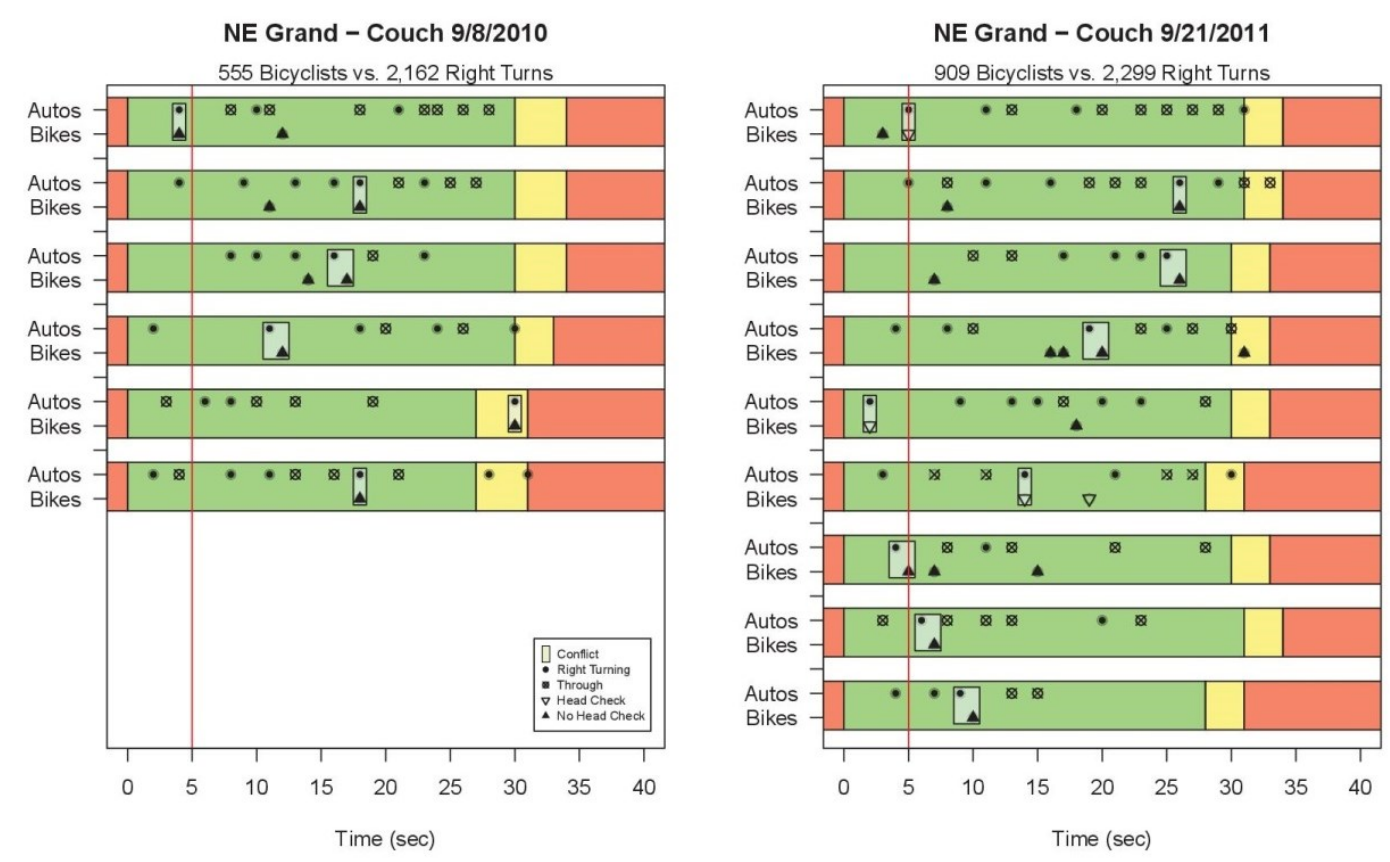

Figure 5: Event Log Before and After at NE Couch St at Grand Ave

Only one conflict was observed during the start-up of the green phase before the installation of the bike box. This conflict occurred with both parties starting through the intersections from a stopped position. Five of the remaining conflicts occurred between six seconds and twenty seconds into the green phase and one conflict happened at the end of the phase. In four of the six observed conflicts, the bike appeared to be in the process of overtaking the motor vehicle when the conflict occurred. All six of the conflicts involved the bicyclist yielding to the movement of the motor vehicle. None of the bicyclists seen in the conflict clips before the installation were observed checking behind them for oncoming traffic (or performing a "head-check").

After the installation of the bike box, three conflicts were observed to have occurred during the start-up of the green phase: two of which occurred between a vehicle and a 
bicyclist who was in movement as he approached the green indication. Two conflicts were observed to have occurred between five seconds and ten seconds of green while the remaining conflicts occurred between fourteen seconds and twenty-five seconds. In all but one of the conflicts (an initial conflict with both parties at the stop bar at change of signal), the bicycle appeared to be overtaking the motor vehicle when the conflict occurred. Five conflicts were resolved by the bicyclist yielding to the turning movement of the motor vehicle while four involved the vehicle yielding to the bicyclist. Four bicyclists were observed looking back at oncoming traffic; however, three head-checks were the bicyclist that was involved in the conflict and one head-check was immediately after the observed conflict.

\subsubsection{SE $7^{\text {th }}$ Ave at Hawthorne Blvd}

The intersection of SE $7^{\text {th }}$ Avenue at Hawthorne Boulevard was observed in the fall prior to and after the installation of the advanced stop box. The bike box was installed on the northbound SE $7^{\text {th }}$ Avenue approach. SE $7^{\text {th }}$ Avenue is a three-lane, two-way roadway with a center two-way left-turn lane. Bike lanes and on-street parking areas are available on both sides of the street before and after the intersection. Since Hawthorne Boulevard is a one-way street traveling eastbound, there is no left-turn refuge for northbound SE $7^{\text {th }}$ Avenue. The bike box installed on the SE Hawthorne approach was observed during Phase I study. Figure 6 shows the camera views at the intersection observed for both periods of study. 


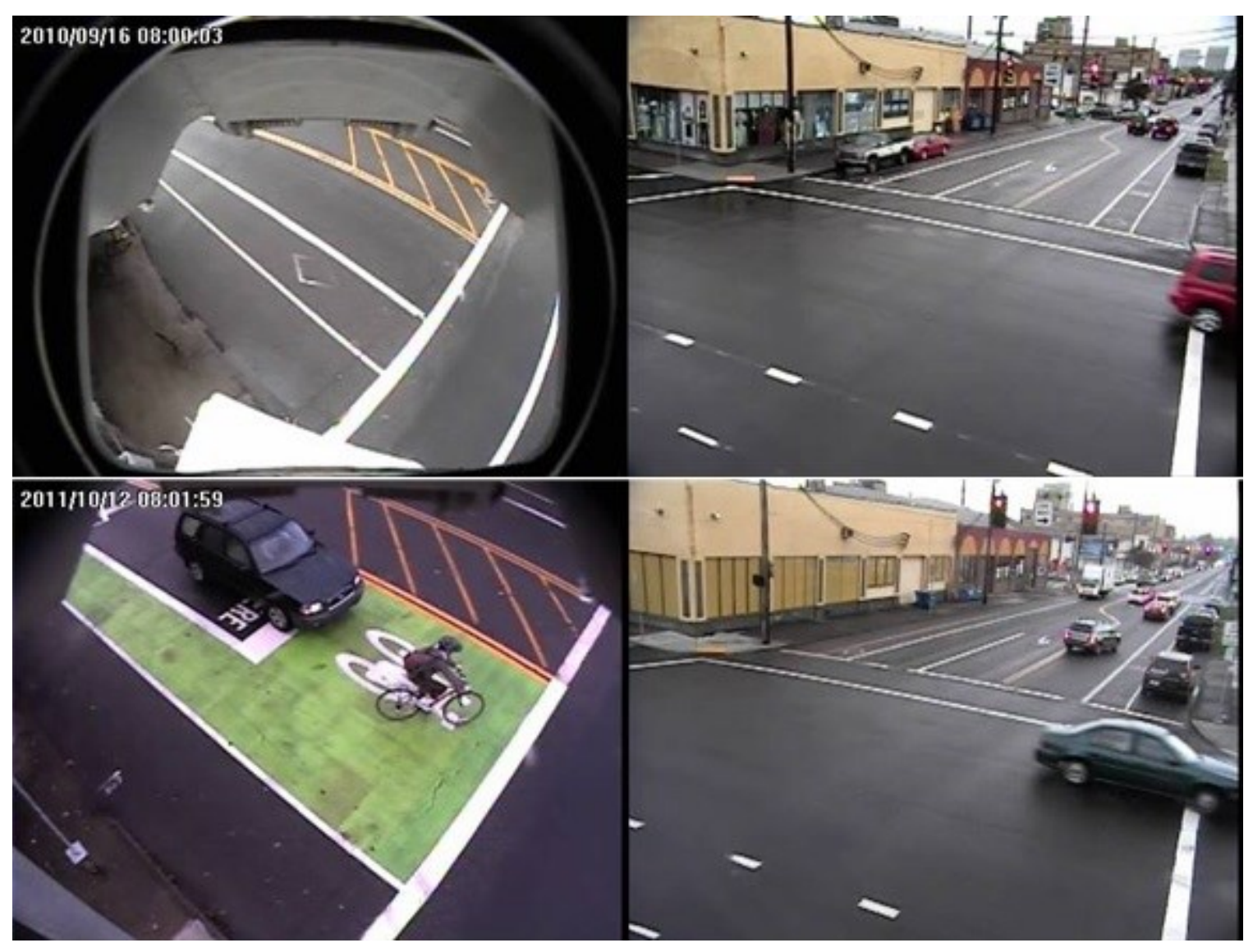

Figure 6: SE 7th Ave at Hawthorne Blvd Camera Views

No conflicts were observed during the twenty-four hour period of study before the bike box was installed at the intersection. For the period of study after the bike box was installed, two minor conflicts were observed. Table 8 summarizes the conflicts observed during both study periods as well as the number of conflicts occurring within the initial green indication.

Table 8: Conflicts at SE 7th Ave at Hawthorne Blvd

\begin{tabular}{|c|c|c|c|c|c|c|}
\hline Period & Minor & Major & Total & Initial Green & Bike Yielded & Bike Passing \\
\hline Before & 0 & 0 & 0 & 0 & 0 & 0 \\
\hline After & 2 & 0 & 2 & 1 & 0 & 2 \\
\hline$\Delta$ & 2 & $\mathbf{0}$ & 2 & 1 & $\mathbf{0}$ & 2 \\
\hline
\end{tabular}


After the narrowing of the conflicts, the videos were observed again to identify events that occurred during each of the conflicts. Figure 7 shows the event log for the two conflicts observed after the bike box was installed.
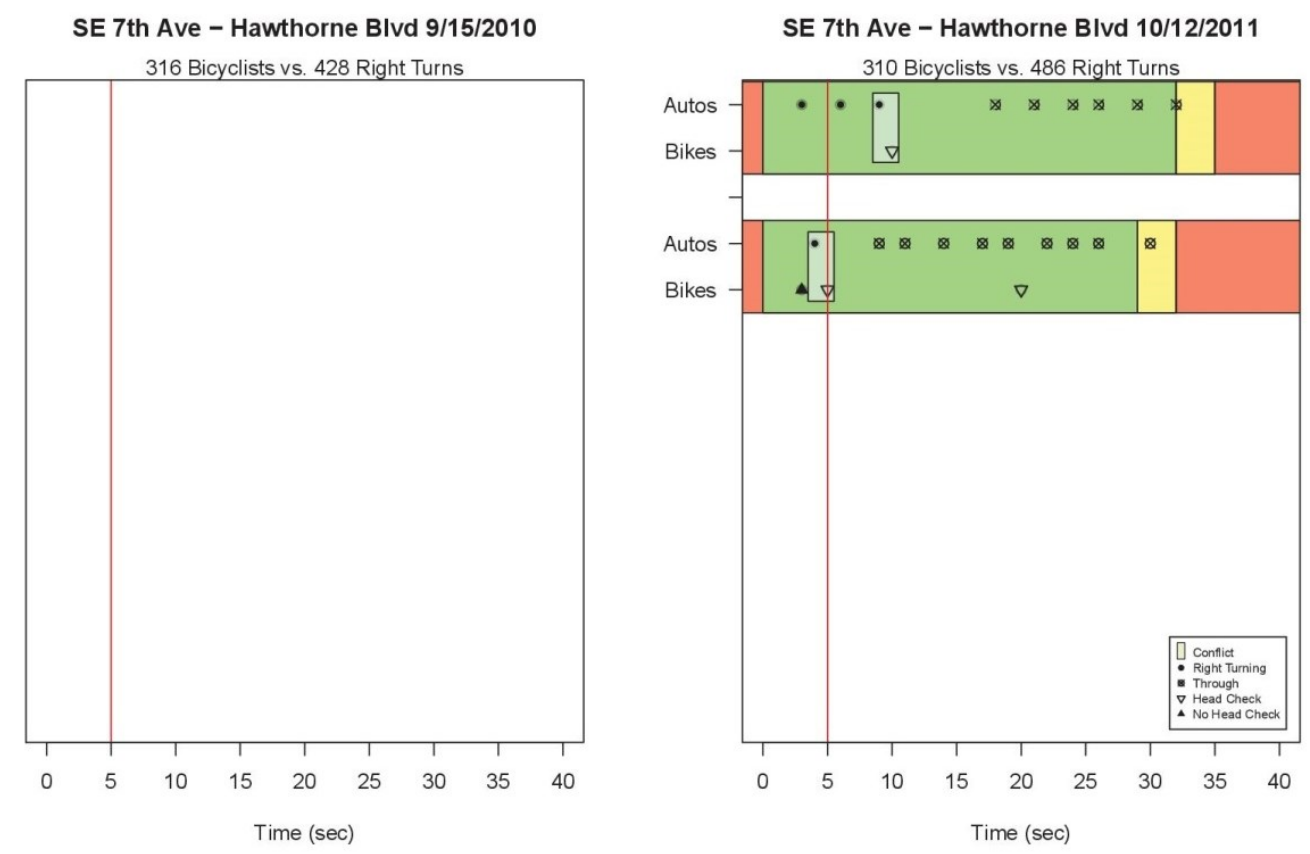

Figure 7: Event Log Before and After at SE 7th Ave at Hawthorne Blvd

Of the two conflicts observed after the installation of the advanced stop box, only one incident occurred within five seconds of the signal turning green. The conflict involved the second bicyclist to pass through the intersection (who was in movement before the signal indication changed to green) and the first motor vehicle (who was at the intersection during red indication). The other incident occurred within ten seconds of the green indication and involved the third right-turning motorized vehicle conflicting with the first bicyclist to approach the intersection. Both conflicts occurred when the bicyclist was in the process of overtaking the motor vehicle and were resolved with the motor 
vehicle yielding to the bicyclist traveling through the intersection. Three of the four bicyclists were observed checking behind them for oncoming traffic; however, two of those three head-checks were the bicyclists who were involved in the observed conflict.

\subsubsection{SE 7th Ave at Madison St}

The intersection of SE $7^{\text {th }}$ Avenue at Madison Street was also observed at similar periods before and after the installation of the advanced stop box about a year apart. This intersection is two blocks north of the study intersection of SE $7^{\text {th }}$ Avenue at Hawthorne Boulevard. The bike box was installed on the southbound SE $7^{\text {th }}$ Avenue approach. Much like the intersection at Hawthorne Boulevard, SE $7^{\text {th }}$ Avenue is a three-lane, twoway roadway with a center two-way left-turn lane. Bike lanes and on-street parking areas are available on both sides of the street on both sides of the intersection. It was observed in the videos that majority of the bicyclists were turning right to use Madison to cross the Hawthorne Bridge. Since Madison Street is a one-way street traveling westbound, the

southbound left-turn from SE $7^{\text {th }}$ Avenue is restricted. Figure 8 shows the available camera views at the intersection for both study periods. 


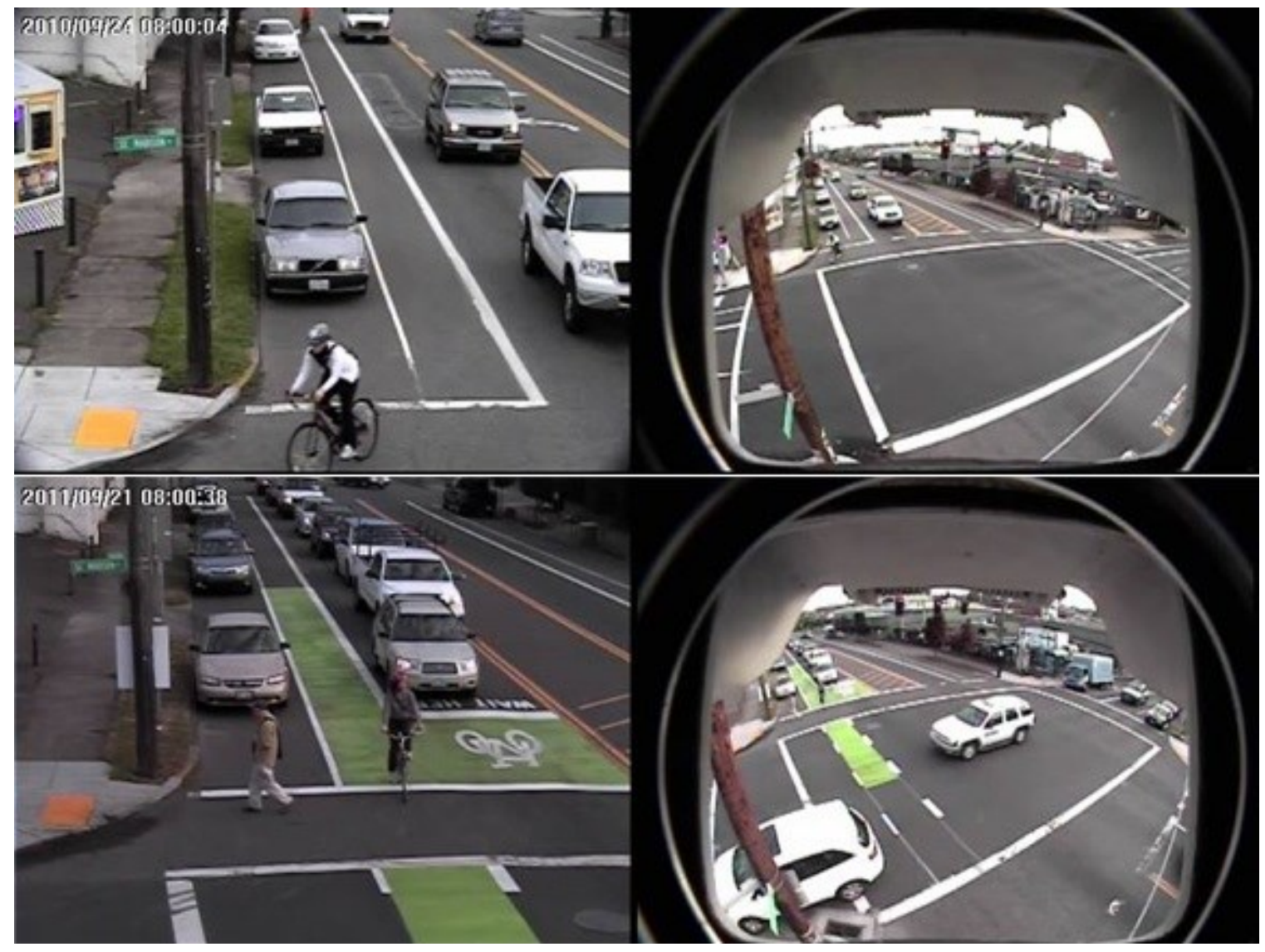

Figure 8: SE 7th Ave at Madison St Camera Views

No conflicts were observed during the twenty-four hour period of study before the bike box was installed at the intersection. For the period of study after the bike box was installed, only one minor conflict was observed. Table 9 summarizes the conflicts observed during both study periods as well as the number of conflicts that occurred within five seconds of the green indication.

\section{Table 9: Conflicts at SE 7th Ave at Madison St}

\begin{tabular}{|c|c|c|c|c|c|c|}
\hline Period & Minor & Major & Total & Initial Green & Bike Yielded & Bike Passing \\
\hline Before & 0 & 0 & 0 & 0 & 0 & 0 \\
\hline After & 1 & 0 & 1 & 0 & 1 & 0 \\
\hline$\Delta$ & 1 & $\mathbf{0}$ & 1 & $\mathbf{0}$ & 1 & $\mathbf{0}$ \\
\hline
\end{tabular}


Figure 9 shows the event log for the one conflict observed after the bike box was installed.
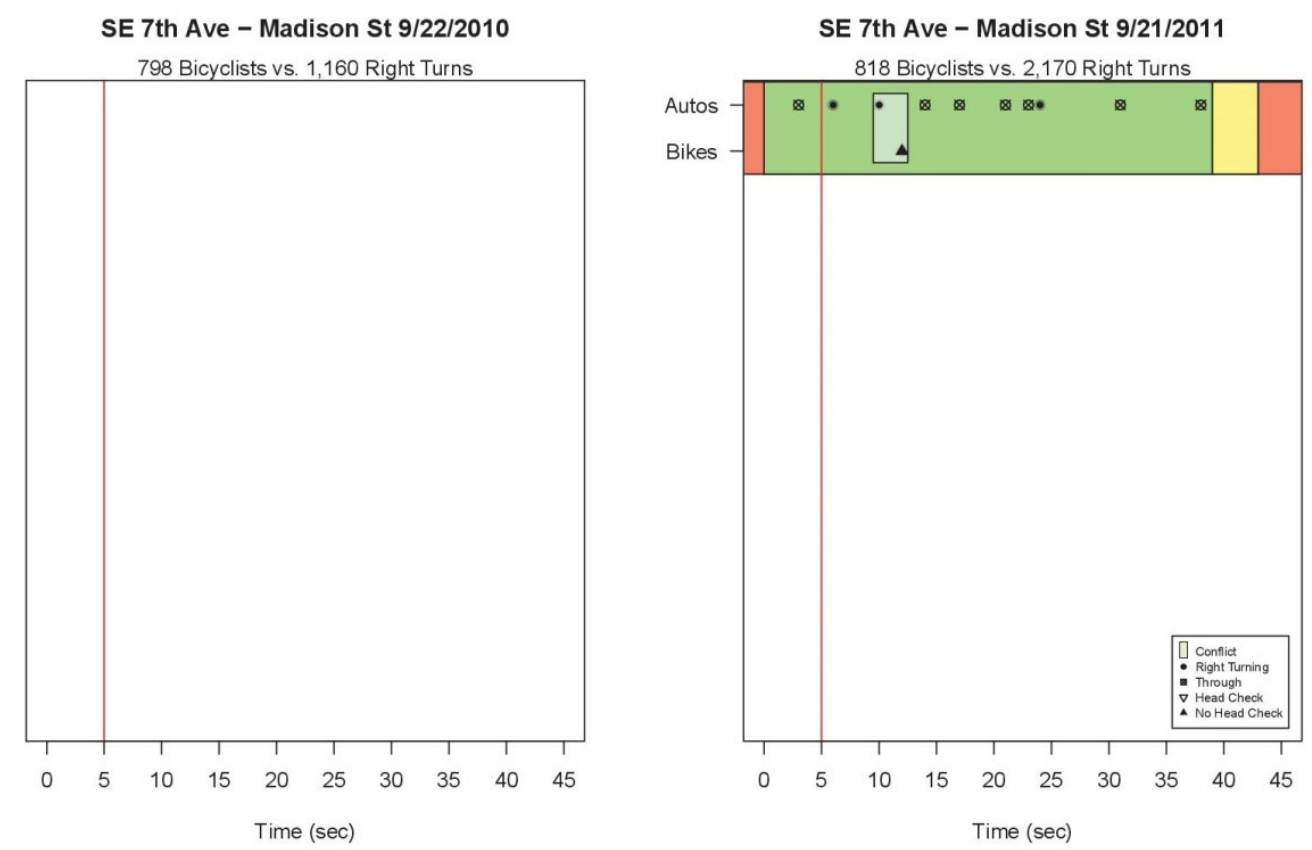

\section{Figure 9: Event Log Before and After at SE 7th Ave at Madison St}

The one conflict observed after the installation of the bike box occurred around fifteen seconds after the green indication and occurred between the second right-turning vehicle and the first (and only bicyclist) to pass through the intersection. The conflict occurred when a motor vehicle was overtaking the bicyclist and was resolved by the bicyclist who yielded to the turning movement of the motor vehicle. The one bicyclist was not observed being attentive to traffic behind them as they passed through the intersection. 


\subsubsection{SE 26 ${ }^{\text {th }}$ Ave NB at Powell Blvd}

The intersection of SE $26^{\text {th }}$ Avenue at Powell Boulevard (viewing northbound) was observed in the fall prior to the installation of the bike box and in the winter season afterwards. The bike box was installed on the both approaches of SE $26^{\text {th }}$ Avenue; however this video only observed the bike box area on the northbound leg. The approach on SE $26^{\text {th }}$ Avenue is a three-lane, two-way roadway with a dedicated left-turn lane at the intersection. Bike lanes are available along both sides of the street on both sides of the intersection. Figure 10 shows the available northbound camera views of the intersection for both study periods.

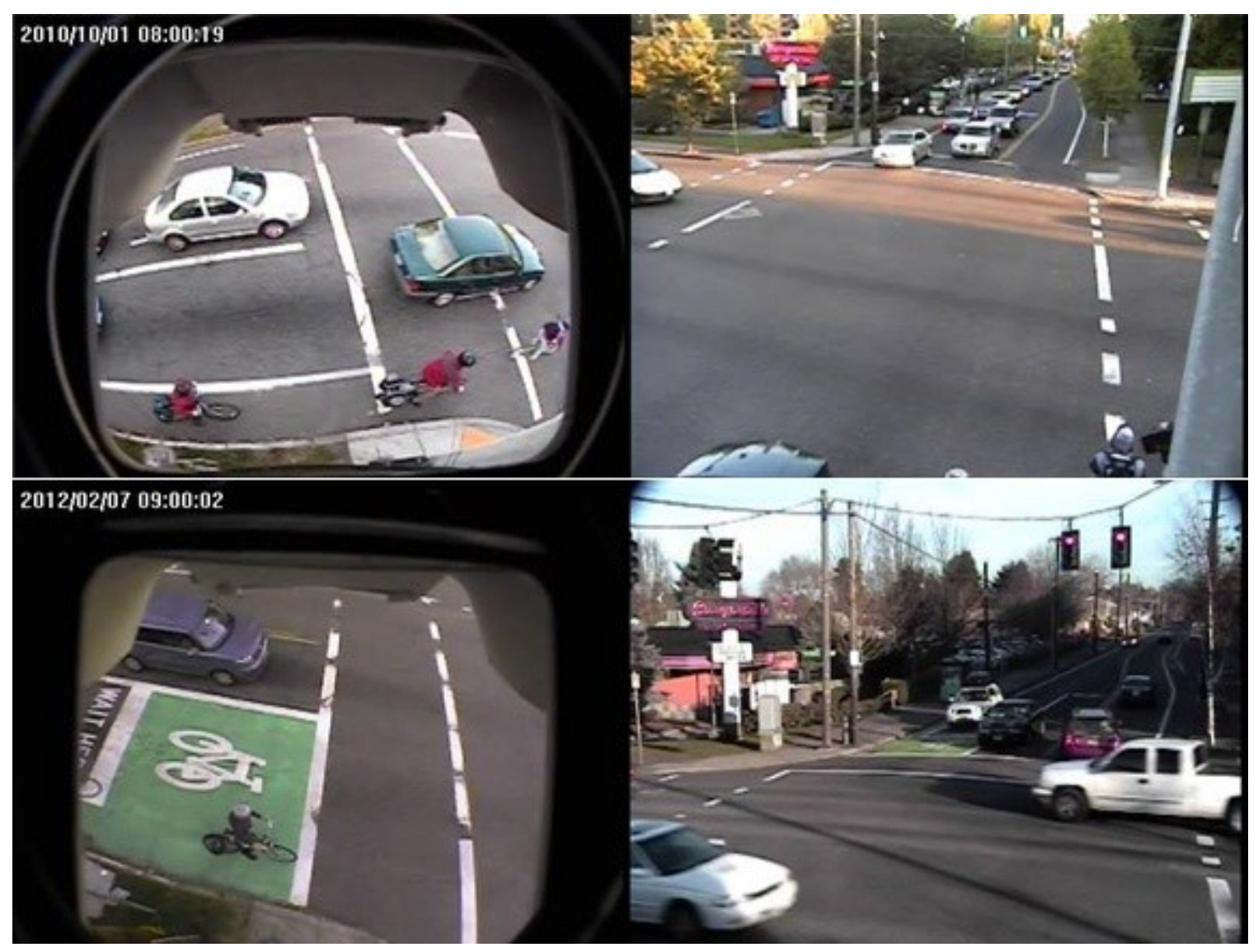

Figure 10: SE 26th Ave NB at Powell Blvd Camera Views 
Five minor conflicts were observed during the twenty-four hour study period before the installation of the bike box. For the twenty-four hour period after the bike box was installed, no conflicts were observed. Table 10 summarizes the conflicts observed for both study periods as well as the number of conflicts observed to have occurred during the initial green period.

Table 10: Conflicts at SE 26th Ave NB at Powell Blvd

\begin{tabular}{|c|c|c|c|c|c|c|}
\hline Period & Minor & Major & Total & Initial Green & Bike Yielded & Bike Passing \\
\hline Before & 5 & 0 & 5 & 1 & 4 & 5 \\
\hline After & 0 & 0 & 0 & 0 & 0 & 0 \\
\hline$\Delta$ & -5 & $\mathbf{0}$ & -5 & -1 & -4 & -5 \\
\hline
\end{tabular}

Events during each observed incident were logged after the narrowing the conflicts. The event log is shown in Figure 11 below.
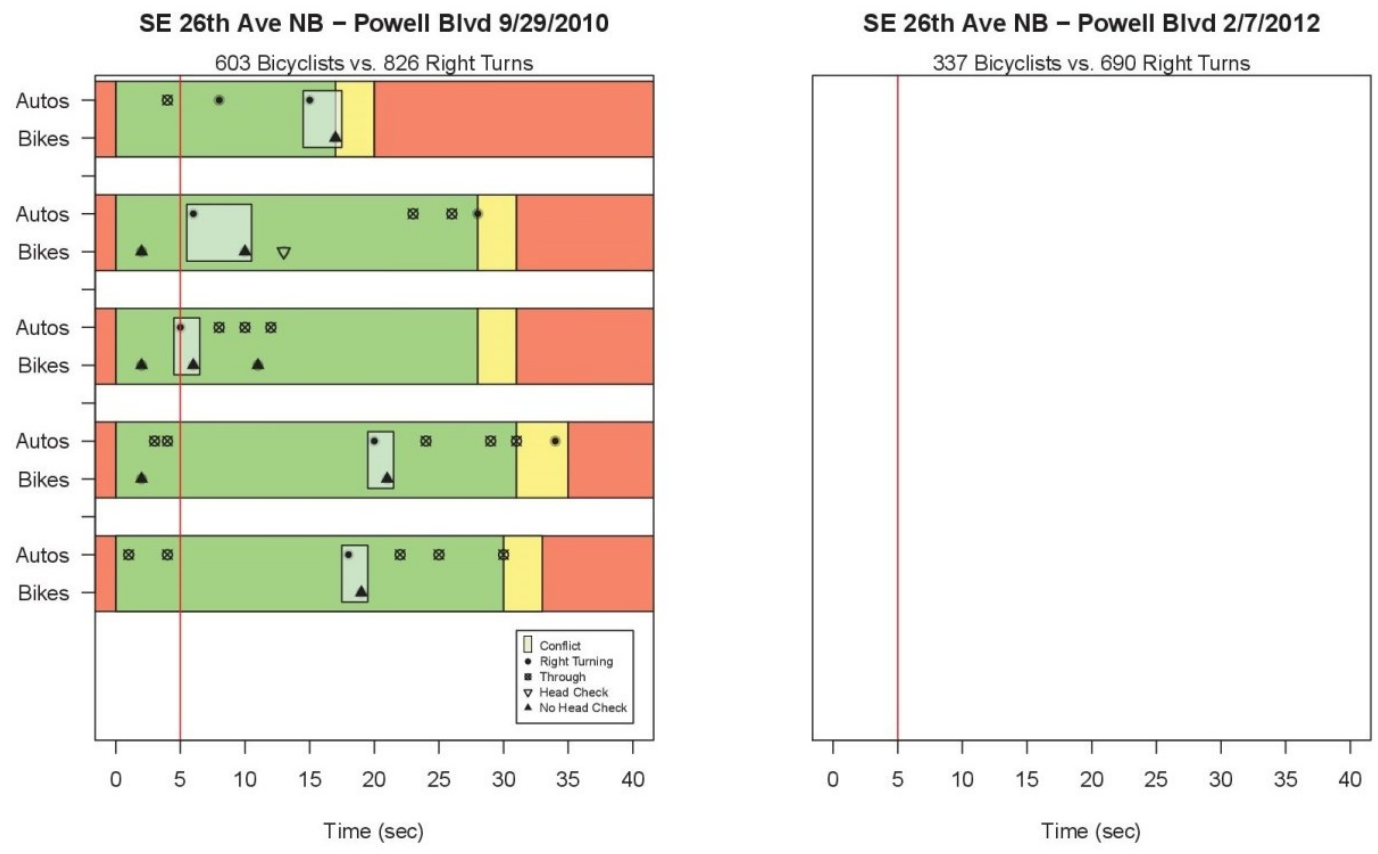

Figure 11: Event Log Before and After at SE 26th Ave NB at Powell Blvd 
Only one conflict before the installation of the bike box occurred within the five second window of the signal displaying a green indication. The conflict occurred between the first right-turning motorized vehicle (who was stopped when the signal changed from red to green) and the second bicyclist to approach the intersection (who was in motion before the signal changed). One of the other conflicts occurred within ten seconds of the green indication and also involved the first right-turning motorized vehicle and the second bicyclist. The other conflicts observed occurred during the later green period of the

phase. All of the conflicts occurred when the bicyclist appeared to be overtaking the motor vehicle. Four of the conflicts were resolved by the bicyclist yielding to the motorist's right-turn movement. Only one bicyclist was observed paying attention to motor vehicles approaching behind them; however, the head-check occurred immediately following a conflict.

\subsubsection{SE 26 ${ }^{\text {th }}$ Ave SB at Powell Blvd}

The intersection of SE $26^{\text {th }}$ Avenue at Powell Boulevard (viewing southbound) was observed in the fall prior to and after the installation of the bike. This bike box is opposite the one explained in the previous section. Like before, the approach on SE $26^{\text {th }}$ Avenue is a three-lane, two-way roadway with a center left-turn refuge at the intersection. Bike lanes are available along both sides of the street on both sides of the intersection. Figure 12 shows the available northbound camera views of the intersection for both study periods. 


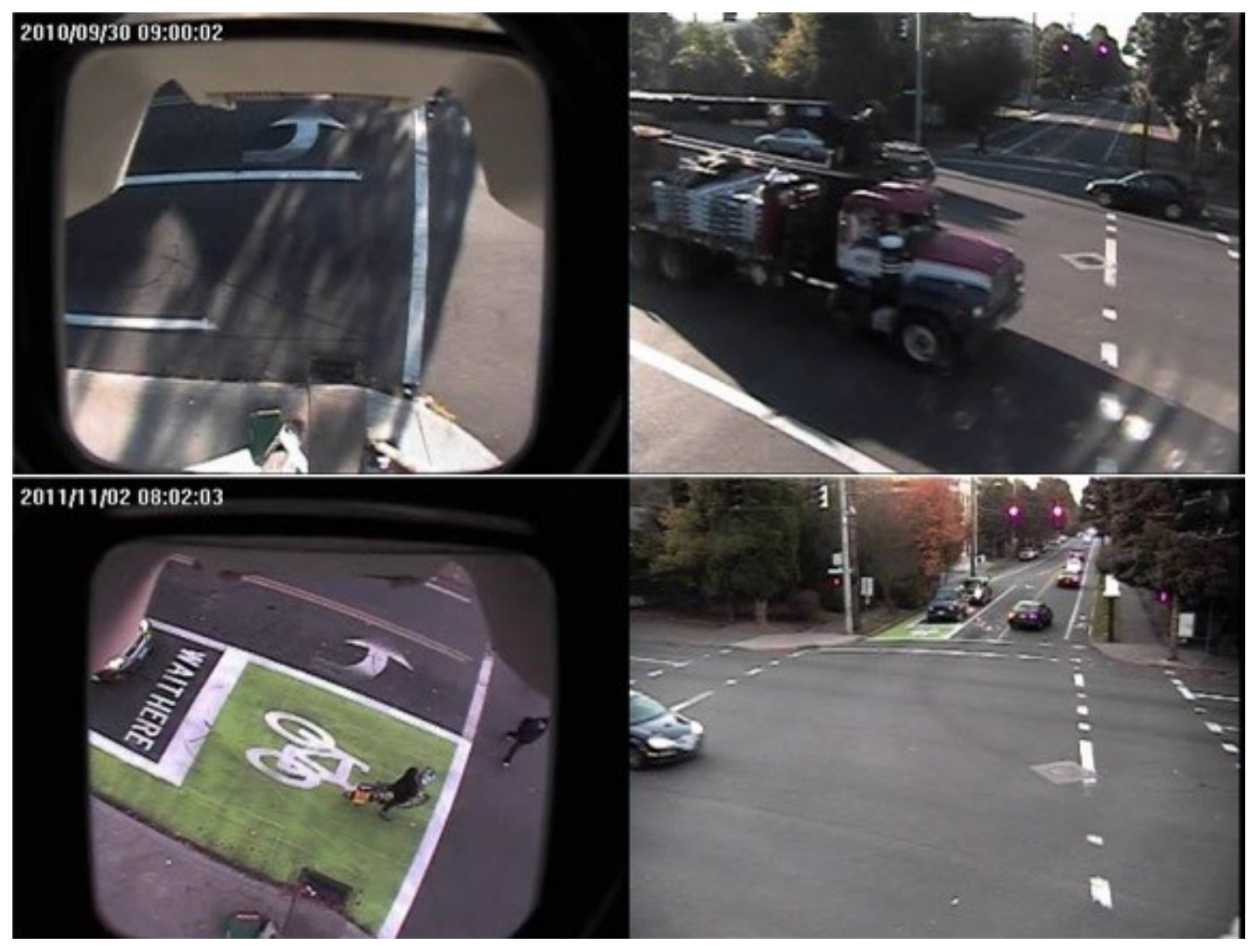

Figure 12: SE 26th Ave SB at Powell Blvd Camera Views

One major conflict was observed during the twenty-four hour period of study before the bike box was installed at the intersection. For the period of study after the bike box was installed, four minor conflicts were observed. Table 11 summarizes the conflicts observed during both study periods.

Table 11: Conflicts at SE 26th Ave SB at Powell Blvd

\begin{tabular}{|c|c|c|c|c|c|c|}
\hline Period & Minor & Major & Total & Initial Green & Bike Yielded & Bike Passing \\
\hline Before & 0 & 1 & 1 & 0 & 1 & 1 \\
\hline After & 4 & 0 & 4 & 0 & 3 & 4 \\
\hline$\Delta$ & 4 & -1 & 3 & $\mathbf{0}$ & 2 & 3 \\
\hline
\end{tabular}


Figure 13 shows the event logs for each of the conflicts recorded during both analysis periods.
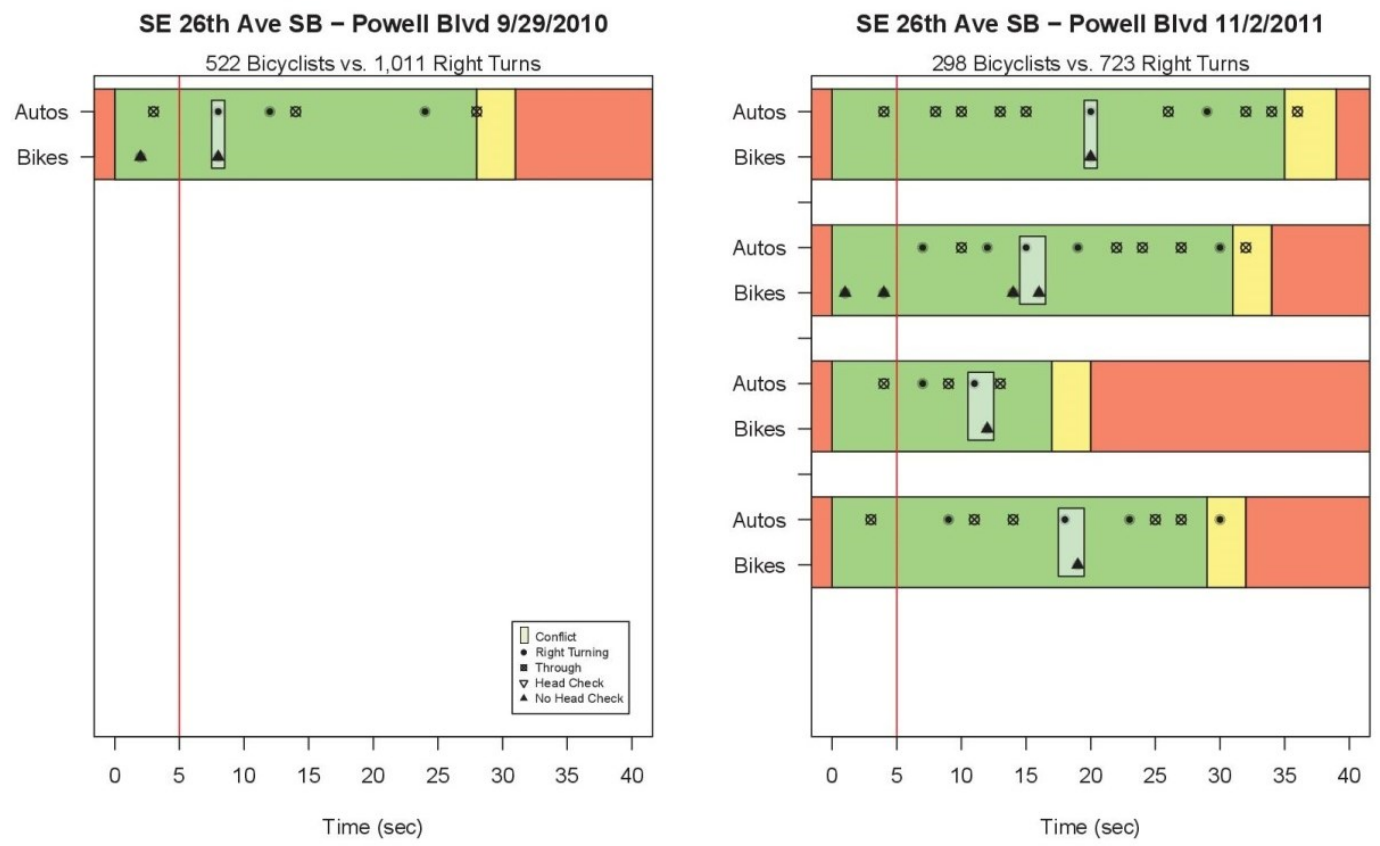

\section{Figure 13: Event Log Before and After at SE 26th Ave SB at Powell Blvd}

No conflicts during either analysis period were observed to have occurred during the start of the green indication. The one conflict observed before the installation of the advanced stop box occurred at about ten seconds into the phase and involved the second motorized vehicle passing through the intersection (first vehicle to make a right turn) and the second bicyclist to approach the intersection. The conflict occurred when the bicycle appeared to be overtaking the motor vehicle and was resolved by the bicyclist yielding to the motor vehicle. No head-check was observed as the bicyclist proceeded through the intersection.

All conflicts that were observed to have happened after the installation of the bike box occurred during later in the green phase. All four conflicts occurred when a bicyclist was 
overtaking a motor vehicle. Three of the four conflicts were resolved by the bicyclist yielding to the motorist's right-turn movement. None of the bicyclists were observed during the conflict periods of being attentive to traffic approaching behind them.

\subsubsection{N Interstate Ave at Alberta St}

The intersection of $\mathrm{N}$ Interstate Avenue at Alberta Street was observed in the fall prior to the installation of the advanced stop box and in the winter afterwards. The bike box was installed on the northbound $\mathrm{N}$ Interstate approach. Interstate Avenue is a single lane, two-way roadway divided by light rail tracks. At the intersection, the roadway expands to include a dedicated left-turn lane. Bike lanes are available on both sides of the street before and after the intersection and on-street parking areas are provided after the intersection. Figure 14 shows the camera views at the intersection observed for both periods of study. 


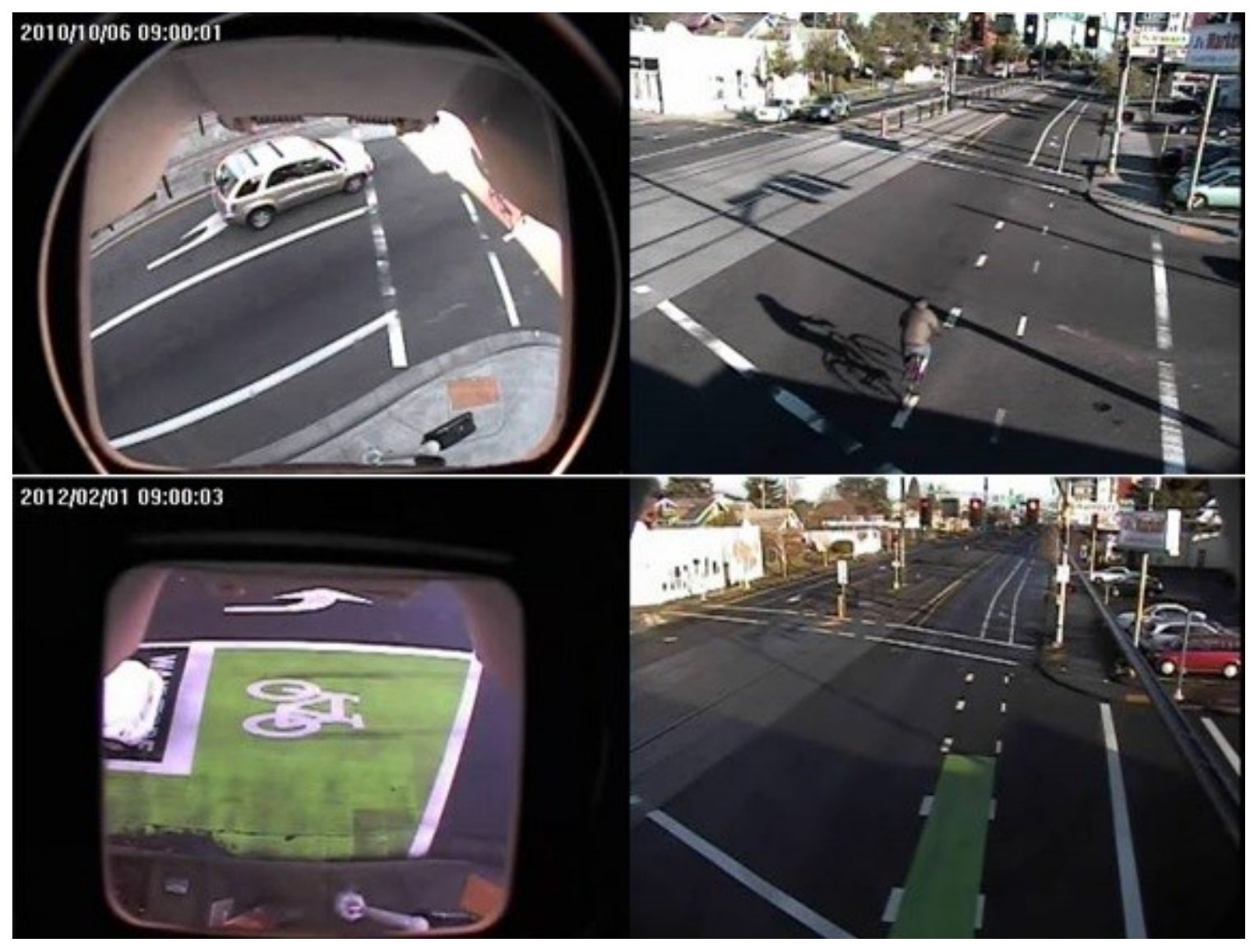

Figure 14: N Interstate Ave at Alberta St Camera Views

Three minor conflicts were observed during the twenty-four hour study period before the installation of the advanced stop box. For the study period after the installation, however, no conflicts were observed. Table 12 summarizes the conflicts observed during both study periods.

Table 12: Conflicts at $\mathbf{N}$ Interstate Ave at Alberta $\mathbf{S t}$

\begin{tabular}{|c|c|c|c|c|c|c|}
\hline Period & Minor & Major & Total & Initial Green & Bike Yielded & Bike Passing \\
\hline Before & 3 & 0 & 3 & 0 & 3 & 0 \\
\hline After & 0 & 0 & 0 & 0 & 0 & 0 \\
\hline$\Delta$ & -3 & $\mathbf{0}$ & -3 & $\mathbf{0}$ & -3 & $\mathbf{0}$ \\
\hline
\end{tabular}


After the narrowing of the conflicts by the expert panel, the entire green phase in which an incident occurred was again observed and logged. Figure 15 shows the event log for each conflict that occurred during the study period before the installation of the bike box.
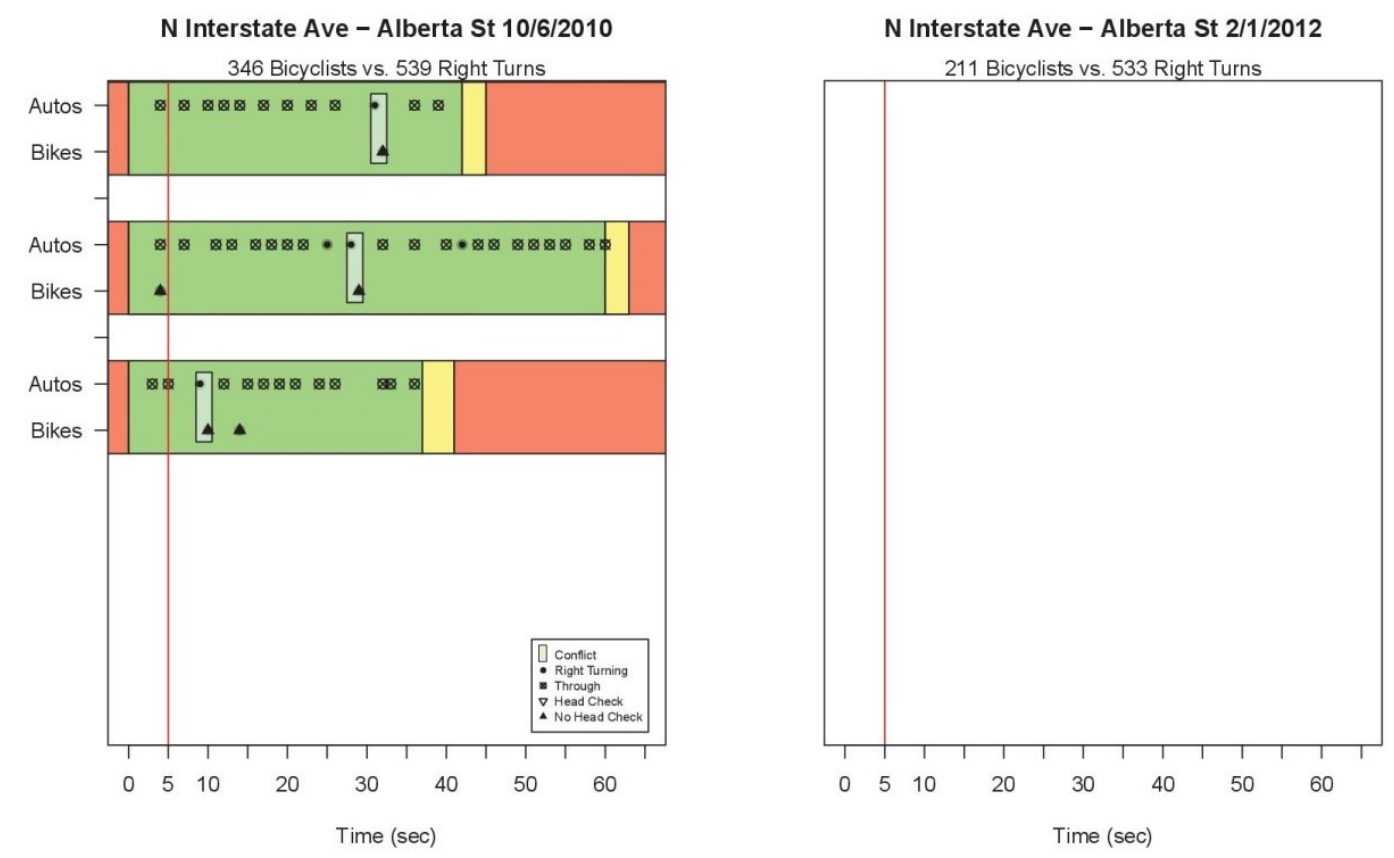

Figure 15: Event Log Before and After at N Interstate Ave at Alberta St

None of the conflicts that were observed happened during the initial start of the green indication. Two of the conflicts, however, occurred between the first right-turning motorized vehicle and the first bicyclist to approach the intersection. In both cases, the incident occurred with the only right-turning vehicle during the green indication. All of the conflicts occurred when the vehicle was overtaking the bicyclist and were resolved by the bicyclist yielding to the motor vehicle. None of the bicyclists were observed during the conflict phases to perform a head-check to view traffic approaching from behind. 


\subsubsection{SE Gladstone St EB at Cesar E Chavez, Blvd}

The intersection of SE Gladstone Street at Cesar E Chavez Boulevard (viewing eastbound) was observed in the fall prior to and after the installation of the advanced stop box. The bike box was installed on both of the approaches from SE Gladstone Street; however, this video only observed the bike box installed on the eastbound leg. The approach on SE Gladstone is a two-lane, two-way roadway with a single lane used for all turning movements. Bike lanes and on-street parking areas are available on both sides of the roadway on each side of the intersection. Figure 16 shows the available eastbound camera views at the intersection observed for both periods of study.

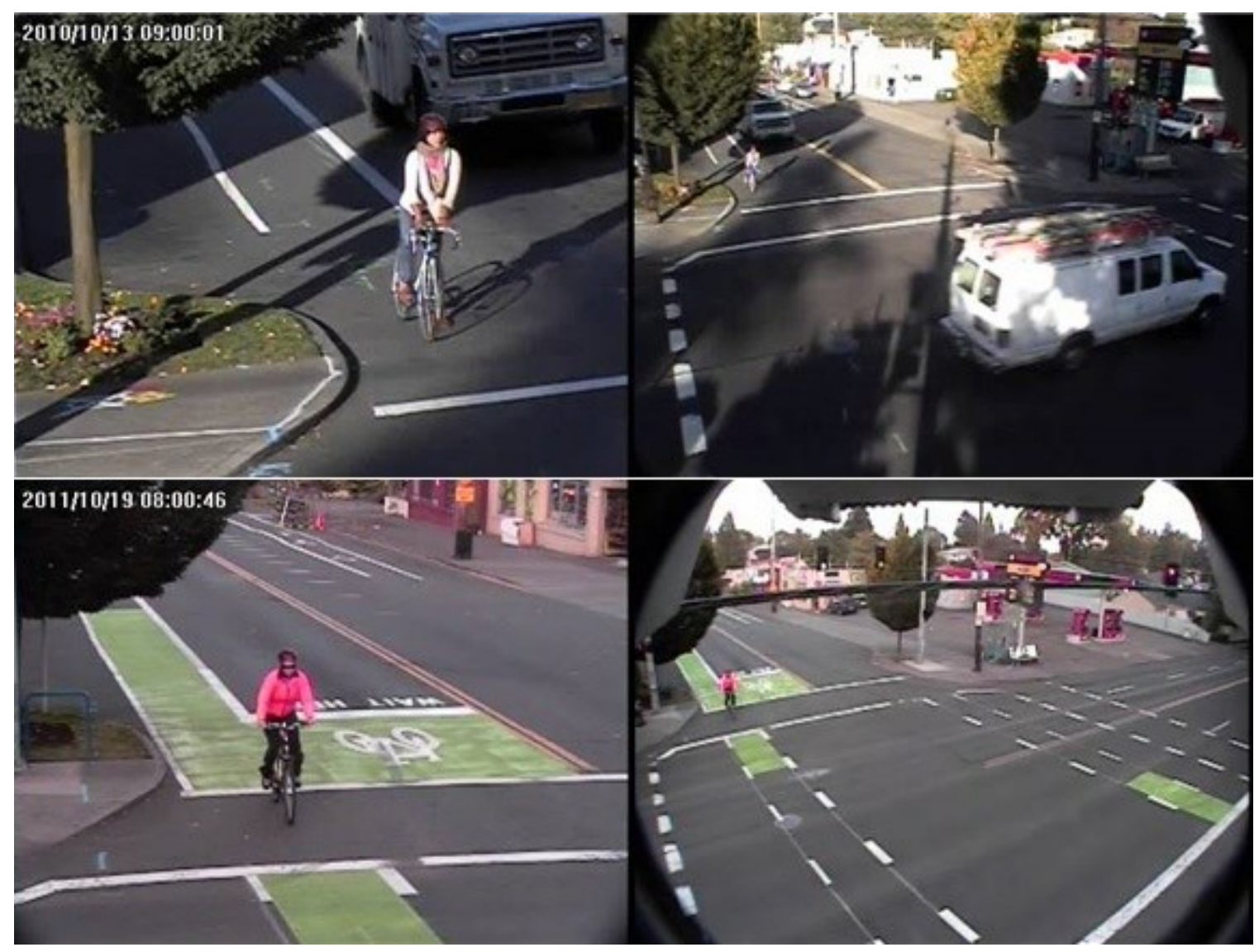

Figure 16: SE Gladstone St EB at Cesar E Chavez Blvd Camera Views 
As seen in Table 13, no conflicts were observed at the intersection for the eastbound direction during either study period.

\section{Table 13: Conflicts at SE Gladstone St EB at Cesar E Chavez Blvd}

\begin{tabular}{|c|c|c|c|c|c|c|}
\hline Period & Minor & Major & Total & Initial Green & Bike Yielded & Bike Passing \\
\hline Before & 0 & 0 & 0 & 0 & 0 & 0 \\
\hline After & 0 & 0 & 0 & 0 & 0 & 0 \\
\hline$\Delta$ & $\mathbf{0}$ & $\mathbf{0}$ & $\mathbf{0}$ & $\mathbf{0}$ & $\mathbf{0}$ & $\mathbf{0}$ \\
\hline
\end{tabular}

\subsubsection{SE Gladstone St WB at Cesar E Chavez, Blvd}

The intersection of SE Gladstone Street at Cesar E Chavez Boulevard (viewing westbound) was observed in the fall prior to and after the installation of the bike box. This bike box is opposite the one explained in the previous section. Like before, the approach on SE Gladstone Street is a two-lane, two-way roadway with a single shared lane used for all turning movements. Bike lanes and on-street parking areas are available along both sides of the street on each side of the intersection. Figure 17 shows the available northbound camera views of the intersection for both study periods. 


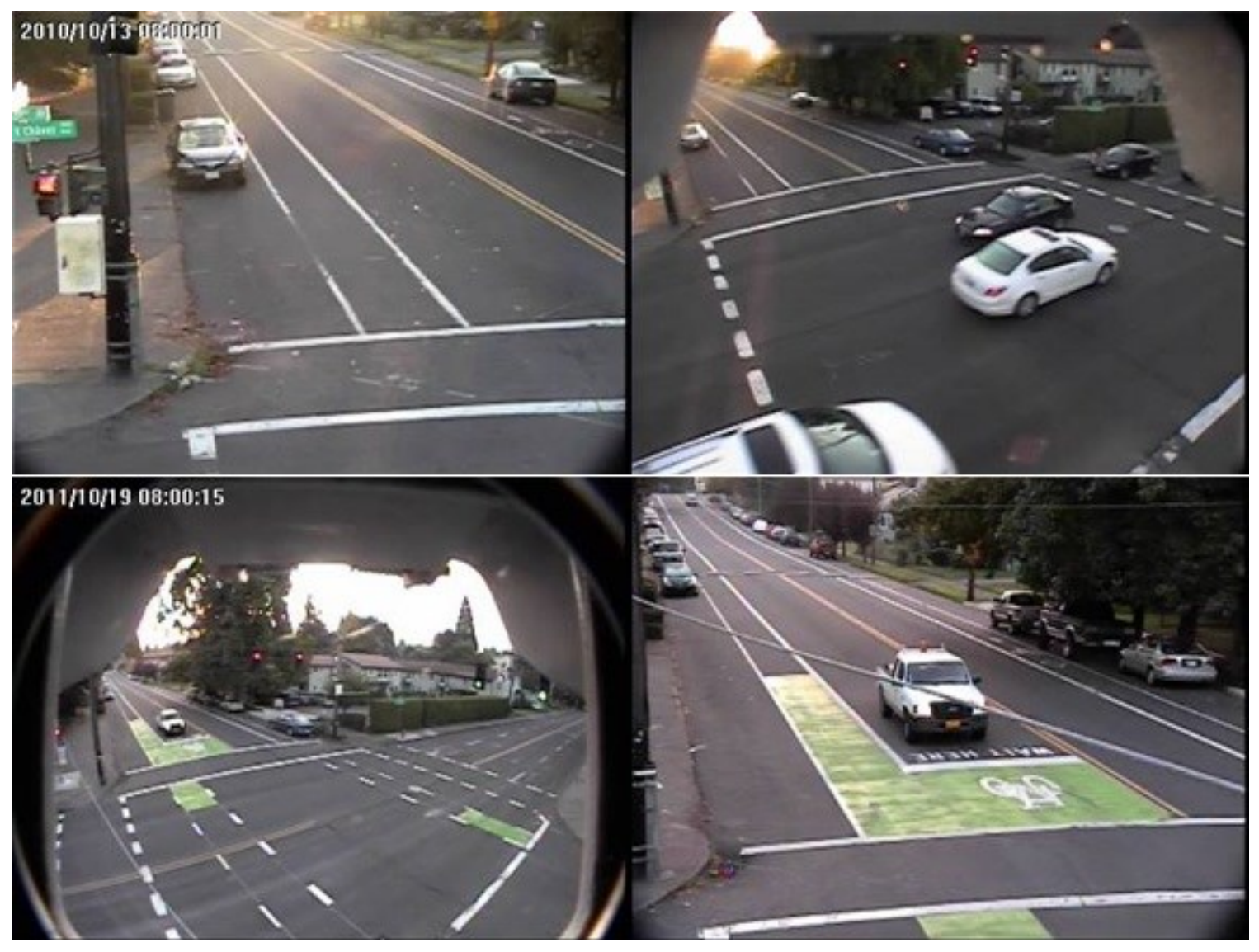

Figure 17: SE Gladstone St WB at Cesar E Chavez Blvd Camera Views

Only one minor conflict was observed in the twenty-four hour study period before the installation of the bike box. No conflicts were witnessed during the study period after the installation of the advance stop box. Table 14 summarizes the conflicts observed during both study periods.

Table 14: Conflicts at SE Gladstone St WB at Cesar E Chavez Blvd

\begin{tabular}{|c|c|c|c|c|c|c|}
\hline Period & Minor & Major & Total & Initial Green & Bike Yielded & Bike Passing \\
\hline Before & 1 & 0 & 1 & 0 & 1 & 1 \\
\hline After & 0 & 0 & 0 & 0 & 0 & 0 \\
\hline$\Delta$ & -1 & 0 & -1 & 0 & -1 & -1 \\
\hline
\end{tabular}


The event log for the one conflict that occurred during the study period before the installation of the bike box is shown in Figure 18.
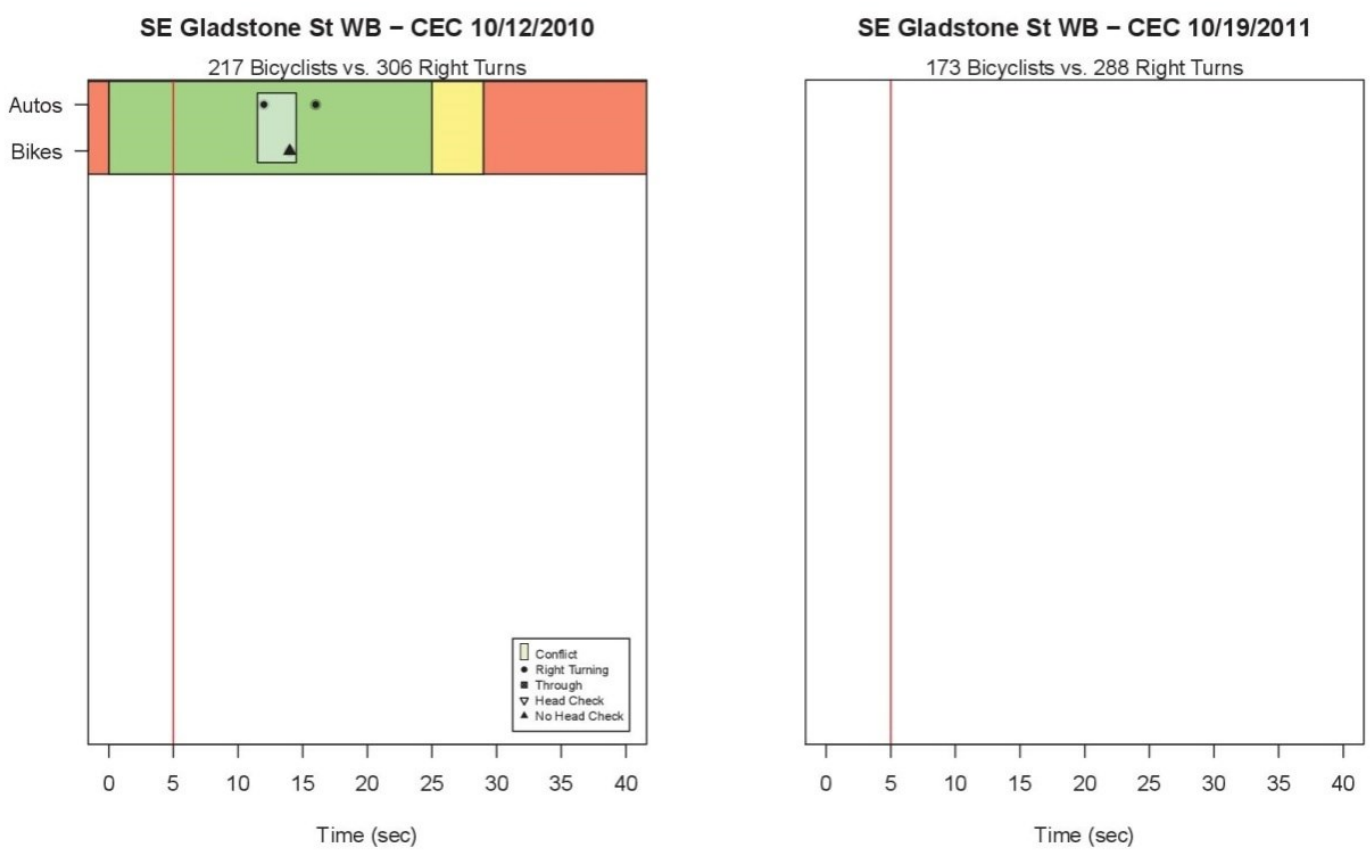

Figure 18: Event Log Before and After at SE Gladstone St WB at CEC

The one conflict that was observed for the westbound direction at the intersection occurred between the first right-turning motorized vehicle and the first bicyclist to approach the intersection. The conflict occurred with the bicyclist overtaking the motor vehicle and was resolved by the bicyclist yielding to the motor vehicle. The bicyclist was not observed performing a head-check.

\subsubsection{SE Lincoln St EB at Cesar E Chavez Blvd}

The intersection of SE Lincoln Street at Cesar E Chavez Boulevard (viewing eastbound) was observed in the fall prior to the advanced stop box and in the winter afterwards. The bike box was installed on both of the approaches from SE Lincoln Street; however, this 
video only observed the bike box installed on the eastbound leg. Although Lincoln is a two-way roadway, the approach on SE Lincoln has only one lane in which motorized traffic must turn left or right (motorized vehicles are not permitted to continue through the intersection or turn onto the street from Cesar E Chavez Boulevard). Bicycles, however, may continue through the intersection into a narrow striped lane. It should be noted that, prior to the installation of the advanced stop box, a striped median was in place to separate the narrow opposing bicycle lane from traffic advancing through the intersection. This striped median was observed being used as queue storage for bicyclists wanting to proceed straight due to the more direct path.

SE Lincoln Street is considered a Neighborhood Greenway by the City of Portland in which bicyclists are permitted to take the lane; therefore, bike lanes are not provided prior to or after the intersection. On-street parking areas are available on both sides of the roadway on each side of the intersection. Figure 19 shows the available eastbound camera views at the intersection observed for both periods of study. 


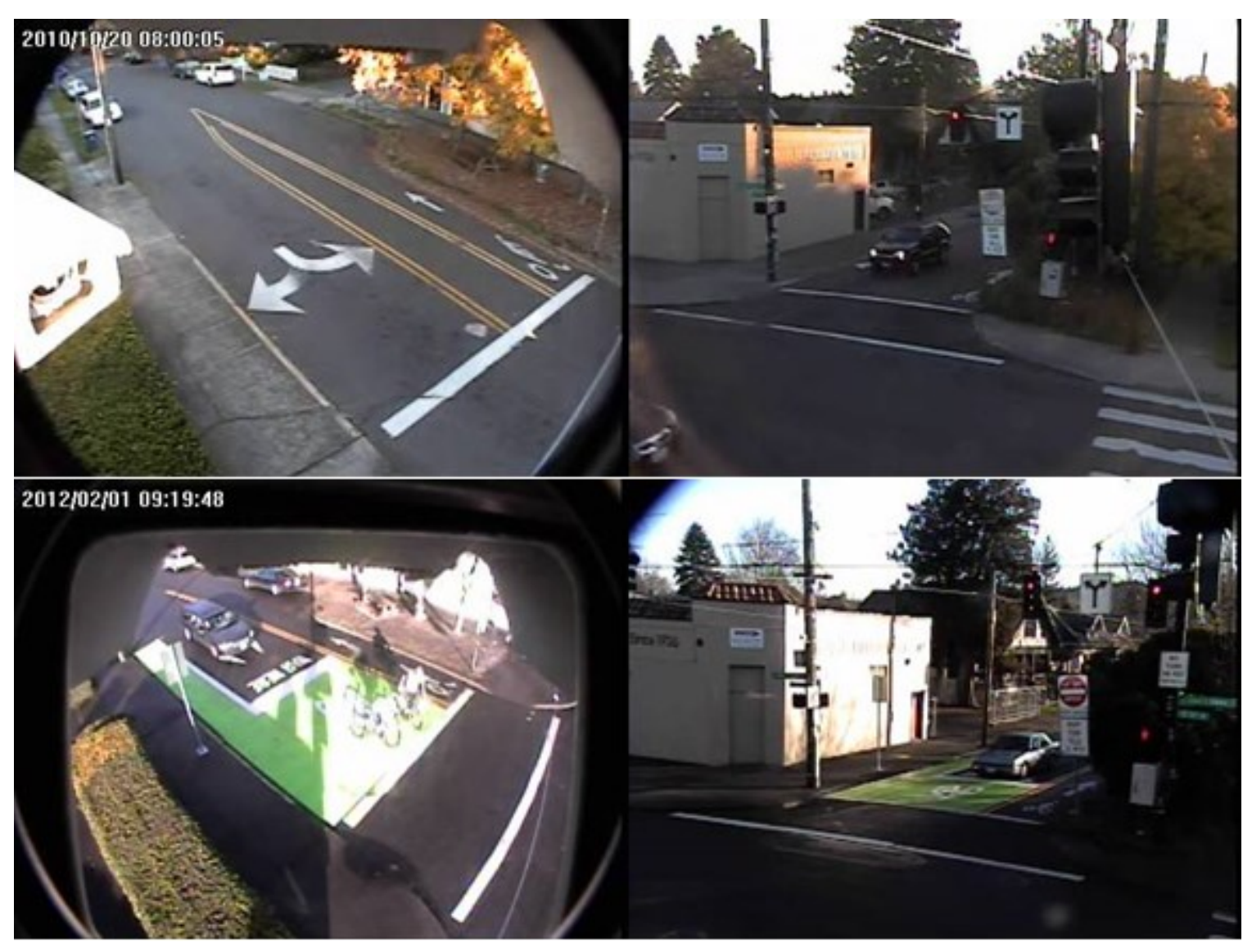

Figure 19: SE Lincoln St EB at Cesar E Chavez Blvd Camera Views

Only one minor conflict was observed in the video for the eastbound direction during the twenty-four hour study period before the installation of the advanced stop box. For the study period after the installation, no conflicts were witnessed. Table 15 summarizes the conflicts that were observed during each study period.

\section{Table 15: Conflicts at SE Lincoln St EB at Cesar E Chavez Blvd}

\begin{tabular}{|c|c|c|c|c|c|c|}
\hline Period & Minor & Major & Total & Initial Green & Bike Yielded & Bike Passing \\
\hline Before & 1 & 0 & 1 & 0 & 1 & 1 \\
\hline After & 0 & 0 & 0 & 0 & 0 & 0 \\
\hline$\Delta$ & -1 & $\mathbf{0}$ & -1 & $\mathbf{0}$ & -1 & -1 \\
\hline
\end{tabular}


Figure 20 shows the event log for the one conflict that was observed for the eastbound direction at the intersection.
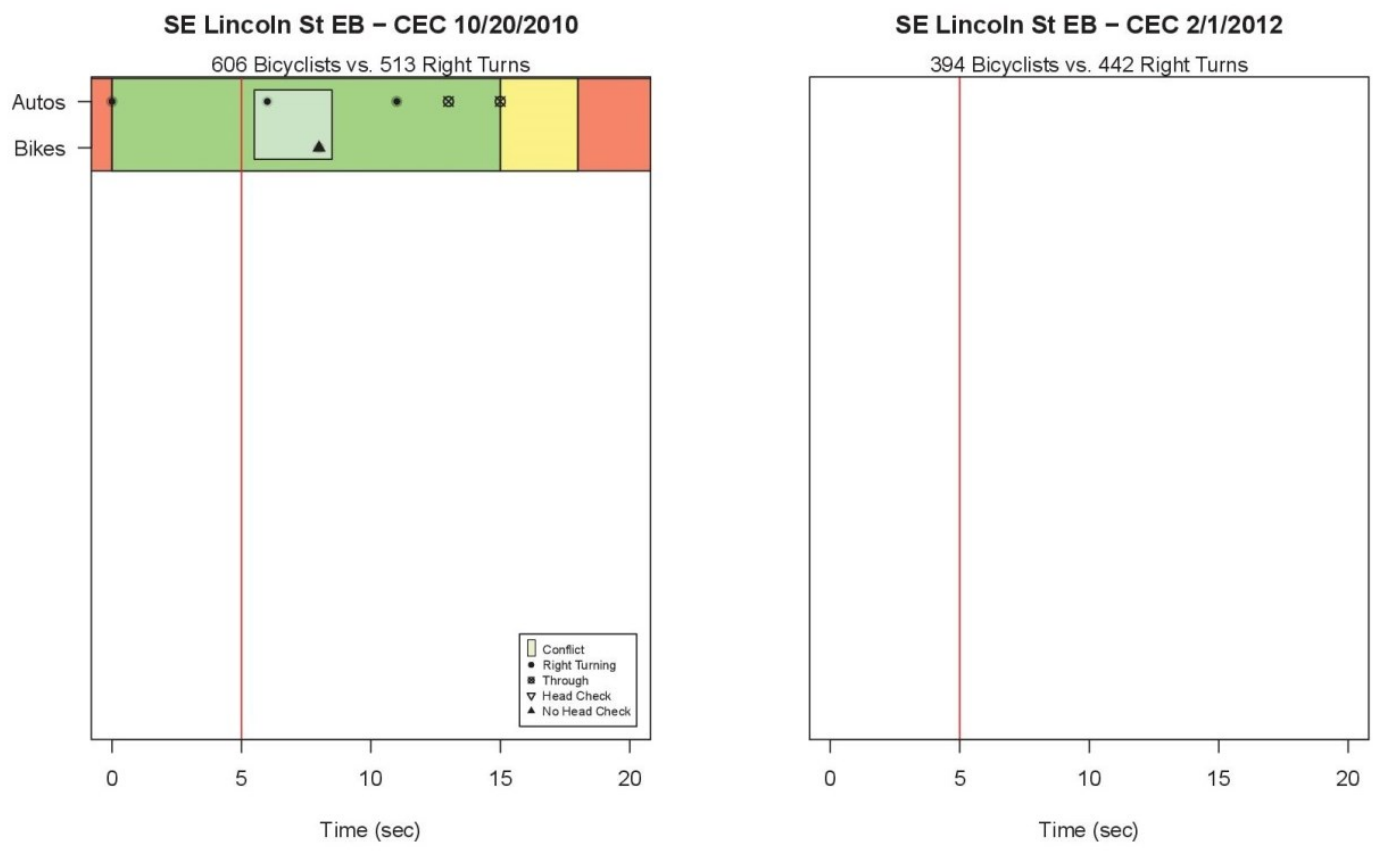

Figure 20: Event Log Before and After at SE Lincoln St EB at CEC

The conflict that occurred was witnessed between five and ten seconds after the green indication and involved the second right-turning vehicle and the first bicyclist to approach the intersection. The conflict occurred when the bicyclist was overtaking the motor vehicle and was resolved by the bicyclist yielding to the motor vehicle. The bicyclist was not observed performing a head-check.

\subsubsection{SE Lincoln St WB at Cesar E Chavez Blvd}

The intersection of SE Lincoln Street at Cesar E Chavez Boulevard (viewing westbound) was observed in the fall prior to the installation of the bike box and in the winter afterwards. This bike box is opposite the one explained in the previous section and is 
similar in design. Like before, the approach on SE Lincoln Street is a two-way roadway, but motorized vehicles are not permitted to travel through the intersection or turn from Cesar E Chavez Boulevard. Bike lanes are not provided beyond the areas for the advanced stop box. On-street parking areas are available along both sides of the street on each side of the intersection. Figure 21 shows the available northbound camera views of the intersection for both study periods.

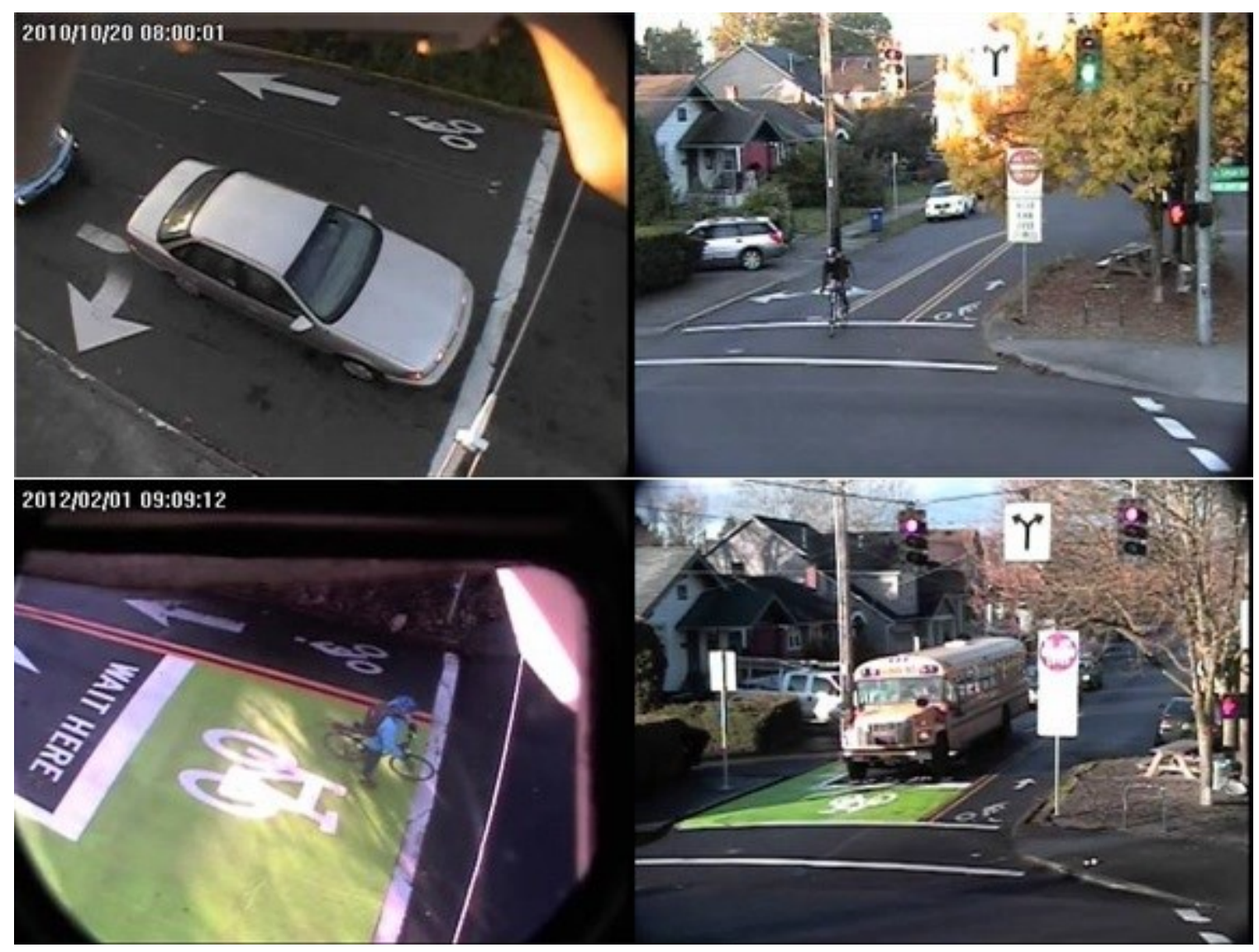

Figure 21: SE Lincoln St WB at Cesar E Chavez Blvd Camera Views

No conflicts were observed during the twenty-four hour study period before the installation of the advanced stop box. After the installation, however, two minor conflicts 
were observed. Table 16 summarizes the conflicts observed for the westbound direction during both study periods.

Table 16: Conflicts at SE Lincoln St WB at Cesar E Chavez Blvd

\begin{tabular}{|c|c|c|c|c|c|c|}
\hline Period & Minor & Major & Total & Initial Green & Bike Yielded & Bike Passing \\
\hline Before & 0 & 0 & 0 & 0 & 0 & 0 \\
\hline After & 2 & 0 & 2 & 1 & 2 & 1 \\
\hline$\Delta$ & 2 & $\mathbf{0}$ & 2 & 1 & 2 & 1 \\
\hline
\end{tabular}

The event $\log$ for each conflict that was observed for the westbound direction at the intersection is shown in Figure 22.
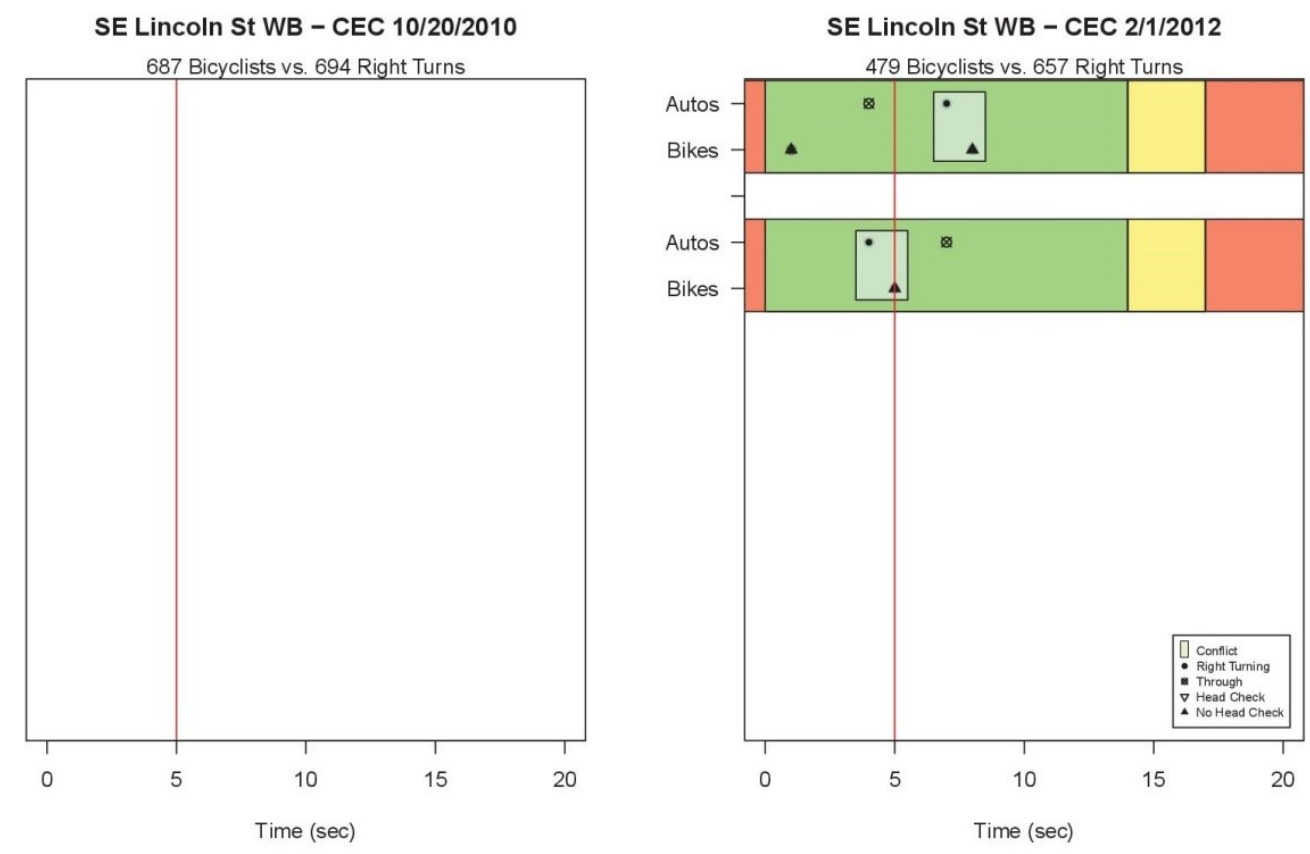

Figure 22: Event Log Before and After at SE Lincoln St WB at CEC

Only one of the two conflicts occurred within the five second start of the green phase; however, the other conflict that was observed occurred within ten seconds. For the conflict that occurred during the initial green, the bike was stopped prior to the green 
indication; however, the bike was located behind the vehicle in the bike lane. Both incidents that were witnessed after the installation of the bike box involved the first rightturning motorized vehicle to enter the intersection during the green indication. The conflict that occurred during the later part of the green phase occurred when the bike was overtaking the motor vehicle. Both conflicts were resolved by the bicyclist yielding to the movement of the motor vehicle. None of the bicyclists were observed looking over their shoulder to identify possible approaching conflicts.

\subsubsection{SE Madison St at Grand Ave}

The intersection of SE Madison Street at Grand Avenue was observed in the fall prior to the installation of the advanced stop box and in the winter afterwards. The bike box was installed on the westbound approach of SE Madison Street in the far right lane (within the right-turn refuge). Madison Street is a three-lane, one-way roadway with two through lanes and one dedicated right-turn lane. Bike lanes are provided before and after the intersection. On-street parking areas are available along the right side of the roadway (which is designated as a bus only lane for travel) for a short span at the start of the block, but once the right-turn refuge develops parking becomes restricted. However, a bus stop is present within the right-turn refuge from which buses can instead travel through the intersection. Figure 23 shows the available camera views of the intersection for both study periods. 


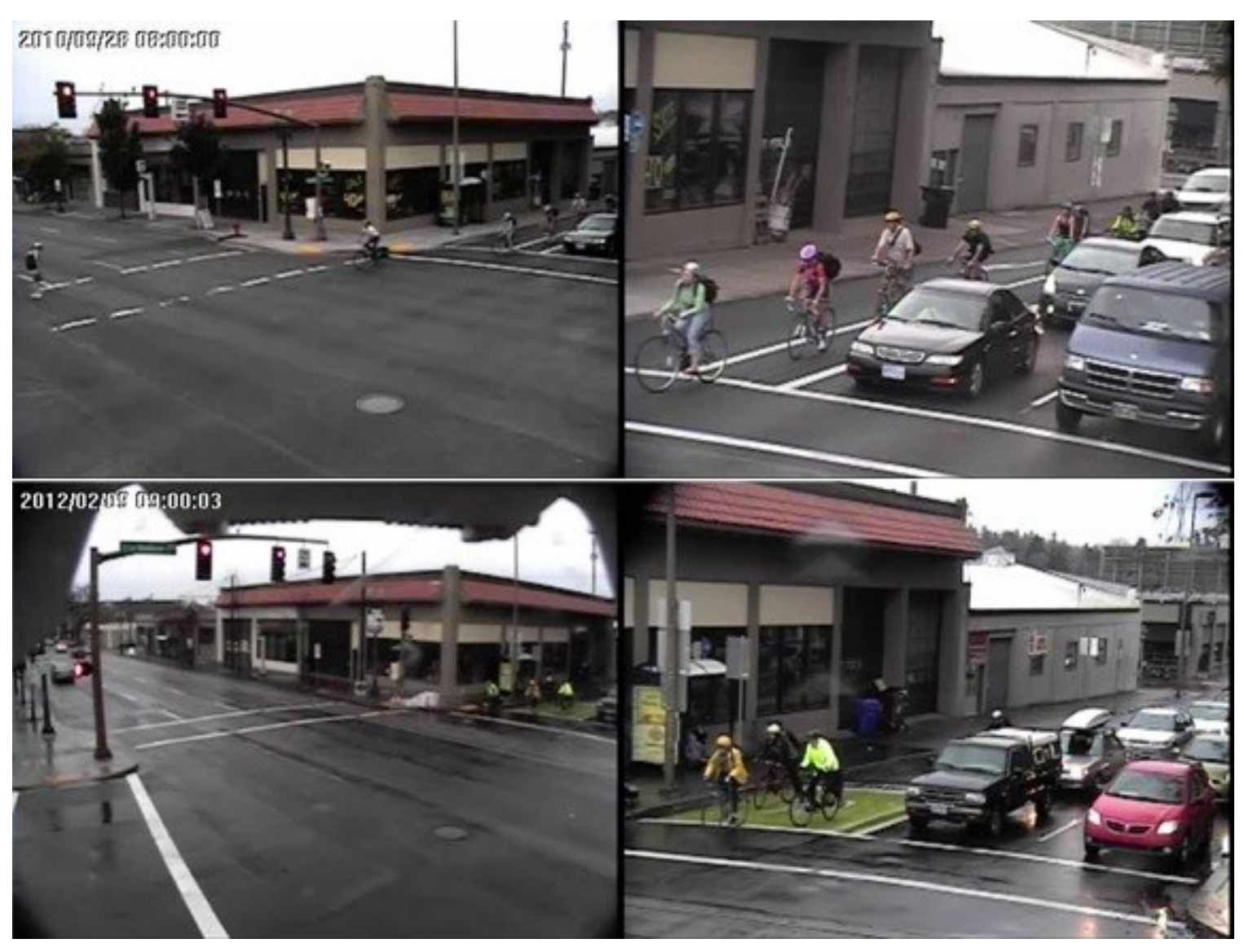

Figure 23: SE Madison St at Grand Ave Camera Views

Two minor conflicts were observed during the twenty-four hour study period before the installation of the bike box. For the study period after the installation of the bike box, no conflicts were witnessed. Table 17 summarizes the observed conflicts during each study period.

Table 17: Conflicts at SE Madison St at Grand Ave

\begin{tabular}{|c|c|c|c|c|c|c|}
\hline Period & Minor & Major & Total & Initial Green & Bike Yielded & Bike Passing \\
\hline Before & 2 & 0 & 2 & 0 & 2 & 1 \\
\hline After & 0 & 0 & 0 & 0 & 0 & 0 \\
\hline$\Delta$ & -2 & $\mathbf{0}$ & -2 & $\mathbf{0}$ & -2 & -1 \\
\hline
\end{tabular}


Figure 22 shows the event log for the conflict that was observed during the green phase of the intersection before the installation of the bike box. The other conflict occurred during the red phase and did not have any events logged.
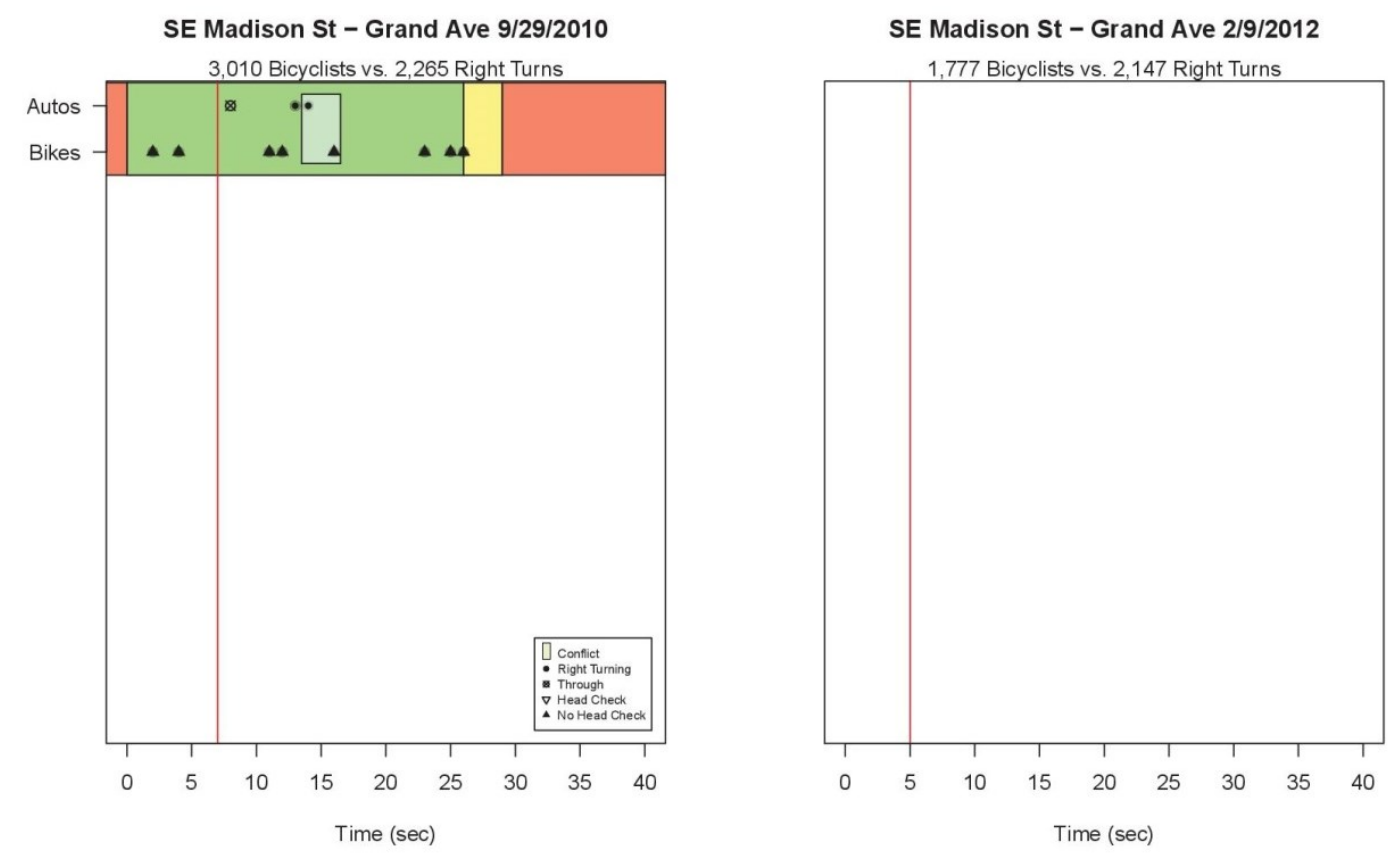

Figure 24: Event Log Before and After at SE Madison St at Grand Ave

The conflict that occurred during the green phase of the signal before the installation of the advanced stop box happened later in the green phase and involved a right-turning motorized vehicle following closely behind another right-turning vehicle. The conflict that occurred during the red phase involved a right-turning vehicle overtaking and turning in front of the bicyclist's path from the middle lane. Both conflicts were resolved by the bicyclist yielding to the motor vehicle. None of the bicyclists were observed performing a head-check. 


\subsubsection{Intersection Analysis by Groups}

Intersections with similar lane configurations were grouped together for additional analysis. This included the study videos that observed individual directions such as eastbound or westbound of the intersections. Only intersections that had conflicts occur during both the before and after periods of study were investigated further.

\subsubsection{SE 26th Ave at Powell Blvd Group}

The conflicts observed for both the northbound and southbound direction at SE $26^{\text {th }}$ Avenue at Powell Boulevard were grouped together for analysis. Table 18 summarizes the conflicts for both directions of travel as well as the number of conflicts observed during the initial green indication.

\section{Table 18: Conflicts at SE 26th Ave at Powell Blvd}

\begin{tabular}{|c|c|c|c|c|c|c|}
\hline Period & Minor & Major & Total & Initial Green & Bike Yielded & Bike Passing \\
\hline Before & 5 & 1 & 6 & 1 & 5 & 6 \\
\hline After & 4 & 0 & 4 & 0 & 3 & 4 \\
\hline$\Delta$ & -1 & -1 & -2 & -1 & -2 & -2 \\
\hline
\end{tabular}

The event $\log$ for each conflict was combined into one graphic for comparison as shown in Figure 25. 

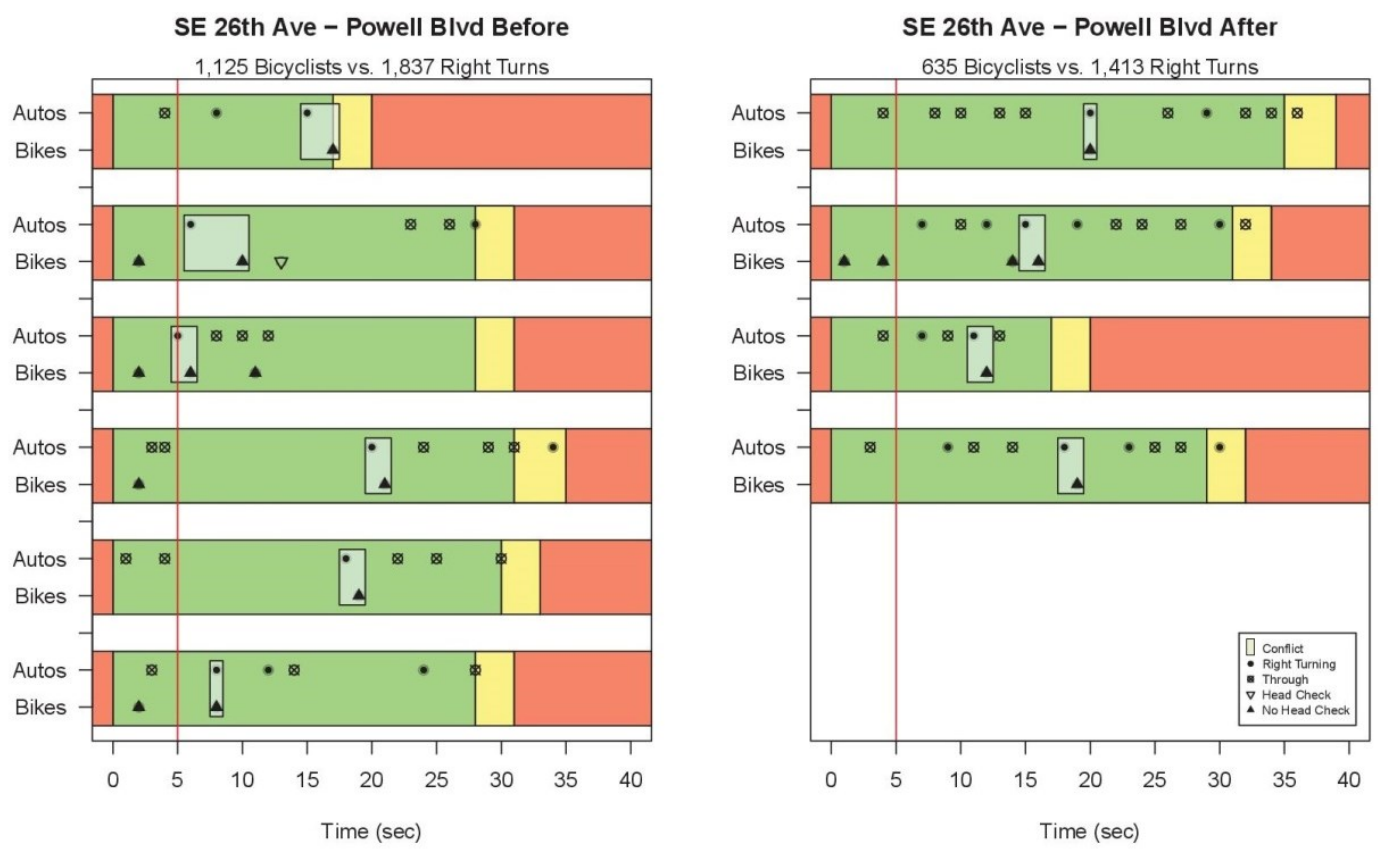

Figure 25: Event Log Before and After Comparing Both Directions of SE 26th Ave at Powell Blvd

Of the six total conflicts that occurred at the intersection during the period of study before the installation of the advanced stop box at SE $26^{\text {th }}$ Avenue at Powell Boulevard, only one happened within five seconds of the signal displaying a green indication and was between a bicyclist who was in motion prior to the change of the signal. Two of the conflicts occurred within ten seconds of the green indication and the remaining three occurred later in the green phase. Five of the six conflicts were resolved by the bicyclist yielding to the right-turning movement of the motor vehicle.

All of the conflicts during the period of study after the installation of the bike box occurred during the latter part of the green phase. Three of the four conflicts were resolved by the bicyclist yielding to the right-turning movement of the motor vehicle. 


\subsubsection{SE Lincoln St at Cesar E Chavez Blvd Group}

The conflicts for both the eastbound and westbound directions at SE Lincoln Street at Cesar E Chavez Boulevard were grouped together for analysis. Table 19 summarizes the conflicts for both directions of travel.

\section{Table 19: Conflicts at SE Lincoln St at Cesar E Chavez Blvd}

\begin{tabular}{|c|c|c|c|c|c|c|}
\hline Period & Minor & Major & Total & Initial Green & Bike Yielded & Bike Passing \\
\hline Before & 1 & 0 & 1 & 0 & 1 & 1 \\
\hline After & 2 & 0 & 2 & 1 & 2 & 1 \\
\hline$\Delta$ & 1 & 0 & 1 & 1 & 1 & $\mathbf{0}$ \\
\hline
\end{tabular}

The event $\log$ for each conflict was combined into one graphic for comparison as shown in Figure 26.
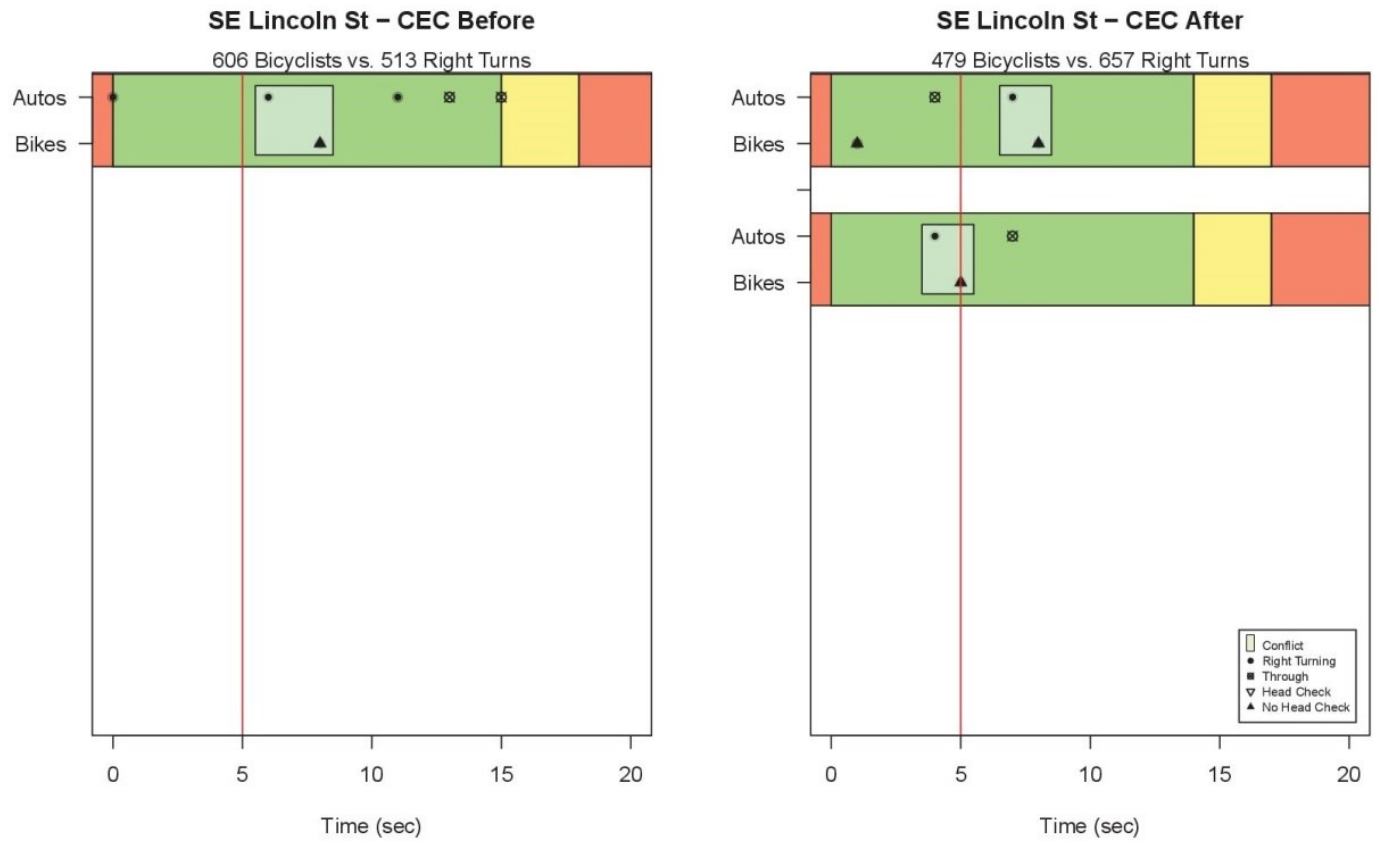

Figure 26: Event Log Before and After Comparing Both Directions of SE Lincoln St at CEC 
All conflicts that occurred during both analysis periods happened within ten seconds of the green indication and were resolved by the bicyclist yielding to the motor vehicle. A low number of motorized vehicles and bicyclists were observed during each phase in which a conflict occurred.

\subsubsection{Normalized Conflict Rates}

To examine if the installation of a bike box had any possible effect on conflict rates at intersections, the data were normalized by number of right-turning motorized vehicles and by number of bicyclists. The data for minor, major, and total conflicts were normalized for both periods of study. A change in total conflict rate from the period before the installation of the bike box to the period after the installation was also calculated.

\subsubsection{Conflict Rate per Hundred Right-Turning Vehicles}

Table 20 summarizes the number of conflicts per hundred right-turning motorized vehicles for each of the study intersections separating multiple views at one intersection by direction of travel. A column calculating the change in total conflicts per hundred right-turning vehicles $(\Delta)$ was included for the purposes of identifying possible locations where the number of conflicts were reduced or possibly increased with the installation of the bike box. The table also groups intersections according to lane configuration (as shown in Table 2) and gives an overall conflict rate taking in account the total amount of observed conflicts at each intersection normalized to the total number of right-turns at each intersection. 
Table 20: Conflicts Normalized to Number of Right Turns

\begin{tabular}{|c|c|c|c|c|c|c|c|c|}
\hline \multirow{2}{*}{ Intersection } & \multicolumn{3}{|c|}{ Before } & \multicolumn{3}{|c|}{ After } & \multirow{2}{*}{$\begin{array}{c}\Delta \\
T_{A}-T_{B} \\
\end{array}$} & \multirow{2}{*}{$\begin{array}{c}\text { Group } \\
\Delta\end{array}$} \\
\hline & Minor & Major & Total & Minor & Major & Total & & \\
\hline $\begin{array}{l}\text { NE Couch St } \\
\text { - Grand Ave }\end{array}$ & 0.19 & 0.09 & 0.28 & 0.35 & 0.04 & 0.39 & 0.11 & 0.11 \\
\hline $\begin{array}{l}\text { SE 7th Ave } \\
\text { - Hawthorne Blvd }\end{array}$ & - & - & - & 0.41 & - & 0.41 & 0.41 & \\
\hline $\begin{array}{l}\text { SE } 7 \text { th Ave } \\
\text { - Madison St }\end{array}$ & - & - & - & 0.05 & - & 0.05 & 0.05 & 0.11 \\
\hline $\begin{array}{l}\text { SE 26th Ave NB } \\
\text { - Powell Blvd }\end{array}$ & 0.61 & - & 0.61 & - & - & - & -0.61 & \\
\hline $\begin{array}{l}\text { SE 26th Ave SB } \\
\text { - Powell Blvd }\end{array}$ & - & 0.10 & 0.10 & 0.55 & - & 0.55 & 0.45 & -0.17 \\
\hline $\begin{array}{l}\text { N Interstate Ave } \\
\text { - Alberta St }\end{array}$ & 0.56 & - & 0.56 & - & - & - & -0.56 & \\
\hline $\begin{array}{l}\text { SE Gladstone St EB } \\
\text { - CEC Blvd }\end{array}$ & - & - & - & - & - & - & 0.00 & \\
\hline $\begin{array}{l}\text { SE Gladstone St WB } \\
\text { - CEC Blvd }\end{array}$ & 0.33 & - & 0.33 & - & - & - & -0.33 & -0.12 \\
\hline $\begin{array}{l}\text { SE Lincoln St EB } \\
\text { - CEC Blvd }\end{array}$ & 0.19 & - & 0.19 & - & - & - & -0.19 & \\
\hline $\begin{array}{l}\text { SE Lincoln St WB } \\
\text { - CEC Blvd }\end{array}$ & - & - & - & 0.30 & - & 0.30 & 0.30 & 0.10 \\
\hline $\begin{array}{l}\text { SE Madison St } \\
\text { - Grand Ave }\end{array}$ & 0.09 & - & 0.09 & - & - & - & -0.09 & -0.09 \\
\hline Overall Conflict Rate & 0.15 & 0.03 & 0.18 & 0.15 & 0.01 & 0.16 & -0.02 & - \\
\hline
\end{tabular}

Five of the study intersections showed a decrease in the amount of conflicts per hundred right-turning vehicles from the period prior to the installation of the advanced stop box to the period after the installation. The largest change was observed for the northbound direction at the intersection of SE $26^{\text {th }}$ Avenue at Powell Boulevard where the 0.61 conflicts per hundred right-turning vehicles found during the before period reduced to zero conflicts during the after period (five conflicts reducing to zero).

In contrast, the conflicts per hundred right-turning vehicles was found to increase at five study intersections. Interestingly, the largest change in the number of conflicts per 
hundred right-turning vehicles occurred on the southbound direction at the intersection of SE $26^{\text {th }}$ Avenue at Powell Boulevard where 0.10 conflicts per hundred right-turning vehicles increased to 0.55 conflicts per hundred right-turning vehicles after the installation of the bike box.

Only one intersection (eastbound direction of SE Gladstone Street at Cesar E Chavez Boulevard) showed no change with the installation of the bike box.

When analyzing the conflict rate of the intersections when grouped by lane configuration, it was observed that the conflict rate increased half of the groups and decreased at the other half. The overall conflict rate was observed to have decreased by 0.02 conflicts per hundred right-turning vehicles when taking in account the data from all intersections.

\subsubsection{Conflict Rate per Hundred Bicycles}

Table 21 summarizes the number of conflicts per hundred bicyclists for each of the study intersections separating multiple views at one intersection by direction of travel. A column calculating the change in total conflicts per hundred bicyclists $(\Delta)$ was included for the purposes of identifying possible locations where the number of conflicts were reduced or possibly increased with the installation of the bike box. 
Table 21: Conflicts Normalized to Number of Bicycles

\begin{tabular}{|c|c|c|c|c|c|c|c|c|}
\hline \multirow{2}{*}{ Intersection } & \multicolumn{3}{|c|}{ Before } & \multicolumn{3}{|c|}{ After } & \multirow{2}{*}{$\begin{array}{c}\Delta \\
T_{A}-T_{B} \\
\end{array}$} & \multirow{2}{*}{$\begin{array}{c}\text { Group } \\
\Delta\end{array}$} \\
\hline & Minor & Major & Total & Minor & Major & Total & & \\
\hline $\begin{array}{l}\text { NE Couch St } \\
\text { - Grand Ave }\end{array}$ & 0.72 & 0.36 & 1.08 & 0.88 & 0.11 & 0.99 & -0.09 & -0.09 \\
\hline $\begin{array}{l}\text { SE 7th Ave } \\
\text { - Hawthorne Blvd }\end{array}$ & - & - & - & 0.65 & - & 0.65 & 0.65 & \\
\hline $\begin{array}{l}\text { SE } 7 \text { th Ave } \\
\text { - Madison St }\end{array}$ & - & - & - & 0.12 & - & 0.12 & 0.12 & 0.27 \\
\hline $\begin{array}{l}\text { SE 26th Ave NB } \\
\text { - Powell Blvd }\end{array}$ & 0.83 & - & 0.83 & - & - & - & -0.83 & \\
\hline $\begin{array}{l}\text { SE 26th Ave SB } \\
\text { - Powell Blvd }\end{array}$ & - & 0.19 & 0.19 & 1.34 & 0.00 & 1.34 & 1.15 & -0.14 \\
\hline $\begin{array}{l}\text { N Interstate Ave } \\
\text { - Alberta St }\end{array}$ & 0.87 & - & 0.87 & - & - & - & -0.87 & \\
\hline $\begin{array}{l}\text { SE Gladstone St EB } \\
\text { - CEC Blvd }\end{array}$ & - & - & - & - & - & - & 0.00 & \\
\hline $\begin{array}{l}\text { SE Gladstone St WB } \\
\text { - CEC Blvd }\end{array}$ & 0.46 & - & 0.46 & - & - & - & -0.46 & -0.25 \\
\hline $\begin{array}{l}\text { SE Lincoln St EB } \\
\text { - CEC Blvd }\end{array}$ & 0.17 & - & 0.17 & - & - & - & -0.17 & \\
\hline $\begin{array}{l}\text { SE Lincoln St WB } \\
\text { - CEC Blvd }\end{array}$ & - & - & - & 0.42 & - & 0.42 & 0.42 & 0.15 \\
\hline $\begin{array}{l}\text { SE Madison St } \\
\text { - Grand Ave }\end{array}$ & 0.07 & - & 0.07 & - & - & - & -0.07 & -0.07 \\
\hline Overall Conflict Rate & 0.20 & 0.04 & 0.24 & 0.29 & 0.02 & 0.31 & $\mathbf{0 . 0 7}$ & - \\
\hline
\end{tabular}

Six intersections displayed a reduction in the number of conflicts per hundred bicyclists after the installation of the bike box, including NE Couch Street at Grand Avenue (which increased in conflicts per hundred right-turning vehicles with the installation of the bike box). The largest decrease in conflicts per hundred bicyclists occurred at $\mathrm{N}$ Interstate Avenue at Alberta Street where 0.87 conflicts per hundred bicyclists reduced to zero conflicts after the installation of the bike box.

Four intersections displayed an increase in the number of conflicts per hundred bicyclists after the installation of the bike box. The southbound direction of SE $26^{\text {th }}$ Avenue at 
Powell Boulevard showed the most increase in conflicts per hundred bicyclists going from 0.19 conflicts per hundred bicyclists to 1.15 conflicts per hundred bicyclists.

When analyzing the conflict rate of the intersections when grouped by lane configuration, it was observed that the conflict rate decreased at four of the six intersection groups. The overall conflict rate was observed to have increased by 0.07 conflicts per hundred bicyclists when taking in account the data from all intersections.

\subsubsection{Conflict Rate per Product of Right-Turning Vehicles and Bicyclists}

A conflict rate normalized to the number of chances for a conflict to occur can be found in Table 22. This conflict rate was calculated by dividing the number of conflicts by the product of the observed number of right-turning vehicles at an intersection and the number of observed bicyclists traveling through. To make the reported value more readable, the rate was adjusted to be per million chances of a conflict to occur. 
Table 22: Conflict Rate per Million Chances for Conflict

\begin{tabular}{|c|c|c|c|c|c|c|c|c|}
\hline \multirow{2}{*}{ Intersection } & \multicolumn{3}{|c|}{ Before } & \multicolumn{3}{|c|}{ After } & \multirow{2}{*}{$\begin{array}{c}\Delta \\
T_{A}-T_{B}\end{array}$} & \multirow{2}{*}{$\begin{array}{c}\text { Group } \\
\Delta\end{array}$} \\
\hline & Minor & Major & Total & Minor & Major & Total & & \\
\hline $\begin{array}{l}\text { NE Couch St } \\
\text { - Grand Ave }\end{array}$ & 3.33 & 1.67 & 5.00 & 1.42 & 0.27 & 1.69 & -3.31 & -3.31 \\
\hline $\begin{array}{l}\text { SE 7th Ave } \\
\text { - Hawthorne Blvd }\end{array}$ & - & - & - & 13.27 & - & 13.27 & 13.27 & \\
\hline $\begin{array}{l}\text { SE 7th Ave } \\
\text { - Madison St }\end{array}$ & - & - & - & 0.56 & - & 0.56 & 0.56 & 1.56 \\
\hline $\begin{array}{l}\text { SE 26th Ave NB } \\
\text { - Powell Blvd }\end{array}$ & 10.04 & - & 10.04 & - & - & - & -10.04 & \\
\hline $\begin{array}{l}\text { SE 26th Ave SB } \\
\text { - Powell Blvd }\end{array}$ & - & 1.89 & 1.89 & 18.57 & - & 18.57 & 16.68 & -0.29 \\
\hline $\begin{array}{l}\text { N Interstate Ave } \\
\text { - Alberta St }\end{array}$ & 16.09 & - & 16.09 & - & - & - & -16.09 & \\
\hline $\begin{array}{l}\text { SE Gladstone St EB } \\
\text { - CEC Blvd }\end{array}$ & - & - & - & - & - & - & 0.00 & \\
\hline $\begin{array}{l}\text { SE Gladstone St WB } \\
\text { - CEC Blvd }\end{array}$ & 15.06 & - & 15.06 & - & - & - & -15.06 & -5.87 \\
\hline $\begin{array}{l}\text { SE Lincoln St EB } \\
\text { - CEC Blvd }\end{array}$ & 3.22 & - & 3.22 & - & - & - & -3.22 & \\
\hline $\begin{array}{l}\text { SE Lincoln St WB } \\
\text { - CEC Blvd }\end{array}$ & - & - & - & 6.36 & - & 6.36 & 6.36 & 2.82 \\
\hline $\begin{array}{l}\text { SE Madison St } \\
\text { - Grand Ave } \\
\end{array}$ & 0.29 & - & 0.29 & - & - & - & -0.29 & -0.29 \\
\hline Overall Conflict Rate & 1.42 & 0.27 & 1.69 & 1.88 & 0.11 & 2.00 & 0.31 & - \\
\hline
\end{tabular}

Six intersections displayed a reduction in the number of conflicts per million chances for a conflict to occur after the installation of the bike box. The largest decrease in conflicts per hundred bicyclists occurred at N Interstate Avenue at Alberta Street where 16.09 conflicts per million chances for a conflict to occur reduced to zero conflicts after the installation of the bike box. This coincides with the results from the previous metric observing conflicts per hundred bicyclists.

Four intersections displayed an increase in the number of conflicts per million chances for a conflict to occur. Similar to conflicts per hundred bicyclists, the southbound 
direction of SE $26^{\text {th }}$ Avenue at Powell Boulevard showed the most increase in conflicts per hundred bicyclists going from 1.89 conflicts per million chances for a conflict to occur to 18.57 conflicts per million chances.

When analyzing the conflict rate of the intersections when grouped by lane configuration, it was observed that the conflict rate decreased at four of the six intersection groups. The overall conflict rate was observed to have increased by 0.31 conflicts per million chances when taking in account the data from all intersections.

\subsubsection{Conflict Rate per Hundred Right-Turning Vehicles for Intersection Groups}

Results for both directions of travel at the intersections of SE $26^{\text {th }}$ Avenue at Powell Boulevard and SE Lincoln Street at Cesar E. Chavez Boulevard were grouped together and normalized to number of right-turning vehicles. Table 23 summarizes the grouped conflict rates per hundred right-turning vehicles for both of these intersections.

Table 23: Intersection Conflicts Normalized to Number of Right Turns

\begin{tabular}{|c|c|c|c|c|c|c|c|}
\hline \multirow{2}{*}{ Intersection } & \multicolumn{3}{|c|}{ Before } & \multicolumn{3}{|c|}{ After } & \multirow{2}{*}{$\begin{array}{c}\Delta \\
T_{A}-T_{B} \\
\end{array}$} \\
\hline & Minor & Major & Total & Minor & Major & Total & \\
\hline $\begin{array}{l}\text { SE 26th Ave } \\
\text { - Powell Blvd }\end{array}$ & 0.27 & 0.05 & 0.33 & 0.28 & - & 0.28 & -0.04 \\
\hline $\begin{array}{l}\text { SE Lincoln St } \\
- \text { CEC Blvd } \\
\end{array}$ & 0.08 & - & 0.08 & 0.18 & - & 0.18 & 0.10 \\
\hline
\end{tabular}

The intersection of SE $26^{\text {th }}$ Avenue at Powell Boulevard showed a minor reduction in the number of conflicts per hundred right-turning vehicles after the installation of the advanced stop box. The intersection of SE Lincoln Street at Cesar E. Chavez Boulevard, 
however, showed a slight increase in the number of conflicts per hundred right-turning vehicles after the installation of the bike box.

\subsubsection{Conflict Rate per Hundred Bicycles for Groups}

The results for both of the grouped intersections were also normalized to number of bicycles traveling through the intersections. Table 24 summarizes the conflict rates per hundred bicycles for the two intersections.

Table 24: Intersection Conflicts Normalized to Number of Bicycles

\begin{tabular}{|c|c|c|c|c|c|c|c|}
\hline \multirow{2}{*}{ Intersection } & \multicolumn{3}{|c|}{ Before } & \multicolumn{3}{|c|}{ After } & \multirow{2}{*}{$\begin{array}{c}\Delta \\
T_{A}-T_{B}\end{array}$} \\
\hline & Minor & Major & Total & Minor & Major & Total & \\
\hline $\begin{array}{l}\text { SE 26th Ave } \\
\text { - Powell Blvd }\end{array}$ & 0.44 & 0.09 & 0.53 & 0.63 & - & 0.63 & 0.10 \\
\hline $\begin{array}{l}\text { SE Lincoln St } \\
- \text { CEC Blvd } \\
\end{array}$ & 0.08 & - & 0.08 & 0.23 & - & 0.23 & 0.15 \\
\hline
\end{tabular}

When the data are normalized to number of conflicts per hundred bicycles, the conflict rate at the intersection of SE $26^{\text {th }}$ Avenue at Powell Boulevard increases, where before when normalized by number of conflicts per hundred right-turning vehicles, the conflict rate lowered.

The intersection of SE Lincoln Street at Cesar E. Chavez Boulevard also showed a slight increase in the number of conflicts per hundred bicycles.

\subsection{Average Time to Conflict}

Since data were gathered for the time of each event occurring at the intersection, the amount of time between the green indication and the conflict could be analyzed to determine if the installation of the advanced stop box had any impact. The amount of 
time between the start of green and when the conflict occurred was averaged over the total number of conflicts for both the before and after scenarios at each intersection. These values are shown in Figure 27.

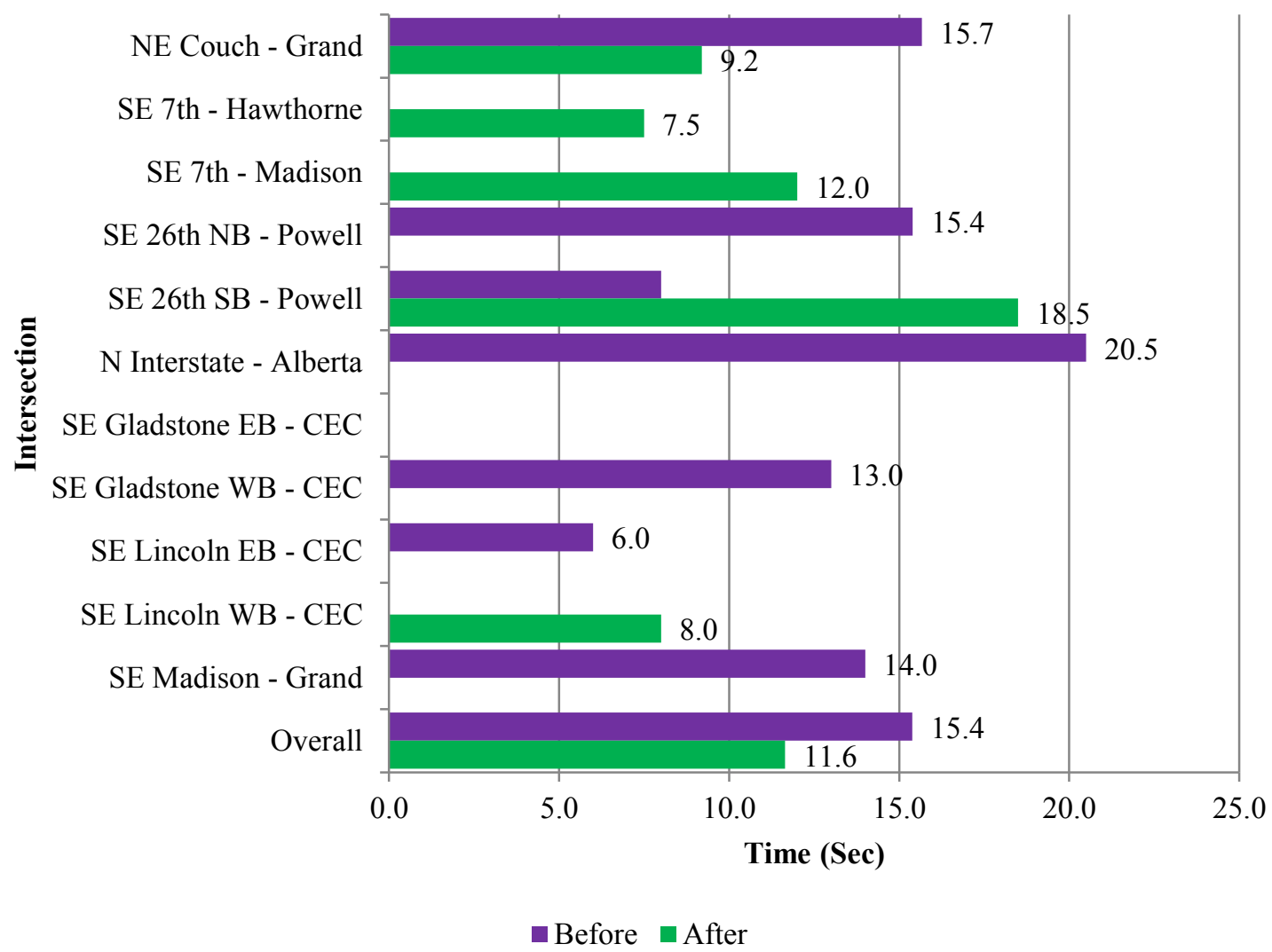

Figure 27: Average Time Into Green for Observed Conflicts

Overall, a decrease was observed in the amount of time between the signal change to green and a conflict occurring. The intersections of NE Couch at Grand Avenue is the only intersection that had conflicts during both study periods to show a decrease in the amount of time between green indication and the conflict occurring. The other intersection with conflicts during both periods was southbound SE $26^{\text {th }}$ Avenue at Powell 
Boulevard, which showed an increase in the amount of time between green indication and a conflict occurring.

\subsection{Crash Data Review}

First, the average annual bike traffic was calculated using the most recent bike volume counted from the video observation, the provided Hawthorne Bridge factors, and growth rates reported with the yearly counts performed by the Portland Bureau of Transportation. The calculated values for each year between 2007 and 2012 are shown in Table 25 .

\section{Table 25: Average Annual Daily Bike Traffic}

\begin{tabular}{|c|c|c|c|c|c|c|}
\hline \multirow{2}{*}{ \# Intersection } & \multicolumn{6}{|c|}{ AADT for Bikes } \\
\hline & 2007 & 2008 & 2009 & 2010 & 2011 & 2012 \\
\hline $\begin{array}{l}1 \text { NE Couch St } \\
\text { - Grand Ave }\end{array}$ & 391 & 500 & 476 & 512 & 545 & 562 \\
\hline $\begin{array}{l}2 \text { SE 7th Ave } \\
\text { - Hawthorne Blvd }\end{array}$ & 156 & 200 & 190 & 204 & 217 & 224 \\
\hline $\begin{array}{l}3 \text { SE 7th Ave } \\
- \text { Madison St }\end{array}$ & 352 & 450 & 428 & 461 & 491 & 507 \\
\hline $\begin{array}{l}4 \text { SE 26th Ave } \\
- \text { Powell Blvd }\end{array}$ & 426 & 545 & 519 & 559 & 595 & 614 \\
\hline $\begin{array}{c}{ }_{5} \mathrm{~N} \text { Interstate Ave } \\
\text { - Alberta St }\end{array}$ & 146 & 187 & 178 & 192 & 204 & 211 \\
\hline${ }_{6} \begin{array}{c}\text { SE Gladston St } \\
\text { - CEC Blvd }\end{array}$ & 160 & 204 & 195 & 210 & 223 & 230 \\
\hline $\begin{array}{r}\text { SE Lincoln St } \\
- \text { CEC Blvd }\end{array}$ & 606 & 776 & 739 & 795 & 846 & 873 \\
\hline $\begin{array}{c}\text { SE Madison St } \\
- \text { Grand Ave }\end{array}$ & 1110 & 1421 & 1353 & 1456 & 1549 & 1599 \\
\hline
\end{tabular}

Table 26 gives a summary of the narrowed crash data grouped by year and a comparison of the crash rate per million entering bicycles (MEB) before and after the bike box was installed. The crashes in the analysis included all bicycle motor vehicle crashes (not just those potentially affected by the bike box installation). For the year the bike box was 
installed, the month of installation was excluded when normalizing the crashes per year. In situations when the exact month of installation was unknown, the range of months when the bike box could have been installed was excluded. It should be noted that only crashes where the bicyclist is injured are typically recorded and many that involve only property damage go unreported.

Table 26: Summary of Crash Data by Year and Crash Rate per MEB

\begin{tabular}{|c|c|c|c|c|c|c|c|c|c|}
\hline \multirow[t]{2}{*}{ Intersection } & \multicolumn{6}{|c|}{ Bike Related Crashes } & \multicolumn{3}{|c|}{ Crash Rate } \\
\hline & 2007 & 2008 & 2009 & 2010 & 2011 & 2012 & Before & After & $\Delta$ \\
\hline $\begin{array}{l}\text { NE Couch St } \\
\text { - Grand Ave }\end{array}$ & 0 & 0 & 0 & 3 & 2 & 2 & 4.81 & 8.87 & 4.06 \\
\hline $\begin{array}{l}\text { SE 7th Ave } \\
\text { - Hawthorne Blvd }\end{array}$ & 0 & 0 & 2 & 0 & 1 & 3 & 9.19 & 29.54 & 20.35 \\
\hline $\begin{array}{l}\text { SE 7th Ave } \\
\text { - Madison St }\end{array}$ & 1 & 0 & 0 & 0 & 1 & 0 & 1.95 & 0.00 & -1.95 \\
\hline $\begin{array}{l}\text { SE 26th Ave } \\
\text { - Powell Blvd }\end{array}$ & 1 & 1 & 1 & 2 & 0 & 1 & 5.60 & 3.59 & -2.01 \\
\hline $\begin{array}{l}\text { N Interstate Ave } \\
\text { - Alberta St }\end{array}$ & 0 & 0 & 0 & 0 & 0 & 1 & 0.00 & 8.52 & 8.52 \\
\hline $\begin{array}{l}\text { SE Gladstone St } \\
\text { - CEC Blvd }\end{array}$ & 0 & 0 & 1 & 1 & 1 & 0 & 9.14 & 0.00 & -9.14 \\
\hline $\begin{array}{l}\text { SE Lincoln St } \\
\text { - CEC Blvd }\end{array}$ & 0 & 0 & 2 & 1 & 0 & 0 & 2.72 & 0.00 & -2.72 \\
\hline $\begin{array}{l}\text { SE Madison St } \\
\text { - Grand Ave } \\
\end{array}$ & 0 & 0 & 1 & 0 & 0 & 0 & 0.41 & 0.00 & -0.41 \\
\hline Total & 2 & 1 & 7 & 7 & 5 & 7 & 3.16 & 3.20 & 0.04 \\
\hline
\end{tabular}

The intersections of NE Couch Street at Grand Avenue, SE $7^{\text {th }}$ Avenue at Hawthorne Boulevard, and N Interstate Avenue at Alberta Street showed an increase in the amount of crashes per million entering bikes per year. Overall, it appears there was a small increase in the crash rate when considering the bike volume and crash totals at all intersections studied. 
It is worth pointing out that SE $7^{\text {th }}$ Avenue at Hawthorne Boulevard has a bike box installed on two approaches: the approach on Hawthorne which is downhill from the Hawthorne Bridge and the approach on SE $7^{\text {th }}$ Avenue. The crash rate at this intersection would reflect the safety of the intersection before and after the installation of the box on SE $7^{\text {th }}$ Avenue.

\subsection{Head Checks}

Head checks were only observed during cycles where a conflict between a vehicle and bicycle had occurred. A head check was counted if the bicyclist made an effort to look over his/her shoulder as they passed through the intersection to observe any possible oncoming conflicts. Table 27 summarizes the head checks that were observed for conflicts occurring at each intersection. 


\section{Table 27: Observed Head Checks}

\begin{tabular}{|c|c|c|c|c|}
\hline \multirow[b]{2}{*}{ Intersection } & \multicolumn{2}{|c|}{ Before } & \multicolumn{2}{|c|}{ After } \\
\hline & $\begin{array}{c}\text { Bikes } \\
\text { Observed }\end{array}$ & Headchecks & $\begin{array}{c}\text { Bikes } \\
\text { Observed }\end{array}$ & Headchecks \\
\hline $\begin{array}{l}\text { NE Couch St } \\
\text { - Grand Ave }\end{array}$ & 9 & 0 & 19 & 4 \\
\hline $\begin{array}{l}\text { SE 7th Ave } \\
\text { - Hawthorne Blvd }\end{array}$ & 0 & 0 & 4 & 3 \\
\hline $\begin{array}{l}\text { SE 7th Ave } \\
\text { - Madison St }\end{array}$ & 0 & 0 & 1 & 0 \\
\hline $\begin{array}{l}\text { SE 26th Ave NB } \\
\text { - Powell Blvd }\end{array}$ & 10 & 1 & 0 & 0 \\
\hline $\begin{array}{l}\text { SE 26th Ave SB } \\
\text { - Powell Blvd }\end{array}$ & 2 & 0 & 7 & 0 \\
\hline $\begin{array}{l}\text { N Interstate Ave } \\
\text { - Alberta St }\end{array}$ & 5 & 0 & 0 & 0 \\
\hline $\begin{array}{l}\text { SE Gladstone St EB } \\
\text { - CEC Blvd }\end{array}$ & 0 & 0 & 0 & 0 \\
\hline $\begin{array}{l}\text { SE Gladstone St WB } \\
\text { - CEC Blvd }\end{array}$ & 1 & 0 & 0 & 0 \\
\hline $\begin{array}{l}\text { SE Lincoln St EB } \\
\text { - CEC Blvd }\end{array}$ & 1 & 0 & 0 & 0 \\
\hline $\begin{array}{l}\text { SE Lincoln St WB } \\
\text { - CEC Blvd }\end{array}$ & 0 & 0 & 3 & 0 \\
\hline $\begin{array}{l}\text { SE Madison St } \\
\text { - Grand Ave } \\
\end{array}$ & 8 & 0 & 0 & 0 \\
\hline Total & 36 & 1 & 34 & 7 \\
\hline
\end{tabular}

A minor amount of bicyclists were found to check on traffic behind them as they traveled through the intersection during both analysis scenarios. However, more bicyclists were found to check behind them after the installation of the bike box. It should be noted that bicyclists that had to avoid a collision with a vehicle as well as any bicyclists traveling behind them were typically the people that looked over their shoulders, usually to make eye contact with the driver following the incident. 


\subsection{Summary}

The following summary of results was made by interpreting the limited data, as summarized in Table 28, and taking in consideration behaviors observed and the environment at each of the study intersections. Since the sample size of observed conflicts is insufficient to draw any significant conclusions, caution should be used when interpreting the results. 
Table 28: Summary of Results

\begin{tabular}{|c|c|c|c|c|c|c|c|c|}
\hline \multirow[b]{2}{*}{ \# } & \multirow[b]{2}{*}{ Intersection } & \multicolumn{3}{|c|}{ Conflicts } & \multicolumn{3}{|c|}{ Conflicts Per } & \multirow[b]{2}{*}{ Crash Rate } \\
\hline & & Minor & Major & $\begin{array}{l}\text { Initial } \\
\text { Green }\end{array}$ & $\begin{array}{c}\text { Hundred } \\
\text { Right- }\end{array}$ & $\begin{array}{c}\text { Hundred } \\
\text { Bicyclists }\end{array}$ & $\begin{array}{c}\text { Million } \\
\text { Chances }\end{array}$ & \\
\hline 1 & $\begin{array}{l}\text { NE Couch St } \\
\text { - Grand Ave }\end{array}$ & +4 & -1 & +2 & + & - & - & + \\
\hline 2 & $\begin{array}{l}\text { SE 7th Ave } \\
\text { - Hawthorne Blvd }\end{array}$ & +2 & $\mathbf{0}$ & +1 & + & + & + & + \\
\hline 3 & $\begin{array}{l}\text { SE 7th Ave } \\
\quad-\text { Madison St }\end{array}$ & +1 & $\mathbf{0}$ & $\mathbf{0}$ & + & + & + & - \\
\hline 4 & $\begin{array}{l}\text { SE 26th Ave NB } \\
\text { - Powell Blvd }\end{array}$ & -5 & $\mathbf{0}$ & -1 & - & - & - & \multirow[b]{2}{*}{ - } \\
\hline 4 & $\begin{array}{l}\text { SE 26th Ave SB } \\
\text { - Powell Blvd }\end{array}$ & +4 & -1 & $\mathbf{0}$ & + & + & + & \\
\hline 5 & $\begin{array}{c}\text { N Interstate Ave } \\
\text { - Alberta St }\end{array}$ & $-\mathbf{3}$ & $\mathbf{0}$ & $\mathbf{0}$ & - & - & - & + \\
\hline 6 & $\begin{array}{l}\text { SE Gladstone St EB } \\
\text { - CEC Blvd }\end{array}$ & $\mathbf{0}$ & $\mathbf{0}$ & $\mathbf{0}$ & & & & \multirow[b]{2}{*}{ - } \\
\hline 6 & $\begin{array}{l}\text { SE Gladstone St WB } \\
\text { - CEC Blvd }\end{array}$ & -1 & $\mathbf{0}$ & $\mathbf{0}$ & - & - & - & \\
\hline 7 & $\begin{array}{l}\text { SE Lincoln St EB } \\
\text { - CEC Blvd }\end{array}$ & -1 & $\mathbf{0}$ & $\mathbf{0}$ & - & - & - & \multirow{2}{*}{-} \\
\hline 7 & $\begin{array}{l}\text { SE Lincoln St WB } \\
\text { - CEC Blvd }\end{array}$ & +2 & $\mathbf{0}$ & +1 & + & + & + & \\
\hline 8 & $\begin{array}{l}\text { SE Madison St } \\
\text { - Grand Ave }\end{array}$ & -2 & $\mathbf{0}$ & - & - & - & - & - \\
\hline & Overall & +1 & -2 & +3 & - & + & + & +0.04 \\
\hline
\end{tabular}


Overall, when the data from all of these intersections are pooled there was an increase in the number of minor conflicts and a decrease in the number of major conflicts observed at the study intersections. A significant majority of the conflicts occurred with the bicycle overtaking the motor vehicle.

In observing the limited amount of conflict data, it was found that five intersections showed an increase in the number of conflicts between bicyclists and motorized vehicles after the installation of a bike box. Five other intersections demonstrated a reduction in the number of conflicts observed after the installation of a bike box. The conflict rate per hundred right-turning vehicles also increased and decreased at the same number of intersections. The conflict rate per hundred bicyclists, however, increased at six of the study intersections; whereas four intersections showed a reduction after the installation of the bike box.

The intersection of NE Couch Street at Grand Avenue showed an increase in the number of minor conflicts after the installation of the advanced stop box. Only one conflict during both periods was observed occurring between a stopped bicyclist and a stopped vehicle. The remaining conflicts occurred with at least the bicyclist in motion. A decrease in the amount of time between the green indication and the conflict occurring was also observed at this intersection. After the installation of the treatment, a smaller percentage of bicyclists were observed yielding to the motor vehicle after a conflict occurred hinting of the possibility that bicyclists are feeling more entitled to their rightof-way. The crash rate at the intersection almost doubled after the installation of the bike box. Even though there is limited data, evidence shows that the intersection may not 
have benefitted from the intersection treatment when looking at only safety impacts. Combined with the fact that the downhill slope and progression of the intersection allows bicycles to maintain speed with or even overtake motor vehicles, the installation of a bike box at a similar intersection may not have much effect on reducing right-hook collisions or conflicts.

The intersection of SE $7^{\text {th }}$ Avenue at Hawthorne Boulevard had two minor conflicts occur after the installation of the bike box whereas none were observed in the before period. Both conflicts that occurred involved a bicyclist approaching a waiting motor vehicle and the motor vehicle yielding to oncoming bicyclists, showing there is likely awareness for the driver to observe oncoming bicyclists behind them. An increase in the crash rate was observed, but the presence of a downhill grade and bicycle facilities (including another bike box) on the Hawthorne approach could be more contributing of factors than the bike box on the $7^{\text {th }}$ Avenue approach.

The intersection of SE $7^{\text {th }}$ Avenue at Madison had only one observed conflict that occurred following the installation of the bike box. The conflict occurred when a vehicle overtook the bicyclist and resulted in the bicyclist yielding before continuing through the intersection. It should be noted that majority of the bicyclists at this location were observed to be turning right to use Madison Street to cross the Hawthorne Bridge. It can be assumed that motor vehicles are knowledgeable of this behavior and are not expecting bicyclists to continue through the intersection when making the right-turn movement. 
Taking in consideration both directions at SE $26^{\text {th }}$ Avenue at Powell Boulevard, a decrease in the amount of total conflicts was observed after the installation of the intersection treatment. None of the conflicts that were observed in either period were between two stopped parties and all conflicts occurred with the bicyclist overtaking the right-turning motor vehicle. With the nearby high-school and the large number of pedestrians crossing Powell Boulevard, motor vehicles were observed waiting in the path of the bicyclist causing a number of the conflicts. The observations at this intersection were challenging because of the significant weather differences in the before and after periods.

Three minor conflicts were observed at the intersection of $\mathrm{N}$ Interstate at Alberta Street. All three conflicts occurred with the motor vehicle overtaking the bicyclist during the latter part of the green phase. The crash rate has increased for this location since the installation of the bike box.

The intersection of SE Gladstone Street at Cesar E Chavez Boulevard showed a decrease in the number of conflicts and the crash rate after the installation of the bike box. Possible contributing factors to the low conflict and crash rates are the facts that the facility at this location is on a neighborhood greenway and has low volumes of motor vehicle traffic.

There was an increase of one conflict at the intersection of SE Lincoln Street at Cesar E Chavez Boulevard after the installation of the bike box. All conflicts observed involved the bicyclist yielding to the motor vehicle's turning movement. Similar to the 
intersection of SE Gladstone Street at Cesar E Chavez Boulevard, the intersection is on a neighborhood greenway and has low volumes of vehicle traffic; however, unlike SE Gladstone, traffic at this intersection is required to make a left or right turning movement.

The intersection of SE Madison Street at Grand Avenue has an atypical installation of the bike box in a dedicated right-turn lane. The intersection had the largest number of bikes traveling through it and had only two conflicts observed in the before period. One conflict that was observed was during the red phase and both conflicts involved a motor vehicle making a right-turn in front of the bicyclist from the middle lane.

When reviewing the crash rates from all of the study intersections, a slight increase in the number of crashes per million entering bikes was observed. The intersections of NE Couch Street at Grand Avenue, SE $7^{\text {th }}$ Avenue at Hawthorne Boulevard, and N Interstate at Alberta showed an increase in the crash rate following the installation of the bike box. The intersection of NE Couch Street at Grand Avenue is located on a downhill slope where bicycles may be able to maintain speed with and possibly overtake motor vehicles, which could be the cause of the crash when the motor vehicle does not expect someone to be passing them on the right before making their turn. The intersection of SE $7^{\text {th }}$ Avenue at Hawthorne Boulevard's crash data could be explained with this same situation since the approach on Hawthorne Boulevard is also downhill and carries a large amount of bicyclists. It is recommended that more crash data be observed and, if possible, only be observed for the approach with the corresponding bike box. 
Although extremely limited, the data received observing head checks from bicyclists show that there may be an increase in the amount of people looking over their shoulders as they pass through the intersection. More observations should be made, especially of bicyclists not involved in or near a conflict with a motor vehicle. This is a potentially promising additional point of research. 


\subsection{CONCLUSIONS}

After reviewing approximately 528 hours of video from 11 different intersection approaches, a conflict analysis was performed to compare the number of conflicts between bicyclists and motor vehicles before and after the installation of an advanced stop box (or bike box). Due to the small sample of conflicts, no tests of statistical significance were conducted. Thus, the conclusions on whether the advanced stop box reduces or increases the amount of conflicts at any of the study intersections are more observational. It is recommended that additional data be gathered over a wider period of time to capture a larger pool of conflicts between bicyclists and motor vehicles.

Additional metrics to quantify what constitutes a conflict should also be considered. A weakness found through the research presented is the subjective definition of a conflict as interpreted by different people. Research identifying a "post encroachment time" has been performed and would incorporate into the study method presented here for a better analysis. The review of a "post encroachment time" quantifies the severity of a conflict by observing the time between when a bicyclist and a motorist both enter or exit a specific area of the intersection and is presented as a numerical value. This value can be the number of frames per second in a video or a time-stamp if a low enough resolution is available.

Even though there are no statistically significant conclusions, it was observed that the bike box was fulfilling its designed uses including to move bicyclists to a more visible area during the red phase, to allow bicyclists to proceed ahead of any initial right-turning 
traffic, to allow bicyclists to avoid breathing direct vehicle fumes, and to allow bicyclists to travel through the intersection in a more convenient and safer manner. 


\subsection{REFERENCES}

Allen, D., S. Bygrave, and H. Harper. "Behavior at Cycle Advance Stop Lines." Transport Research Laboratory, 2005.

Buch, T. S. and S. U. Jensen. "Sikkerhedseffekter af tilbagetrukne stopstreger. (Translate: Safety Effects of staggered stoplines)" Trafitec, 2012.

Dingus, Thomas A., et al. The 100-car naturalistic driving study, Phase II-results of the 100-car field experiment. No. HS-810 593. 2006.

Guttinger, V. "Conflict Observation in Theory and Practice." International Study of Traffic Conflict Techniques. (1984): 17-24.

Herrstedt, Lene, et al. "Safety of cyclists in urban areas." Strategic Highway Research Program (SHRP) and Traffic Safety on Two Continents, Proceedings of the Conference. No. VTI 1A, Part 2. 1994.

Hong-bo, Qian, and Zhang Hui-ling. "Bicycle Traffic Organization and Treatment at Signalized Intersection." Intelligent Computation Technology and Automation, 2009. ICICTA'09. Second International Conference on. Vol. 3. IEEE, 2009.

Hummer, Joseph E. "Traffic Conflict Studies." (1994).

Hunter, William W., et al. "Evaluation of blue bike-lane treatment in Portland, Oregon." Transportation Research Record: Journal of the Transportation Research Board 1705.1 (2000): 107-115. 
Hunter, William W. "Evaluation of innovative bike-box application in Eugene, Oregon." Transportation Research Record: Journal of the Transportation Research Board 1705.1 (2000): 99-106.

Parker Jr, M. R., and Charles V. Zegeer. Traffic Conflict Techniques for Safety and Operations. Observers Manual. No. FHWA-IP-88-027. 1989.

Pucher, John, Jennifer Dill, and Susan Handy. "Infrastructure, programs, and policies to increase bicycling: an international review." Preventive Medicine 50 (2010): S106-S125.

Transport for London. "Review of procedures associated with the development and delivery of measures designed to improve safety and convenience for cyclists." (2005).

Wall, G. T., D. G. Davies, and M. Crabtree. Capacity implications of Advanced Stop Lines for cyclists. Transport Research Laboratory, 2003. 


\subsection{APPENDIX}

\subsection{R Script}

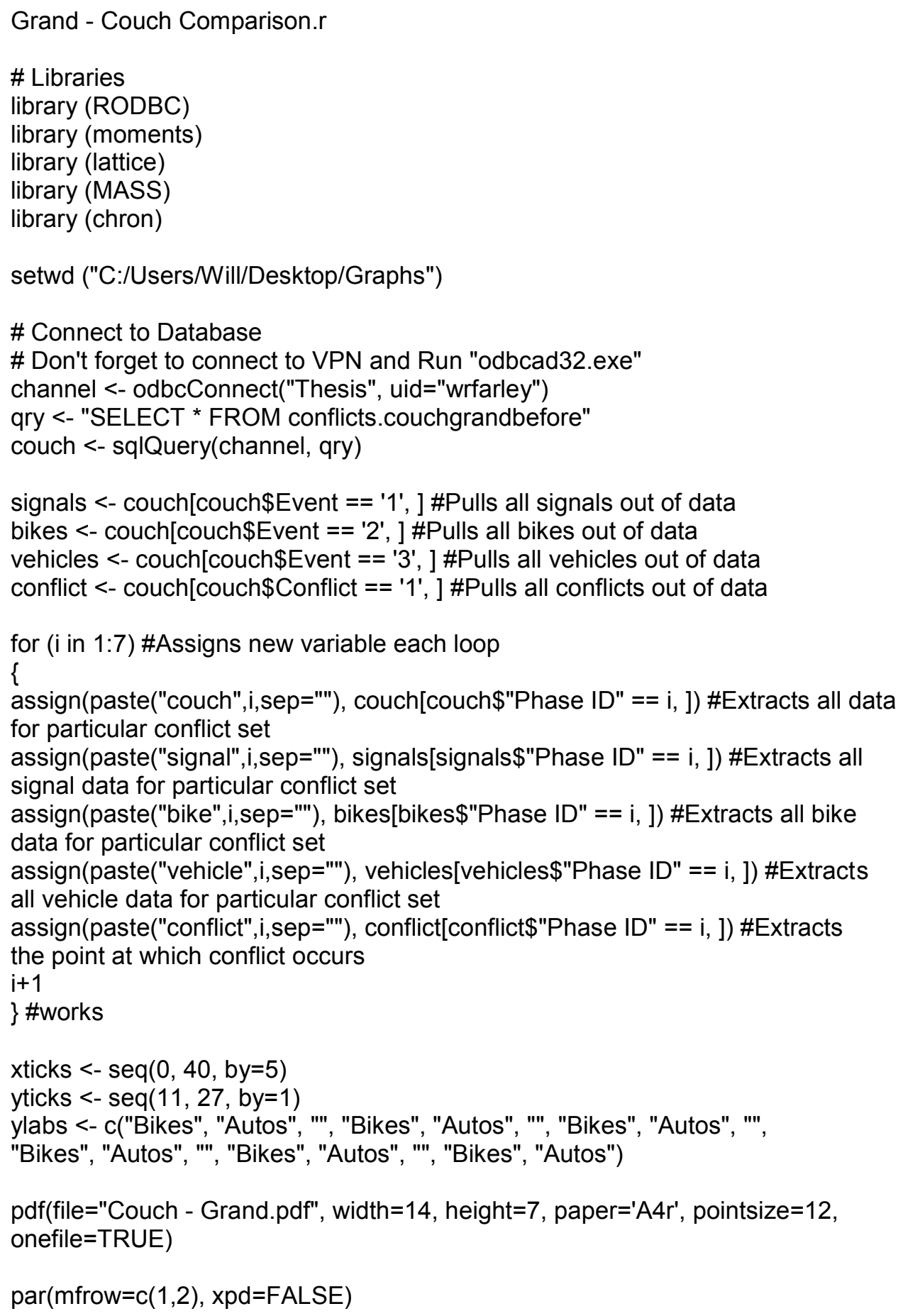


\#Conflict 1

check1 <- bike1[bike1\$Check == '1', ] \#Cyclist checks behind when traveling through intersection

nocheck1 <- bike1[bike1\$Check == '0', ] \#Cyclist does not check behind right $1<-$ vehicle1[vehicle1\$Direction == 'Right', ] \#Pulls out right turning vehicles

straight1 <- vehicle1[vehicle1\$Direction == 'Straight', ] \#Pulls out straight turning vehicles

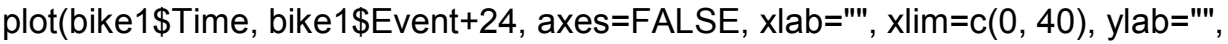
ylim=c(1.75,27))

par(new=TRUE)

plot(vehicle1\$Time, vehicle1\$Event+24, axes=FALSE, $x l a b=" ', x \lim =c(0,40)$, ylab="', ylim $=c(1.75,27))$

rect(xleft=signal $1 \$$ Time[1], xright=signal $1 \$$ Time[2], ybottom=25.5, ytop=27.5,

col="\#00FF00A0")

rect(xleft=signal $1 \$$ Time[2], xright=signal $1 \$$ Time[3], ybottom=25.5, ytop=27.5,

col="\#FFFF00A0")

rect(xleft=signal $1 \$$ Time[1]-2, xright=signal $1 \$$ Time[1], ybottom=25.5, ytop=27.5, col="\#FF0000A0")

rect(xleft=signal1 $\$$ Time[3], xright=42, ybottom=25.5, ytop=27.5, col="\#FF0000A0")

rect(xleft=conflict1\$Time[1]-.5, xright=conflict1\$Time[length(conflict1\$Time)]+.5,

ybottom=25.75, ytop=27.25, col="\#E0EEEEA0")

points(check1\$Time, check1\$Event+24, pch=25)

points (nocheck1\$Time, nocheck1\$Event+24, pch=17)

points(straight $1 \$$ Time, straight 1 EEvent +24 , pch=13)

points(right1\$Time, right 1 Event+24, pch=20)

\#Conflict 2

check2 <- bike2[bike2\$Check == '1', ] \#Cyclist checks behind when traveling through intersection

nocheck2 <- bike2[bike2\$Check == '0', ] \#Cyclist does not check behind

right2 <- vehicle2[vehicle2\$Direction == 'Right', ] \#Pulls out right turning

vehicles

straight2 <- vehicle2[vehicle2\$Direction == 'Straight', ] \#Pulls out straight

turning vehicles

par(new=TRUE)

plot(bike2\$Time, bike2\$Event+21, axes=FALSE, $x l a b=" ', x \lim =c(0,40)$, ylab="',

ylim=c(1.75,27))

par(new=TRUE)

plot(vehicle2\$Time, vehicle2\$Event+21, axes=FALSE, $x l a b=" ', x \lim =c(0,40)$, ylab="', ylim $=c(1.75,27))$

rect(xleft=signal2 $\$$ Time[1], xright=signal2 $\$$ Time[2], ybottom=22.5, ytop=24.5,

col="\#00FF00A0")

rect(xleft=signal2\$Time[2], xright=signal2\$Time[3], ybottom=22.5, ytop=24.5,

col="\#FFFF00A0")

rect $(x l e f t=s i g n a l 2 \$$ Time[1]-2, xright=signal2 $\$$ Time[1], ybottom=22.5, ytop=24.5,

col="\#FF0000A0") 
rect(xleft=signal2\$Time[3], xright=42, ybottom=22.5, ytop=24.5, col="\#FF0000A0") rect $(x$ left=conflict2\$Time[1]-.5, xright=conflict2\$Time[length(conflict2\$Time)]+.5, ybottom=22.75, ytop=24.25, col="\#E0EEEEA0")

points(check2\$Time, check2\$Event $+21, \mathrm{pch}=25$ )

points(nocheck2\$Time, nocheck2\$Event+21, pch=17)

points(straight2\$Time, straight2\$Event $+21, \mathrm{pch}=13$ )

points(right2\$Time, right2\$Event+21, pch=20)

\#Conflict 3

check3 <- bike3[bike3\$Check == '1', ] \#Cyclist checks behind when traveling through intersection

nocheck3 <- bike3[bike3\$Check == '0', ] \#Cyclist does not check behind

right3 <- vehicle3[vehicle3\$Direction == 'Right', ] \#Pulls out right turning

vehicles

straight3 <- vehicle3[vehicle3\$Direction == 'Straight', ] \#Pulls out straight

turning vehicles

$\operatorname{par}($ new $=$ TRUE)

plot(bike3\$Time, bike3\$Event+18, axes=FALSE, $x l a b=" ', x \lim =c(0,40)$, ylab="',

ylim $=c(1.75,27))$

par(new=TRUE)

plot(vehicle3\$Time, vehicle3\$Event+18, axes=FALSE, $x l a b=" "$, $x \lim =c(0,40)$, ylab="", ylim=c(1.75,27))

rect(xleft=signal3\$Time[1], xright=signal3\$Time[2], ybottom=19.5, ytop=21.5,

col="\#00FF00A0")

rect(xleft=signal3\$Time[2], xright=signal3\$Time[3], ybottom=19.5, ytop=21.5,

col="\#FFFF00A0")

rect $(x$ left=signal3\$Time[1]-2, xright=signal3\$Time[1], ybottom=19.5, ytop=21.5,

col="\#FF0000A0")

rect(xleft=signal3\$Time[3], xright=42, ybottom=19.5, ytop=21.5, col="\#FF0000A0")

rect $(x$ left=conflict3\$Time[1]-.5, xright=conflict3\$Time[length(conflict3\$Time)]+.5,

ybottom=19.75, ytop=21.25, col="\#E0EEEEA0")

points(check3\$Time, check3\$Event+18, pch=25)

points(nocheck3\$Time, nocheck3 $\$$ Event+18, pch=17)

points(straight3\$Time, straight3\$Event+18, pch=13)

points(right3\$Time, right3\$Event+18, pch=20)

\#Conflict 4

check4 <- bike4[bike4\$Check == '1', ] \#Cyclist checks behind when traveling through intersection

nocheck4 <- bike4[bike4\$Check == '0', ] \#Cyclist does not check behind

right4 <- vehicle4[vehicle4\$Direction == 'Right', ] \#Pulls out right turning

vehicles

straight4 <- vehicle4[vehicle4\$Direction == 'Straight', ] \#Pulls out straight

turning vehicles

par(new=TRUE)

plot(bike4\$Time, bike4\$Event+15, axes=FALSE, $x l a b=" ', x \lim =c(0,40)$, ylab="',

ylim=c(1.75,27)) 
par(new=TRUE)

plot(vehicle4\$Time, vehicle4\$Event+15, axes=FALSE, $x l a b=" ', x \lim =c(0,40)$, ylab="', ylim=c(1.75,27))

rect(xleft=signal4\$Time[1], xright=signal4\$Time[2], ybottom=16.5, ytop=18.5, col="\#00FF00A0")

rect(xleft=signal4\$Time[2], xright=signal4\$Time[3], ybottom=16.5, ytop=18.5, col="\#FFFFOOA0")

rect $(x l e f t=$ signal4\$Time[1]-2, xright=signal4\$Time[1], ybottom=16.5, ytop=18.5, col="\#FF0000A0")

rect(xleft=signal4\$Time[3], xright=42, ybottom=16.5, ytop=18.5, col="\#FF0000A0")

rect $(x$ left=conflict $4 \$$ Time[1]-.5, xright=conflict $4 \$$ Time[length (conflict4\$Time)]+.5,

ybottom=16.75, ytop=18.25, col="\#E0EEEEA0")

points(check4\$Time, check4 $\$$ Event+15, pch=25)

points(nocheck4\$Time, nocheck4 $\$$ Event +15 , pch=17)

points(straight 4 Time, straight 4 Event $+15, p c h=13$ )

points(right4\$Time, right4\$Event+15, pch=20)

\#Conflict 5

check5 <- bike5[bike5\$Check == '1', ] \#Cyclist checks behind when traveling through intersection

nocheck5 <- bike5[bike5\$Check == '0', ] \#Cyclist does not check behind

right5 <- vehicle5[vehicle5\$Direction == 'Right', ] \#Pulls out right turning

vehicles

straight5 <- vehicle5[vehicle5\$Direction == 'Straight', ] \#Pulls out straight

turning vehicles

par(new=TRUE)

plot(bike5\$Time, bike5\$Event+12, axes=FALSE, $x l a b=" ', x \lim =c(0,40)$, ylab="',

ylim=c(1.75,27))

par(new=TRUE)

plot(vehicle5\$Time, vehicle5\$Event+12, axes=FALSE, $x l a b=" ', x \lim =c(0,40)$, ylab="', ylim $=c(1.75,27))$

rect(xleft=signal5 $\$$ Time[1], xright=signal5 $\$$ Time[2], ybottom=13.5, ytop=15.5,

col="\#00FF00A0")

rect $(x$ left=signal5 $\$$ Time[2], $x$ right=signal5 $\$$ Time[3], ybottom=13.5, ytop=15.5,

col="\#FFFF00A0")

rect(xleft=signal5\$Time[1]-2, xright=signal5\$Time[1], ybottom=13.5, ytop=15.5, col="\#FF0000A0")

rect(xleft=signal5\$Time[3], xright=42, ybottom=13.5, ytop=15.5, col="\#FF0000A0")

rect $(x$ left=conflict5\$Time[1]-.5, xright=conflict5\$Time[length(conflict5\$Time)]+.5,

ybottom=13.75, ytop=15.25, col="\#E0EEEEA0")

points(check5\$Time, check5\$Event+12, pch=25)

points(nocheck5\$Time, nocheck5\$Event+12, pch=17)

points(straight5\$Time, straight5\$Event+12, pch=13)

points(right5\$Time, right5\$Event+12, pch=20)

\#Conflict 6

check6 <- bike6[bike6 $\$$ Check == '1', ] \#Cyclist checks behind when traveling through intersection 
nocheck6 <- bike6[bike6\$Check == '0', ] \#Cyclist does not check behind right6 <- vehicle6[vehicle6\$Direction == 'Right', ] \#Pulls out right turning vehicles

straight6 <- vehicle6[vehicle6\$Direction == 'Straight', ] \#Pulls out straight turning vehicles

par(new=TRUE)

plot(bike6\$Time, bike6\$Event+9, axes=FALSE, $x l a b=" ', x \lim =c(0,40)$, ylab="', ylim $=c(1.75,27))$

par(new=TRUE)

plot(vehicle6\$Time, vehicle6\$Event+9, axes=FALSE, $x l a b=" ', x \lim =c(0,40)$, ylab="', ylim=c(1.75,27))

rect(xleft=signal6 $\$$ Time[1], xright=signal6\$Time[2], ybottom=10.5, ytop=12.5, col="\#00FF00A0")

rect(xleft=signal6\$Time[2], xright=signal6\$Time[3], ybottom=10.5, ytop=12.5, col="\#FFFF00A0")

rect $(x$ left=signal6 $\$$ Time[1]-2, xright=signal6 $\$$ Time[1], ybottom=10.5, ytop=12.5, col="\#FF0000A0")

rect(xleft=signal6\$Time[3], xright=42, ybottom=10.5, ytop=12.5, col="\#FF0000A0")

rect $(x$ left=conflict6\$Time[1]-.5, xright=conflict6\$Time[length(conflict6\$Time)]+.5, ybottom=10.75, ytop=12.25, col="\#E0EEEEA0")

points(check6 $\$$ Time, check6 $\$$ Event +9 , pch $=25$ )

points(nocheck6\$Time, nocheck6\$Event +9 , pch $=17$ )

points(straight6\$Time, straight6\$Event +9 , pch=13)

points(right6\$Time, right6\$Event+9, pch=20)

abline(v=5, col="red") \#Can be adjusted for startup times

axis $(2$, las $=2$, labels=ylabs, at=yticks)

axis $(1$, at=xticks)

title(main="NE Grand - Couch 9/8/2010", xlab="Time (sec)")

mtext("555 Bicyclists vs. 2,162 Right Turns")

legend(31.5, 5.25, c("Conflict", "Right Turning", "Through", "Head Check", "No Head

Check"), pch $=\mathrm{c}(26,19,13,25,17)$, , cex $=.6)$

box ()

\#2nd Graph

qry <- "SELECT * FROM conflicts.logcouchafter"

couch <- sqlQuery(channel, qry)

signals <- couch[couch\$Event == '1', ] \#Pulls all signals out of data

bikes <- couch[couch $\$ E$ vent $==$ '2', ] \#Pulls all bikes out of data

vehicles <- couch[couch\$Event == '3', ] \#Pulls all vehicles out of data

conflict <- couch[couch\$Conflict == '1', ] \#Pulls all conflicts out of data

for (i in 1:9) \#Assigns new variable each loop

\{

assign(paste("couch",i,sep=""), couch[couch\$"Phase ID" == i, ]) \#Extracts all data for particular conflict set

assign(paste("signal",i,sep=""), signals[signals\$"Phase ID" == i, ]) \#Extracts all signal data for particular conflict set

assign(paste("bike",i,sep="'), bikes[bikes\$"Phase ID" == i, ]) \#Extracts all bike 
data for particular conflict set

assign(paste("vehicle",i,sep=""), vehicles[vehicles\$"Phase ID" == i, ]) \#Extracts

all vehicle data for particular conflict set

assign(paste("conflict",i,sep="'), conflict[conflict\$"Phase ID" == i, ]) \#Extracts

the point at which conflict occurs

$\mathrm{i}+1$

\} \#works

xticks <- seq $(0,40$, by $=5)$

yticks <- $\operatorname{seq}(2,27$, by=1)

ylabs <- c("Bikes", "Autos", "', "Bikes", "Autos", "', "Bikes", "Autos", "',

"Bikes", "Autos", "', "Bikes", "Autos", "', "Bikes", "Autos", "', "Bikes", "Autos",

"', "Bikes", "Autos", "', "Bikes", "Autos")

\#Conflict 1

check1 <- bike1[bike1\$Check == '1', ] \#Cyclist checks behind when traveling through intersection

nocheck1 <- bike1[bike1\$Check == '0', ] \#Cyclist does not check behind

right $1<-$ vehicle1[vehicle1\$Direction == 'Right', ] \#Pulls out right turning vehicles

straight1 <- vehicle1[vehicle1\$Direction == 'Straight', ] \#Pulls out straight

turning vehicles

plot(bike1\$Time, bike1\$Event+24, axes=FALSE, $x l a b=" ', x \lim =c(0,40)$, ylab="',

ylim=c(1.75,27))

par(new=TRUE)

plot(vehicle1\$Time, vehicle1\$Event+24, axes=FALSE, $x l a b=" ', x \lim =c(0,40)$, ylab="', ylim $=c(1.75,27))$

rect(xleft=signal $1 \$$ Time[1], xright=signal $1 \$ T$ ime[2], ybottom=25.5, ytop=27.5,

col="\#00FF00A0")

rect(xleft=signal $1 \$$ Time[2], $x$ right=signal $1 \$$ Time[3], ybottom=25.5, ytop=27.5,

col="\#FFFF00A0")

rect(xleft=signal $1 \$$ Time[1]-2, xright=signal1 $\$$ Time[1], ybottom=25.5, ytop=27.5,

$\mathrm{col}=" \# \mathrm{FF} 0000 \mathrm{A0}$ ")

rect(xleft=signal $1 \$$ Time[3], xright=42, ybottom=25.5, ytop=27.5, col="\#FF0000A0")

rect $(x$ left=conflict1\$Time[1]-.5, xright=conflict1\$Time[length(conflict1\$Time)]+.5,

ybottom=25.75, ytop=27.25, col="\#E0EEEEA0")

points(check1\$Time, check1\$Event+24, pch=25)

points(nocheck1\$Time, nocheck1\$Event+24, pch=17)

points(straight 1 T Time, straight 1 Event +24 , pch=13)

points(right1\$Time, right1\$Event+24, pch=20)

\#Conflict 2

check2 <- bike2[bike2\$Check == '1', ] \#Cyclist checks behind when traveling through intersection

nocheck2 <- bike2[bike2\$Check == '0', ] \#Cyclist does not check behind

right2 <- vehicle2[vehicle2\$Direction == 'Right', ] \#Pulls out right turning

vehicles

straight2 <- vehicle2[vehicle2\$Direction == 'Straight', ] \#Pulls out straight

turning vehicles 
par(new=TRUE)

plot(bike2\$Time, bike2\$Event+21, axes=FALSE, $x \operatorname{lab}=" '$ ", $x \lim =c(0,40)$, ylab="', ylim $=c(1.75,27))$

par(new=TRUE)

plot(vehicle2\$Time, vehicle2\$Event+21, axes=FALSE, $x l a b=" ', x \lim =c(0,40)$, ylab="', ylim=c(1.75,27))

rect(xleft=signal2 $\$$ Time[1], xright=signal2 $\$$ Time[2], ybottom=22.5, ytop=24.5, col="\#00FF00A0")

rect(xleft=signal2 $\$$ Time[2], xright=signal2 $\$$ Time[3], ybottom=22.5, ytop=24.5,

col="\#FFFF00A0")

rect(xleft=signal2\$Time[1]-2, xright=signal2 $\$$ Time[1], ybottom=22.5, ytop=24.5, col="\#FF0000A0")

rect(xleft=signal2\$Time[3], xright=42, ybottom=22.5, ytop=24.5, col="\#FF0000A0")

rect $(x$ left=conflict2\$Time[1]-.5, xright=conflict2\$Time[length(conflict2\$Time)]+.5,

ybottom=22.75, ytop=24.25, col="\#E0EEEEA0")

points(check2\$Time, check2\$Event+21, pch=25)

points(nocheck2\$Time, nocheck2\$Event+21, pch=17)

points(straight $2 \$$ Time, straight $2 \$$ Event $+21, p c h=13$ )

points(right2\$Time, right2\$Event+21, pch=20)

\#Conflict 3

check3 <- bike3[bike3\$Check == '1', ] \#Cyclist checks behind when traveling through intersection

nocheck3 <- bike3[bike3\$Check == '0', ] \#Cyclist does not check behind

right3 <- vehicle3[vehicle3\$Direction == 'Right', ] \#Pulls out right turning

vehicles

straight3 <- vehicle3[vehicle3\$Direction == 'Straight', ] \#Pulls out straight

turning vehicles

par(new=TRUE)

plot(bike3\$Time, bike3\$Event+18, axes=FALSE, $x l a b=" ', x \lim =c(0,40)$, ylab="',

ylim $=c(1.75,27))$

par(new=TRUE)

plot(vehicle3\$Time, vehicle3\$Event+18, axes=FALSE, $x l a b=" ', x \lim =c(0,40)$, ylab="', ylim=c(1.75,27))

rect $(x$ left=signal3 $\$$ Time[1], xright=signal3 $\$$ Time[2], ybottom=19.5, ytop=21.5,

col="\#00FF00A0")

rect(xleft=signal3\$Time[2], xright=signal3\$Time[3], ybottom=19.5, ytop=21.5,

col="\#FFFF00A0")

rect $(x$ left=signal3\$Time[1]-2, xright=signal3\$Time[1], ybottom=19.5, ytop=21.5,

col="\#FF0000A0")

rect(xleft=signal3\$Time[3], xright=42, ybottom=19.5, ytop=21.5, col="\#FF0000A0")

rect(xleft=conflict3\$Time[1]-.5, xright=conflict3\$Time[length(conflict3\$Time)]+.5,

ybottom=19.75, ytop=21.25, col="\#EOEEEEA0")

points(check3 $\$$ Time, check3\$Event+18, pch=25)

points(nocheck3\$Time, nocheck3\$Event+18, pch=17)

points(straight 3 Time, straight $3 \$$ Event +18 , pch=13)

points(right3\$Time, right $3 \$$ Event +18 , pch=20) 


\section{\#Conflict 4}

check4 <- bike4[bike4\$Check == '1', ] \#Cyclist checks behind when traveling through intersection

nocheck4 <- bike4[bike4\$Check == '0', ] \#Cyclist does not check behind right4 <- vehicle4[vehicle4\$Direction == 'Right', ] \#Pulls out right turning vehicles

straight4 <- vehicle4[vehicle4\$Direction == 'Straight', ] \#Pulls out straight turning vehicles

par(new=TRUE)

plot(bike4\$Time, bike4\$Event+15, axes=FALSE, $x \operatorname{lab}=" '$ ", $x \lim =c(0,40)$, ylab="', ylim=c(1.75,27))

par(new=TRUE)

plot(vehicle4\$Time, vehicle4\$Event+15, axes=FALSE, $x l a b=" ', x \lim =c(0,40)$, ylab="'", ylim $=c(1.75,27))$

rect(xleft=signal4\$Time[1], xright=signal $4 \$$ Time[2], ybottom=16.5, ytop=18.5,

col="\#00FF00A0")

rect(xleft=signal $4 \$$ Time[2], xright=signal $4 \$$ Time[3], ybottom=16.5, ytop=18.5,

col="\#FFFF00A0")

rect $(x$ left=signal $4 \$$ Time[1]-2, xright=signal $4 \$$ Time[1], ybottom=16.5, ytop=18.5, col="\#FF0000A0")

rect $(x$ left=signal4\$Time[3], xright=42, ybottom=16.5, ytop=18.5, col="\#FF0000A0")

rect $(x$ left=conflict 4 Time[1]-.5, xright=conflict 4 \$Time[length(conflict4\$Time)]+.5,

ybottom=16.75, ytop=18.25, col="\#E0EEEEA0")

points (check4\$Time, check4\$Event+15, pch=25)

points(nocheck4\$Time, nocheck4\$Event+15, pch=17)

points(straight 4 T Time, straight 4 Event +15 , pch=13)

points(right4\$Time, right 4 \$Event $+15, \mathrm{pch}=20$ )

\#Conflict 5

check5 <- bike5[bike5\$Check == '1', ] \#Cyclist checks behind when traveling through intersection

nocheck5 <- bike5[bike5 $\$$ Check == '0', ] \#Cyclist does not check behind

right5 <- vehicle5[vehicle5\$Direction == 'Right', ] \#Pulls out right turning vehicles

straight5 <- vehicle5[vehicle5\$Direction == 'Straight', ] \#Pulls out straight

turning vehicles

par(new=TRUE)

plot(bike5\$Time, bike5\$Event+12, axes=FALSE, $x l a b=" ', x \lim =c(0,40)$, ylab="',

ylim=c(1.75,27))

par(new=TRUE)

plot(vehicle5\$Time, vehicle5\$Event+12, axes=FALSE, $x l a b=" ', x \lim =c(0,40), y l a b=" '$, ylim $=c(1.75,27))$

rect(xleft=signal5 $\$$ Time[1], xright=signal5 $\$$ Time[2], ybottom=13.5, ytop=15.5,

col="\#00FF00A0")

rect(xleft=signal5\$Time[2], xright=signal5\$Time[3], ybottom=13.5, ytop=15.5,

col="\#FFFF00A0")

rect $(x$ left=signal5 $\$$ Time[1]-2, $x$ right=signal5 $\$$ Time[1], ybottom=13.5, ytop=15.5,

col="\#FF0000A0") 
rect(xleft=signal5\$Time[3], xright=42, ybottom=13.5, ytop=15.5, col="\#FF0000A0") rect $(x$ left=conflict5\$Time[1]-.5, xright=conflict5\$Time[length(conflict5\$Time)]+.5, ybottom=13.75, ytop=15.25, col="\#E0EEEEA0")

points(check5\$Time, check5\$Event+12, pch=25)

points(nocheck5\$Time, nocheck5 $\$$ Event+12, pch=17)

points(straight5 $\$$ Time, straight5 $\$$ Event +12 , pch=13)

points(right5\$Time, right5\$Event+12, pch=20)

\#Conflict 6

check6 <- bike6[bike6 $\$$ Check == '1', ] \#Cyclist checks behind when traveling through intersection

nocheck6 <- bike6[bike6 $\$$ Check == '0', ] \#Cyclist does not check behind

right6 <- vehicle6[vehicle6\$Direction == 'Right', ] \#Pulls out right turning

vehicles

straight6 <- vehicle6[vehicle6\$Direction == 'Straight', ] \#Pulls out straight

turning vehicles

par(new=TRUE)

plot(bike6\$Time, bike6\$Event+9, axes=FALSE, $x l a b=" ', x \lim =c(0,40)$, ylab="',

ylim $=c(1.75,27))$

par(new=TRUE)

plot(vehicle6 $\$$ Time, vehicle6 $\$$ Event +9 , axes=FALSE, $x l a b=" ', x \lim =c(0,40)$, ylab="', ylim=c(1.75,27))

rect(xleft=signal6\$Time[1], xright=signal6\$Time[2], ybottom=10.5, ytop=12.5,

col="\#00FF00A0")

rect(xleft=signal6 $\$$ Time[2], $x$ right=signal6 $\$$ Time[3], ybottom=10.5, ytop=12.5,

col="\#FFFF00A0")

rect $(x$ left=signal6 $\$$ Time[1]-2, xright=signal6 $\$$ Time[1], ybottom=10.5, ytop=12.5,

col="\#FF0000A0")

rect(xleft=signal6\$Time[3], xright=42, ybottom=10.5, ytop=12.5, col="\#FF0000A0")

rect $(x$ left=conflict6\$Time[1]-.5, xright=conflict6\$Time[length(conflict6\$Time)]+.5,

ybottom=10.75, ytop=12.25, col="\#E0EEEEA0")

points(check6\$Time, check6 $\$$ Event +9 , pch $=25$ )

points(nocheck6\$Time, nocheck6\$Event+9, pch=17)

points(straight6\$Time, straight6\$Event +9 , pch=13)

points(right6\$Time, right6\$Event +9 , pch=20)

\#Conflict 7

check7 <- bike7[bike7\$Check == '1', ] \#Cyclist checks behind when traveling through intersection

nocheck7 <- bike7[bike7\$Check == '0', ] \#Cyclist does not check behind

right7 <- vehicle7[vehicle7\$Direction == 'Right', ] \#Pulls out right turning

vehicles

straight7 <- vehicle7[vehicle7\$Direction == 'Straight', ] \#Pulls out straight

turning vehicles

par(new=TRUE)

plot(bike7\$Time, bike7\$Event+6, axes=FALSE, $x l a b=" ', x \lim =c(0,40)$, ylab="',

ylim=c(1.75,27)) 
par(new=TRUE)

plot(vehicle7\$Time, vehicle7\$Event+6, axes=FALSE, $x l a b=" ', x \lim =c(0,40)$, ylab="', ylim=c(1.75,27))

rect(xleft=signal7 $\$$ Time[1], xright=signal $\$$ \$Time[2], ybottom=7.5, ytop=9.5, col="\#00FF00A0")

rect(xleft=signal7 $\$$ Time[2], xright=signal7 $\$$ Time[3], ybottom=7.5, ytop=9.5,

col="\#FFFF00A0")

rect(xleft=signal7 $\$$ Time[1]-2, xright=signal7 $\$$ Time[1], ybottom=7.5, ytop=9.5,

col="\#FF0000A0")

rect(xleft=signal7 $\$$ Time[3], xright=42, ybottom=7.5, ytop=9.5, col="\#FF0000A0")

rect $(x$ left=conflict7\$Time[1]-.5, xright=conflict7 \$Time[length(conflict7\$Time)]+.5,

ybottom=7.75, ytop=9.25, col="\#E0EEEEA0")

points(check $7 \$$ Time, check 7 Event $+6, p c h=25$ )

points(nocheck7\$Time, nocheck7\$Event+6, pch=17)

points(straight7\$Time, straight7\$Event $+6, p c h=13$ )

points(right7\$Time, right7\$Event+6, pch=20)

\#Conflict 8

check8 <- bike8[bike8 \$Check == '1', ] \#Cyclist checks behind when traveling through intersection

nocheck8 <- bike8[bike8\$Check == '0', ] \#Cyclist does not check behind

right8 <- vehicle8[vehicle8\$Direction == 'Right', ] \#Pulls out right turning

vehicles

straight8 <- vehicle8[vehicle8\$Direction == 'Straight', ] \#Pulls out straight

turning vehicles

par(new=TRUE)

plot(bike8\$Time, bike8\$Event+3, axes=FALSE, $x l a b=" ', x \lim =c(0,40)$, ylab="',

ylim=c(1.75,27))

par(new=TRUE)

plot(vehicle8\$Time, vehicle8\$Event+3, axes=FALSE, $x l a b=" ', x \lim =c(0,40)$, ylab="', ylim=c $(1.75,27))$

rect $(x$ left=signal8 $\$$ Time[1], xright=signal8 $\$$ Time[2], ybottom $=4.5$, ytop $=6.5$,

col="\#00FF00A0")

rect $(x$ left=signal8 $\$$ Time[2], xright=signal $8 \$$ Time[3], ybottom=4.5, ytop=6.5,

col="\#FFFF00A0")

$\operatorname{rect}(x$ left=signal8 $\$$ Time[1]-2, xright=signal8 $\$$ Time[1], ybottom=4.5, ytop=6.5,

col="\#FF0000A0")

rect $(x$ left=signal8 $\$$ Time[3], xright=42, ybottom=4.5, ytop=6.5, col="\#FF0000A0")

rect $(x$ left=conflict8 $\$$ Time[1]-.5, xright=conflict8 $\$$ Time[length (conflict8 $\$$ Time)]+.5,

ybottom $=4.75$, ytop=6.25, col="\#E0EEEEA0")

points(check8 $\$$ Time, check8 $\$$ Event +3 , pch $=25$ )

points (nocheck8 $\$$ Time, nocheck8 $\$$ Event +3, pch $=17$ )

points(straight8 $\$$ Time, straight8 $\$$ Event +3, pch $=13$ )

points(right8 $\$$ Time, right8 $\$$ Event +3 , pch=20)

\#Conflict 9

check9 <- bike9[bike9\$Check == '1', ] \#Cyclist checks behind when traveling through intersection 
nocheck9 <- bike9[bike9\$Check == '0', ] \#Cyclist does not check behind right9 <- vehicle9[vehicle9\$Direction == 'Right', ] \#Pulls out right turning vehicles

straight9 <- vehicle9[vehicle9\$Direction == 'Straight', ] \#Pulls out straight turning vehicles

par(new=TRUE)

plot(bike9\$Time, bike9\$Event+0, axes=FALSE, $x l a b=" ', x \lim =c(0,40)$, ylab="', ylim=c(1.75,27))

par(new=TRUE)

plot(vehicle9\$Time, vehicle9\$Event+0, axes=FALSE, $x l a b=" ', x \lim =c(0,40)$, ylab="', ylim=c(1.75,27))

rect(xleft=signal9 $\$$ Time[1], xright=signal9 $\$$ Time[2], ybottom=1.5, ytop=3.5,

col="\#00FF00A0")

rect(xleft=signal9 $\$$ Time[2], $x$ right=signal9 $\$$ Time[3], ybottom=1.5, ytop=3.5, col="\#FFFF00A0")

rect $(x$ left=signal9 $\$$ Time[1]-2, xright=signal9 $\$$ Time[1], ybottom=1.5, ytop=3.5, col="\#FF0000A0")

rect(xleft=signal9\$Time[3], xright=42, ybottom=1.5, ytop=3.5, col="\#FF0000A0") rect $(x$ left=conflict9\$Time[1]-.5, xright=conflict9\$Time[length(conflict9\$Time)]+.5, ybottom=1.75, ytop=3.25, col="\#E0EEEEA0")

points(check9 $\$$ Time, check9 $\$$ Event +0, pch $=25$ )

points(nocheck9\$Time, nocheck9\$Event $+0, p c h=17$ )

points(straight9\$Time, straight9\$Event $+0, p c h=13$ )

points(right9 $\$$ Time, right9 $\$$ Event $+0, p c h=20$ )

abline(v=5, col="red") \#Can be adjusted for startup times

$\operatorname{axis}(2$, las $=2$, labels=ylabs, at=yticks)

axis $(1$, at=xticks)

$\operatorname{par}(\mathrm{xpd}=\mathrm{TRUE})$

title(main="NE Grand - Couch 9/21/2011", xlab="Time (sec)")

mtext("909 Bicyclists vs. 2,299 Right Turns")

box ()

dev.off () 